\title{
Characterization of aerodynamic drag force on single particles: Final report
}

Kale, S.R.

Oct 1987

West Virginia Univ., Morgantown (USA). Dept. of Mechanical and Aerospace Engineering

Reproduced and Distributed by:

U.S. DEPARTMENT OF ENERGY

Office of Scientific and Technical Information

P.O. Box 62

Oak Ridge, TN 37831 


\section{DISCLAIMER}

This report was prepared as an account of work sponsored by an agency of the United States Government. Neither the United States Government nor any agency Thereof, nor any of their employees, makes any warranty, express or implied, or assumes any legal liability or responsibility for the accuracy, completeness, or usefulness of any information, apparatus, product, or process disclosed, or represents that its use would not infringe privately owned rights. Reference herein to any specific commercial product, process, or service by trade name, trademark, manufacturer, or otherwise does not necessarily constitute or imply its endorsement, recommendation, or favoring by the United States Government or any agency thereof. The views and opinions of authors expressed herein do not necessarily state or reflect those of the United States Government or any agency thereof. 


\section{DISCLAIMER}

Portions of this document may be illegible in electronic image products. Images are produced from the best available original document. 


\section{DISCLAIMER}

This report was prepared as an account of work sponsored by an agency of the United States Government. Neither the United States Government nor any agency thereof, nor any of their employees, makes any warranty, express or implied, or assumes any legal liability or responsibility for the accuracy, completeness, or usefulness of any information, apparatus, product, or process disclosed, or represents that its use would not intringe privately uwied iight3. Reference herein th any specific commercial product, process, or service by trade name, trademark, manufacturer, or otherwise does not necessarily constitute or imply its endorsement, recommendation, or favoring by the United States Government or any agency thereof. The views and opinions of authors expressed herein do not necessarily state or reflect those of the United States Government or any agency thereof.

This report has been reproduced directly from the best available copy.

Available from the National Technical Information Service, U. S. Department of Commerce, Springfield, Virginia 22161.

\section{Price: Printed Copy A06}

Microfiche A01

Codes are used for pricing all publications. The code is determined by the number of pages in the publication. Information pertaining to the pricing codes can be found in the current issues of the following publications, which are generally available in most libraries: Energy Research Abstracts (ERA); Government Reports Announcements and Index (GRA and I); Scientific and Technical Abstract Reports (STAR); and publication NTIS-PR-360 available from NTIS at the above address. 
DOE/MC/23161-2529

(DE88001001)

Distribution Category UC-111

\title{
Characterization of Aerodynamic Drag Force on Single Particles
}

\author{
Final Report
}

S.R. Kale

Work Performed Under Contract No.: DE-FG21-86MC23161

\author{
For \\ U.S. Department of Energy \\ Office of Fossil Energy \\ Morgantown Energy Technology Center \\ P.O. Box 880 \\ Morgantnwn, West Virginia 26507-0880 \\ By \\ Mechanical and Aerospace Engineering Department \\ West Virginia University \\ Mnrgantown, WV 26505
}

October 1987 


\section{ACKNOWLEDGEMENTS}

The author gratefully acknowledges the guidance and cooperation of Dr. Rodney J. Anderson, Chief, Separation and Aerosol Sciences Branch, METC, throughout the course of this contract. The assistance of Dr. W. Phil Webster, formerly with the Separation and Aerosol Sciences Branch, METC, in setting up the experimental apparatus is also acknowledged. The electronics and control systems for the electrodynamic balance were designed and assembled by Mr. Larry $O$. Lawson and Mr. Greg E. Fasching of the Instrumentation Branch, METC. Their efforts are gratefully acknowledged. Assistance in conducting the experiments was provided by Mr. S. Sivakumar of the Department of Mechanical and Aerospace. Engineering, WVU, and his efforts are acknowledged. 


\section{ABSTRACT}

An electrodynamic balance was used for accurately measuring the drag coefficient and also for recording the size and shape of spheres, and coal and oil shale particles $(100 \mu \mathrm{m}$ to $200 \mu \mathrm{m}$ in size). Most previous studies of drag on particles pertain to spherical particles. Studies on nonspherical, isometric particles such as cubes, cones and tetrahedrons have been generally restricted to Stokes flow. Very little data is available on particles of interest to fossil fuel applications, viz., coal and oil shale.

The electrodynamic balance consisted of a central, and two end electrodes to which AC and DC potentials, respectively, were applied. The resulting electric field stably suspended a charged particle. An air jet entered through a hole in the bottom electrode and exited through a hole in the top electrode; and was calibrated with a Laser Doppler Anemometer. A suspended particle was back illuminated by a light emitting diode and viewed by a high resolution video camera through holes in the central electrode. The image was analyzed for particle position contrul and was calibrated to give the diameter of spheres, or the area equivalent diameter of nonspherical particles. The drag coefficient was calculated from the air velocity and the DC voltage required to keep the particle at the balance center. The particle Reynolds number varied from 0.2 to 13. Three particles each of coal and oil shale were captured and photographed by a scanning electron microscope and the motion of all the particles was recorded on video tape.

Drag coefficient v8. Reynolds number data for spheres agreed well with available correlations within the experimental uncertainties. Data for thirteen particles each of coal and oil shale indicated a power law relationship between drag coefficient and Reynolds number. All these particles exhibited higher drag than spheres and were also observed to rotate. The rotation, however, did not affect the drag coefficient. The choice of characteristic dimension affects the drag characteristics of oil shale more strongly than for coal. This observation is attributed to the flake-like shape of oil shale while the coal was chunky. Models of oil shale particles as ellipsoids and rectangular flakes support this conclusion. 
Acknowledgements $\ldots \ldots \ldots \ldots \ldots \ldots \ldots \ldots \ldots \ldots \ldots \ldots \ldots \ldots \ldots \ldots \ldots$

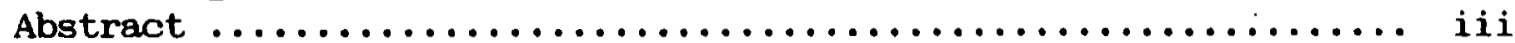

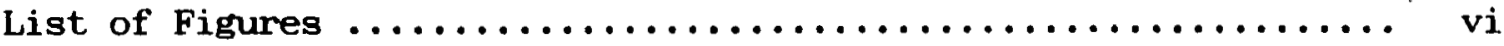

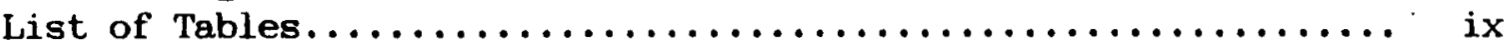

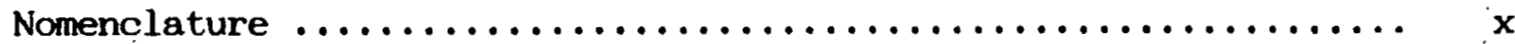

Chapter

1. INTRODUCTION............................ 1

2. SUMMARY OF PREVIOUS RESEARCH.................. 5

2.1 Drag Mcasurements of Bimple Fartiloles.......... 6

2.2 Charactert 3.A.tion of Nonepherioal Particles........ 9

2.3 Experimental Techniques................... 9

2.4 Particle Rotation...., ................. 10

3. EXPERIMENTAL APPARATUS..................... 14

3.1 The Electrodynamic Balance................. 14

3.2 Power Supply and Particle Imaging System......... 15

3.3 Air Supply System...................... 16

3.4 Laser Doppler Anemometer (LDA) Systen............ 17

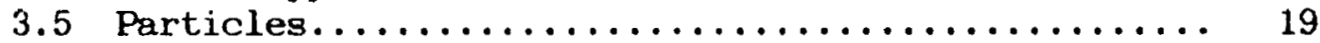

3.6 Data Acquisition and Analysis System........... 19

4. EXPERIMENTAL PROCEUURES $\ldots \ldots \ldots \ldots \ldots \ldots \ldots \ldots \ldots \ldots \ldots \ldots$

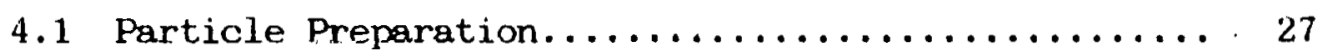

4.2 Particle Suspension Method................. 27

4.3 Balance Level Adjustments................. 28

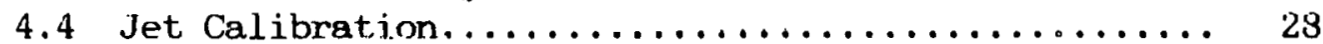

4.5 Imaging System Calibration................ 30

4.5 .1 Optimization of System Settings.......... 30

4.5.2 Imaging System Calibration............. 31

4.6 Drag Measurementэ..................... 32

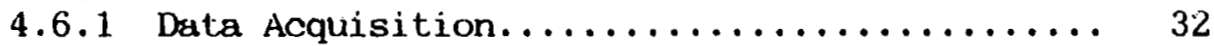

4.6.2 Data Analysis Procedure................ 33

4.7 Experimental Uncertainities............... 36

5. RESUนTS............................. 46

5.1 Drag Characteristics of Spherical Particles....... 46

5.2 Drag Characteristics of Coal Particles.......... 47

5.3 Drag Characteristics of Oil Shale Particles........ 47

5.4 Rotational Characteristics of Coal and Oil

Shale Particles........................ 48 
6.

DISCUSSION

71

6.1 Drag Characteristics of Spherical Particles....... 71

6.2 Drag Characteristics of Coal Particles........... 74

6.3 Drag Characteristics of Oil Shale Particles........ 77

6.3.1 Rectangular Flake Model............... 79

6.3.2 Ellipsoidal Flake Model............... 81

6.3.3 Effect of Shape on Drag

Characteristics................... 82

$\checkmark$

6.4 Particle Rotation....................... 83

7. CONCLUSIONS

97

7.1 Conclusions.......................... 97

7.2 Recommendations for Future Work.............. 98

References................................... 99

Appendix I Uncertainty Estimates in Drag Measurements.......... 101

$\mathbf{v}$ 


\section{LIST OF FIGURES}

Figure

1.1

Sketch of a Nonspherical Particle in a Fluid Flow......

Page

1.1. Illustration of a Typical Electrodynamic Balance........

2.1. Comparison of Experiment, Theory, and Empirical Formulae for Drag Coefficient of a Sphere with Smooth Surface. (From white, 1974)............... 12

2.2. Drag Coefficient vs. Reynolds Number Variations from Petty.john and Christiansen $(1948) \ldots \ldots \ldots \ldots \ldots \ldots$

3.1. Cross-sectional View of the Electrodynamic Balance..... 21

3.2. Photograph of the Electrodynaimc Balance Facility...... 22

3.3. Schematic Diagram of the Power Supply and Particle Imaging System.......................... 23

3.4. Schematic Diagram of the Air Supply System........... 24

3.5. Schematic Diagram of the Laser Doppler Anemometer System................................. 25

3.6. Schenatic Diagram of the Fiber Optic Probe......... 26

4.1. SEM Photograph of $105 \mu \mathrm{m}$ Diameter Glass Spheres....... 37

4.2. SEM Photograph of $136 \mu \mathrm{m}$ Diameter PSL Spheres......... 38

4.3. SEM Photograph of $160 \mu \mathrm{m}$ Diameter PSL Spheres......... 39

4.4. SEM Photograph of Montana Rosebud Coal Particles in the Size Range from $105 \mu \mathrm{m}$ to $148 \mu \mathrm{m} . \ldots \ldots \ldots . \ldots . \ldots . . .40$

4.5. SEM Photograph of Colorado Mahogany Oil Shale Particles in the Size Range from $105 \mu \mathrm{m}$ to $148 \mu \mathrm{m} . \ldots$. .

4.6. Photograph of a $160 \mu \mathrm{m}$ Diameter PSL Sphere suspended in the Electrodynamic Balance as seen on the Video Monitor.................................

4.7. Jet Velocity Profiles.................... 43

4.8. Calibration Curve for the Laminar Flowmeter.......... 44

4.9. Forces on a Particle suspended in an Electrodynamic Balance................................ 45

5.1(a). Drag Coefficient vs. Reynolds Number for Five Glass Microspheres of Diameter 105 man............ 50 
5.1(b). Drag Coefficient vs. Reynolds Number for Five Glass Microspheres of Diameter 105 m...............

5.2(a). Drag Coefficient vs. Reynolds Number for Five PSL Microspheres of Diameter $136 \mu \mathrm{m} . \ldots \ldots \ldots \ldots \ldots \ldots \ldots$

5.2(b). Drag Coefficient vs. Reynolds Number for Five PSL Microspheres of Diameter $136 \mu \mathrm{m} . \ldots \ldots \ldots \ldots \ldots \ldots \ldots$

5.3(a). Drag Coefficient v8. Reynolds Number for Five PSL Microspheres of Diameter 160 m...................

5.3(b). Dras Coefficient v8. Reynolds Number for Five PSL Microspheres of Dismeter $160 \mathrm{~mm} . \ldots \ldots \ldots \ldots \ldots \ldots \ldots \ldots$

5.4(a). Drag Coefficient vs. Reynolds Number for Five Coal Particles................................. 56

5.4(b). Drag Coefficient vs. Reynolds Number for Five Coal Particles. ................................

5.4(c). Drag Coefficient vs. Reynolds Number for Three Coal Particles................................. 58

5.5(a). SEM Photograph of Coal Particle no. C-11........... 59

5.5(b). SEM Photograph of Coal Particle no. C-12........... 60

5.5(c). SEM Photograph of Coal Particle no. C-13............ 61

5.6(a). Drag Coefficient vs. Reynolds Number for Five Oil Shale Particles............................. 62

5.6(b). Drag Coefficient vs. Reynolds Number for Five Oil

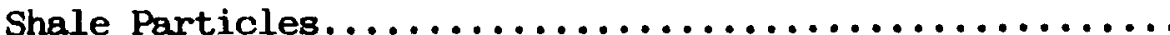

5,6(c). Drag Coefficient vs. Reynolds Number for Three Oil Shale Particles............................ 64

5.7(a). SEM Photograph of Oil Shale Particle no. OS-11....... 65

5.7(b). SEM Photograph of Oil Shale Particle no. OS-12....... 66

5.7(c). SFM Photograph of Oil Shale Particle no. OS-13....... 67

5.8. Effects of AC Field Frequency on the Rotation of an Oil Shale Particle at two Jet Velocities.......... 68

5.9. Rotational Characteristics of Three Coal Particles................................

5.10. Rotational Characteristics of Three Oil Shale Particles................................ 
6.1. Drag Data for Ten Spheres of Diameter $105 \mu \mathrm{m} . \ldots \ldots \ldots \ldots$

6.2. Drag Data for Ten Spheres of Diameter 136 m......... 87

6.3. Drag Data for Ten Spheres of Diameter $160 \mu \mathrm{m} . \ldots \ldots \ldots$

6.4. Drag Data for Thirteen Coal Particles.............. 89

6.5. Fluid Flow around a Nonspherical Particle with

Rough Surface........................... 90

6.6. Drag Data for Thirteen Oil Shale Particles........... 91

6.7. Two Orthogonal Views for Three Flake Shapes.......... 92

6.8. Effects of Shape on the Drag Characteristics of an Oil Thale Purlicle (OS-12). The Harticle has been approximated as a Rectangular Flake............... 93

6.9. Effects of Shape on the Drag Characteristics of an Oil Shale Particle (OS-12). The Particle has been approximated as an Ellipsoid................... 94

6.10. Forces on a Nonspherical Particle suspended in an Electrodynamic Balance....................... 95

6.11. Principle for Measuring Particle Rotation Velocity by a Single Component Laser Doppler Anemometer........ 96 


\section{LIST OF TABLES}

Table

3-1

Salient Features of the Fiber Optic Probe..

4-1 . Densities of Test Particles................... 35

6-1 Power Law Regression on Data for Spheres............. 71

6-2 Power Law Regression on Data for Coal

Particles................................ 75

6-3 Power Law Regression on Data for Oil Shale

Particles. 


\section{NOMENCLATURE}

a

A

$A_{1}, A_{2}$

$A_{1}^{\prime}, A_{2}^{\prime}$

${ }^{A p}$

$\mathrm{A}_{\mathrm{p}, \mathrm{t}}$

$\mathrm{A}_{\mathrm{p}}^{\prime}$

$\mathrm{C}_{0-3}$

$\mathrm{C}_{\mathrm{d}}$

$\mathrm{C}_{\mathrm{d}}$

$C_{d, t}$

$d$

de

$d_{e}^{\prime}$

e

E

$F_{D}$

$F_{E}$

g

h

$k_{1}, k_{2}$

$k_{1}^{\prime}, k_{2}^{\prime}$

K

$\mathrm{K}_{\mathrm{A}}$

$\mathrm{K}_{\mathrm{B}}, \mathrm{K}_{\mathrm{B}}^{\prime}$

$\mathrm{k}_{\mathrm{D}}$
Semi ma.jor axig

Pro,jected area

Projected area normal to jet flow

Projected area normal to jet flow for model

Projected area

True projected area for model

Mean projected area for model

Laminar flowmeter calibration constants

Drag coefficient

Drag coefficient for model

Corrected drag coefficient for model

Diameter

Area equivalert diameter

Area equivalent diameter for model

Ratio of major to minor axes

Exponent

Aerodynamic drag force

Electrostatic force

Gravitational constant

Height

Tmaging system alibration constants

Imaging system calibration constants

Pre-exponent constant

Aerodynamic shape factor

Balance constants

Shape factor 


\begin{tabular}{|c|c|}
\hline $\mathbf{K}_{\mathbf{P}}$ & Particle shape constant \\
\hline $\mathrm{K}_{\mathrm{S}}$ & Shape correction facor \\
\hline $\mathbf{m}$ & Particle mass \\
\hline$m_{t}$ & True mass for model \\
\hline $\mathbf{n}$ & Exponent \\
\hline $\mathrm{N}$ & Number of cycles \\
\hline $\mathbf{P}$ & Pixel count \\
\hline $\mathbf{q}$ & Particle charge \\
\hline $\mathbf{R}$ & Particle radius \\
\hline$R_{\max }$ & Maximum particle radius \\
\hline Ro & Roynolda number \\
\hline $\operatorname{Re}_{1}$ & $\begin{array}{l}\text { Reynolds number based on area equivalent diameter } \\
\text { of model }\end{array}$ \\
\hline $\mathrm{Re}_{2}$ & $\begin{array}{l}\text { Reynolds number based on mass equivalent diameter } \\
\text { of model }\end{array}$ \\
\hline $\operatorname{Re}^{\prime}$ & Corrected Reynolds number for model from data \\
\hline$S$ & Shape constant \\
\hline $\mathrm{t}$ & Thickness \\
\hline $\mathbf{T}$ & Temperature \\
\hline $\mathrm{T}_{\mathrm{D}}$ & Aerodynamic torque \\
\hline$u_{\mathbf{f}}$ & Fluid velocity \\
\hline$u_{p}$ & Particle velocity \\
\hline $\mathrm{U}$ & Jet centerline velocity \\
\hline $\mathrm{U}_{\mathrm{o}}$ & Fluid velocity \\
\hline$v_{\max }$ & Maximum tip velocity for a rotating partiole \\
\hline$v_{t}$ & Terminal/settling velocity \\
\hline $\mathrm{V}$ & Laminar flowmeter output voltage \\
\hline$v_{d c}$ & Balance DC voltage \\
\hline
\end{tabular}




$\begin{array}{ll}\text { Vdc,0 } & \text { Balance DC voltage with no air flow } \\ \mathrm{V}_{\mathrm{p}} & \text { Particle velocity } \\ \mathrm{w} & \text { Width } \\ \mathrm{W} & \text { Particle Weight } \\ \mathrm{X}, \mathrm{Y}, \mathrm{Z} & \text { Cartesian coondinates }\end{array}$

\section{Greek}

$\omega$

$\mu$

$\rho$

$\rho_{2}$

$P_{\mathbf{a}}$

$\boldsymbol{\beta}$

$\lambda$

$\nu$
Angular velocity

Dynamic viscosity

Particle material density

Fluid density

Density of air

Angle between relative motion vector and a vector normal to the disk surface

wavelength

Kinematic viscosity 
Chapter 1

\section{INTRODUCTION}

Single particles, as individuals and as a group, are encountered in a large variety of applications. Some typical examples include coal utilization (combustion and gasification); oil shale utilization; powder technology and material handling; catalysis; biomechanics (blood flow); respirable dusts; and pollutant dispersion. Knowledge of particle dynamics and the associated fluid dynamics is used in several different ways depending on the application. Whereas solid-fluid contacting is important in some cases, other cases may involve aggregation or dispersion of the solid phase. In all these cases, however, basic information on particle behavior and its effect on the fluid flow is necessary.

Currently, most applications involving non spherical or irregularly shaped particles rely heavily on correlations based on laboratory scale experiments. Such an approach, while being most practical, suffers from drawbacks, the most notable of which is lack of knowledge on the proooog fundamontala. Undorotandably, the studies aimed at obtaining information on basic physics of flow with irregular particles have defied generalization and, consequently, such studies have been limited to well defined shapes. Because of their shape, spheres have been the focus of most investigations, both theoretically and experimentally. Circular cylinders and cones have also been studied and data is also available on some isometric shapes such as rectangular rhomboids and octahedrons. More often than not, results from these studies with isometric particles are extended to irregular shaped particles with some empirical correction factors. Irregular shaped particles themselves have not been studied as extensively to obtain basic information, particularly, drag characterization.

Figure 1.1 shows a nonspherical particle in a steady flow field, characterized by velocity, $U_{0}$. The net aerodynamic force, $F_{D}$, and the net torque, $\mathrm{T}_{\mathrm{D}}$, on the particle result in a particle motion which has been characterized by velocity $\left(V_{p}\right)$ and angular velocity $(\omega)$. For spheres in a steady uniform flow, the torque is negligible but for most irregular shapes the rotation caused by the torque can be significant. In general, the fluid flow field itself can vary in space and time, causing accelerations to come into play. The study of the dynamic interaction between a single particle and the fluid is the first step in predicting the behavior of a particle-laden flow. Information generated on this aspect can then be used in predicting the behavior of particles in turbulent flows, fluidized beds, pneumatic transport and other applications.

During the last decade, the electrodynamic balance has provided major breakthroughs in suspending and studying single particles, see Davis (1980). In its simplest form, the electrodynamic balance consists of two end electrodes with a DC potential applied to them, and a central (or ring) electrode with an AC potential applied to it. The electrodes can be made in different shapes and one such typical configuration is shown 
in Figure 1.2. The shape of the electrodes results in strong focusing of the electric field which in turn suspends a charged particle stably at the balance center. In the present study a hole was provided in each end electrode, one for air jet entry and the other for exit, see Figure 1.2. By establishing a flow over a suspended particle, the DC potential required to suspend the particle at the center decreases and this change, together with the jet velocity can be used to interpret the drag coefficient $\left(C_{d}\right)$ as a function of Reynolds number (Re) based on particle diameter. The candidate particles comprised spheres (glass and Polystyrene Latex, PSL) and nonspherical particles (coal and oil shale).

This report presents results of the above mentioned experiments: A background review of related literature is given in the next chapter (Chapter 2). Chapters 3 and 4 detail the experimental apparatus used and the procedures followed, respectively. The results are presented in Chapter 5 followed by a discussion in Chapter 6. Finally, conclusions are presented in Chapter 7. Figures for each chapter have been positioned at the end of the respective chapter and a common blbliography. is included after Chapter 7. 


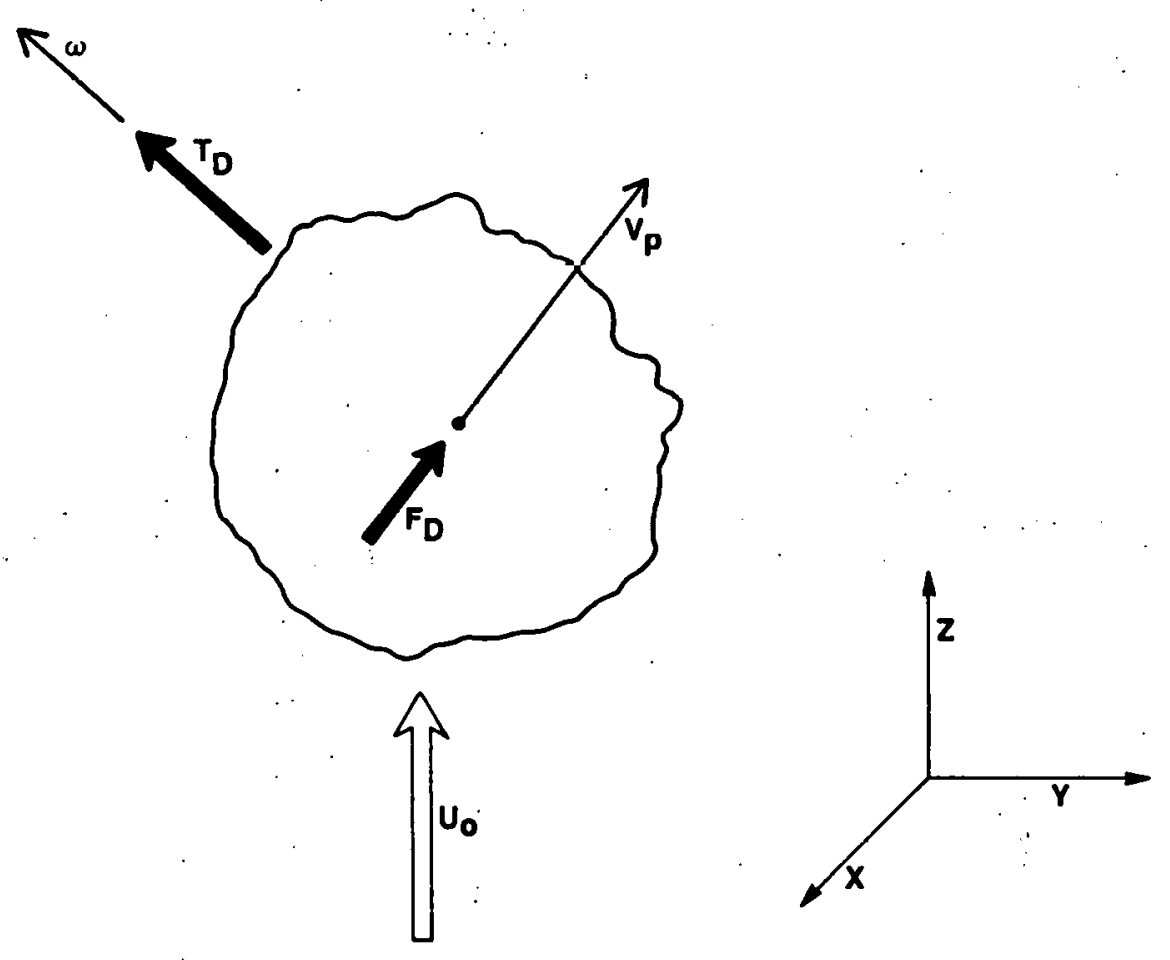

Figure 1.1. Sketch of a Nonspherical Particle in a Fluid Flow 


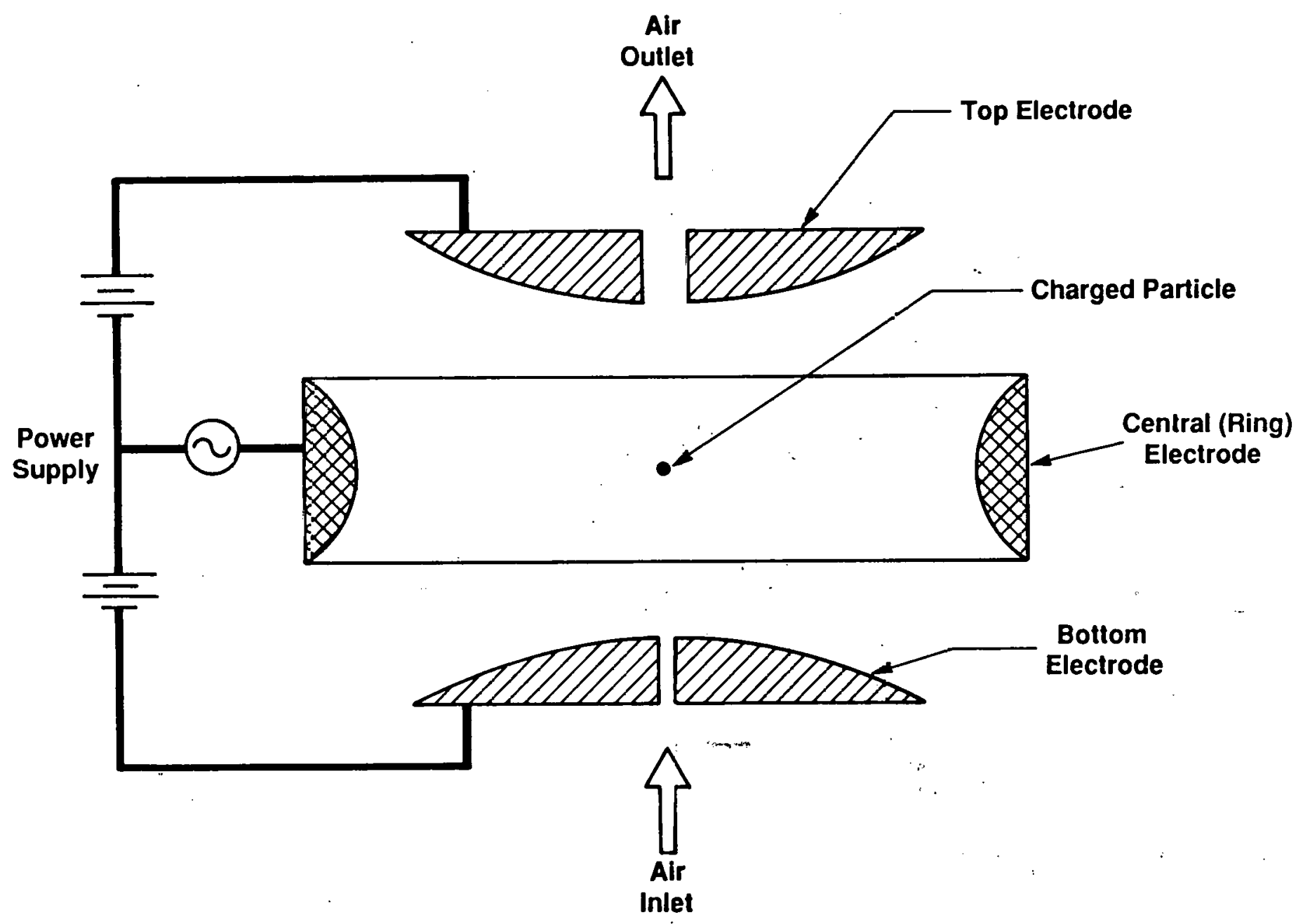

Figure 1.2. Illustration of a Typical Electradynamic Balance. 


\section{Chapter 2}

\section{SUMMARY OF PREVIOUS RESEARCH}

An extensive body of previous research has produced a wealth of information on some classes of problems. Given the massive anount of published literature on particle-fluid phenomena related to drag measurements, it is not possible to present all of it here. The major studies in this area are presented below in Section 2.1. Section 2.2 gives a summary of various techniques used to characterize nonspherical particles. Different experimental approaches used in the study of single particle dynamics are given in Section 2.3 followed by a brief summary on literature related to particle rotation (Section 2.4).

\subsection{Drag Measurements of Single Particles}

An extensive review of drag on single particles has been given by Clift and Gauvin (1971). In addition to their own data they have compared it with that of almost one hundred other researchers. They conclude that the drag experienced by a single particle moving through a fluid is dependent not only on the solid and fluid properties and the relative velocity, but also on several other factors. These factors according to them are, amongst others, fluid turbulence, acceleration, particle shape and orientation, and particle-fluid mass transfer. Regarding drag on a sphere, they have offered piecewise fits to the standard curve up to a Reynolds number of 90,000. A recent survey of similar drag data is given by Flemmer and Banks (1986) who have compared their correlation with that of six other investigators. For Reynolds numbers up to 300,000 , they offer the following correlation:

$$
C_{d}=\frac{24}{\operatorname{Re}} \cdot 10^{E}
$$

where,

$$
E=0.261 \operatorname{Re}^{0.369}-0.105 \operatorname{Re}^{0.431}-\frac{0.124}{1+\left(\log _{10} \operatorname{Re}\right)^{2}}
$$

After surveying several proposed correlations, White (1974), has proposed the following correlation:

$$
C_{d}=\frac{24}{R e}+\frac{6}{1+\operatorname{Re}^{0.5}}+0.4
$$

This relation for drag coefficient is applicable with an accuracy of $\pm 10 \%$ until the onset of turbulence, $R e=200,000$, at which point there are abrupt changes in drag behavior. This curve is shown in Figure 2-1 for Reynolds numbers from 0.1 to 1,000,000. Interestingly, the above correlation has not been evaluated by Flemmer and Banks (1986) in their study, and the error in their proposed correlation, $\pm 10 \%$, is same as that proposed by White for equation 2-3 above.

A large number of studies both experimental and theoretical, on the aerodynamics/hydrodynamics, of single particles are restricted to Stokes 
flow regime, viz., Reynolds number less than unity.

An exhaustive study on the dynamics of nonspherical particles in a fluid flow was performed by Pettyjohn and Christiansen (1948). Using settling columns, they studied the drag characteristics on a variety of isometric particles, such as cubes, octahedrons, tetrahedrons, cube octahedrons and spheres, with different test fluids. They were thus able to study drag coefficients up to a Reynolds numbers of 10,000 and conclude that the drag data is sensitive to the characteristic dimension used. Using the sphericity of a particle, they developed correction factors to Stokes' law (Reynolds number less than 0.05) and also for the turbulent regime, (Reynolds number between 2,000 and 100,000). In the intermediate range, Reynolds number between 0.05 and 2,000 they have presented a chart for drag calculation which is reproduced in Figure 2.2. According to their experiments, particle rotation can have a significant effect on drag characteristics. Besides being time consuming, their approach is difficult to adapt for single, non-isometric parricles. While sphericity can adequately describe the dynamics of isometric particles, it is unlikely that it will be an adequate parameter in describing the dynamics of particles such as coel and oil ahalo. In both these cases, the relative orientation of the particle and fluid flow will result in dynamics which cannol be adequately described by the sphericity alone.

An extensive treatise on this subject can be found in Brenner $(-1963$ and 1964). He has also studied the effects of irregular shapes on particle dynamics and hus shown, mathematically, that propeller-like particles will spin as they settle in a fluid. The behavior of single particles of nonspherical shape has also been studied by Dahneke (1973). For Stokes flow regime he has offered correlation factors for well defined geometrical shapes, such as spheres, discs, cylinders, spheroids, and cubes. He has also extended his results to free molecular flow. However during the mathematical formulation he has made an assumption that lift on particles is zero, an assumption which is generally not true for irregular bodies.

A similar study on the drag of isometric particles is provided by Carmichael (1982). He has measured the drag coefficient and shape correlation factor $\left(K_{S}\right)$ for a circular cylinder, square prism, double cone, spheroid, rectangular parallelopiped, cube, octahedron, and tetrahedron for Stokes flow regime, and has proposed the following modification to Stokes' law:

$$
\mathrm{C}_{\mathrm{d}}=\frac{24}{\mathrm{R} e} \cdot \mathrm{K}_{\mathrm{S}}
$$

The measured and calculated values of $\mathrm{K}_{\mathrm{S}}$ vary between 0.7 and 1.22 .

Drag data for nonspherical particles at higher Reynolds numbers have been obtained by Kamiwano et al. (1984). They studied the drag on single particles in a settling tank using a digital image tracking system. Their particles included acrylic plastic, bakelite, carbon, and aluminium ranging in size from $1.50 \mathrm{~mm}$ to $3.12 \mathrm{~mm}$ (total of eight particles) 
encompassing a Reynolds number range from 150 to 1,000. Their data indicate that the drag coefficient on nonspherical particles is greater than that for spheres of equal volume, with the increase being up to $30 \%$ in some cases. Their data are, however, not exhaustive and sketchy details are given on the particle shape. No photographs are presented for the particles.

Zenz and Othmer (1960) have compared standard data for spheres with drag data for disks and cylinders over a Reynolds number range from 0.01 to 100,000 . They have mentioned the work of several other researchers also and studied the effects of orientation on drag characteristics, such as disks in horizontal and vertical orientations. It is interesting to note that the Reynolds number in the former case was ' based on disk diameter but in the latter case it was based on twice the disk thickness. The latter is equal to four times the hydraulic radius of the projected area perpendicular to the direction of motion. This assumption implicitly indicates that the characteristic dimension of a particle is orientation dependent, which is generally true. They have also referenced experiments on free settling rates of cubes, spheres, tetrahedron and octahedron for Reynolds numbers in the range from 0.01 to 20,000 , but not provided detailed quantitative dat.a. Thesr conclude that there exlsts a large amount of highly scattered published data for various types of particles, and point out that most experimenters' failure to report data on particle shape renders it of little practical value.

The drag force on single particles has recently been measured by Davis (1985) using an electrodynamic balance. He used spherical and nonspherical particles with sizes up to $24.5 \mu \mathrm{m}$. The drag coefficient has not been calculated explicitly but has been presented as a ratio of drag force/particle weight as a function of jet flow rate. Like several other researchers, this data, too, is valid for stokes flow regime. From this data it is possible that shape factors for drag force correlation can be obtained. More recently, Davis et al. (1987) have extended these experiments to obtain more drag data. They have presented data up to Reynolds number of 0.6 and it shows that shape has a significant effect on drag. Their data for spheres in the Stokes flow regime agrees well with the theoretical calculations.

In general, the drag force (FD) on irregular particles has been assumed to be of the following form, Beddow (1980):

$$
F_{D}=3 \pi \mathrm{d} \mu U_{o} \cdot K_{A}
$$

where $d$ is the surface area equivalent diameter; $\mu$, the viscosity of the fluid; $U_{0}$, the fluid velocity; and $K_{A}$, the aerodynamic shape factor. As can be seen, this equation is a modification of the standard relation for Stokes flow regime,

$$
\mathrm{F}_{\mathrm{D}}=3 \pi \mu \mathrm{dU}
$$

He has, however, not stated explicitly the Reynolds number range over 
which this relation is valid. In general, a relation of the type $(2-5)$ is valid only for Stokes flow regime, unless $\mathrm{K}_{\mathrm{A}}$ is itself made a function of Reynolds number. No clarification of this effect has been offered by Beddow and, therefore, the applicability of the data presented will be very limited. The shape factors for some isometric shapes have been presented and these are applicable for Reynolds numbers less than 0.1 . For cube, octahedron, and tetrahedron, this shape factor varies from 0.96 to 0.99 , with $\mathrm{K}_{\mathrm{A}}$ for sphere being unity.

Ogawa (1984) has briefly discussed the drag on a particle for Stokes flow regime. For irregular shaped particles he has proposed substitution of an equivalent diameter as the representative dimension. He has, however, not given any basis for the gelection of an equivalent diameter, nor discussed its effect on the drag characteristics.

Several researchers have reported on the motion of nonspherical narticles in two-phase flow situations. Must of these situations are application specific but in order to develnp models, they require a lelation between particle drag coefficient and Reynolds number. A few typical cases are discussed Lelow.

Besnard and Harlow (1986) have studied the motion of a single disk-like ellipsoid in a fluid. Additionally, they have also included degrees of freedom associated with translation, lift, orientation, and angular velocity. For Stokes flow regime they have assumed the classicul relation:

$$
\overrightarrow{F_{D}}=6 \pi \mu R\left(\overrightarrow{u_{f}}-\overrightarrow{u_{p}}\right)
$$

For high speed flows they have ussumed an equatinn of the form:

$$
F_{D}=K_{\Gamma} \rho \pi R^{2}\left|\overrightarrow{u_{f}}-\overrightarrow{u_{p}}\right|^{2}
$$

where $\mathbf{K}_{\mathrm{p}}$ is a particle shape constant which also depends on the orientation of the particle relative to the local mean flow. For the case of an ellipsoid they have offered the following expression:

$$
\mathrm{F}_{\mathrm{D}}=\mathrm{K}_{\mathrm{D} p_{2}} \mathrm{~S}\left|\overrightarrow{\mathrm{u}_{\mathrm{f}}}-\overrightarrow{\mathrm{u}_{\mathrm{p}}}\right|\left(\overrightarrow{\mathrm{u}_{\mathrm{f}}}-\overrightarrow{\mathrm{u}_{\mathrm{p}}}\right)
$$

where $S=\pi a^{2}\left(\cos ^{2} \beta+e^{2} \cdot \sin ^{2} \beta\right)^{\frac{1}{2}}$, and

$$
\mathrm{e}=\frac{\mathbf{b}}{\mathbf{a}}
$$

Here, $\beta$ is the included angle between the relative motion vector and a vector normal to the disk surface. This explicit relation does away with calculating drag coefficient as a function of Reynolds number. On the basis of equation 2-9a such a correlaliun can be develnped. It will be instructive to extend their model to study the drag characteristics in greater detail. It is, however, not clear whether such an analysis can be extended to three dimensional particles. 
The hydraulic transport of particles has attracted great attention to confined two-phase flows. In most of these cases, the physics of these systems is dominated by particle-particle interactions and also by wall effects, in addition to the dynamics of individual particles. Pettyjohn and Christiansen (1948) have shown that nonspherical but isometric particles, such as, cubes and tetrahedrons, behave differently from spherical particles in a.flow. Yin et al. (1986) have shown from experiments on pneumatic transport of powdered materials that particles with the same sphericity behave differently in a slurry flow. Even in light of the conclusions of Pettyjohn and Christiansen (1948), such a conclusion is not all together unexpected. As a scalar descriptor of particle shape, the sphericity does not provide any information on the dynamics of a particle which is orientation dependent. A higher order descriptor for particle shape and orientation, vector or dyadic in nature, may be necessary to fully describe the particle motion.

\subsection{Characterization of Nonspherical Particles}

Particle characterization has been a subject of study in its own right for some time now. Beddow and Meloy (1980) have proposed several techniques for characterizing particles. These include amongat nthers, Fourior and Walsh lransforms. By their very nature, these transforms are applicable only to two-dimensional shapes or projected images/pictures of three-dimensional particles. Both methods produce a family of characteristic values for a given shape and these are then related to one another to arrive at a "particle signature". From the description given in section 2.1 it can be seen that most researchers have preferred to correlate drag properties with such constants as surface area equivalent diameter and volume equivalent diameter. Several other commonly proposed characteristic dimensions are (i) free falling diameter, (ii) Stokes diameter, (iii) sieve diameter, (iv) projected area diameter, and (v) drag diameter. Each of these parameters are convenient in some situations and provide the researcher with a simple technique for quantifying the size of an irregular particle.

Given the number of techniques for characterizing a particle, particularly, its equivalent diameter, it is obvious that this data cannot be obtained for each particle in a given sample of powdered material. The logistics of the above effort aside, it will be nearly impossible to make meaningful conclusions about the flow of such a powder. On a smaller scale, it is quite difficult to even obtain data on the dynamics of a single irregular particle in a given flow field.

Based on the work of Mandelbrot (1982), a technique involving fractals has been proposed by Farin et al. (1984). The attractive feature of this characterization technique is that it provides a one-parameter method for describing the surface irregularities. This parameter, however, cannot adequately describe the shape of a three-dimensional nonspherical particle nor provide a characteristic dimension for its size.

\subsection{Experimental Techniques}

A wide variety of experimental techniques have been used to study 
the aerodynamics/hydrodynamics of single particles. By far the most widely used technique to study one or more particles at a time has been the settling chamber where the free fall can be studied. The technique provides data for one particle at one velocity and, as such, is limited in use.

This apparatus has been modified to hydrodynamically levitate a particle and study its dynamics. As with the parent design, this modification, too, limits the study to one particle at one velocity, viz., its terminal velocity. Consequently, several particle-fluid combinations have to be studied in order to compile a meaningful data set. Interestingly enough, most of the researchers, a notable exception being Pettyjohn and Christiansen (1948), have not provided an uncertainty analysis on their data and procedures.

In addition to hydrodynamic levilation, experiments on single particles have also been performed using accoustic and electric levitation techniques. Mass transfer frnm a liquid drop was studied by Trinh and Hsu (1987) using an acoustic levitator. They studied changes in shape and size of a drop as it evgporated in their levitator, and point out that the drop shapes obtained were not spherical because uf non-uniform acoustic pressure. This effect was obscrved to decrease as the drop got smaller at which point surface tension maintained a spherical shupe. They successfully suspended drops up to $1 \mathrm{~mm}$ in diameter.

In recent years, the electrodynamic balance has shown itself to be a powerful tool in studying a variety of single particle phenomena. This modern version of Millikan's oil drop experiment was revived by wuerker et al. (1959) and has been recently modified by Davis and Ray (1980). Together with a high speed digital computer, this device, shown schematically in Figure 1.2, has been used by several investigators to study a variety of single particle phenomena such as combustion (Gavalas and Flagan, 1986), explosive boiling (Maloney et al., 1986), light scattering (Davis and Periasamy, 1985), and mass transfer (Kale et al., 1987).

Essentially, an electrodynamic balance consists of a pair of top and bottom electrodes across which a DC potential is applied. In addition, a third electrode, also called the central or ring electrode, is provided with an AC potential applied to it. A combination of these potentials together with an appropriate electrode shape and size establishes an electric field in the balance enclosure in which a charged particle can be stably suspended for long time periuls. Holos in the elertrodes can provide optical access to the interinr and holes in the bottom and top electrodes enable a jet to enter and exit the balance. This type of un electrodynamic balance was successfully used by Davis (1985) and Davis et al. (1987) to study the drag characteristics of single particles.

\subsection{Particle Rotation}

In a typical situation, nonspherical (and in some instances spherical) particles are likely to rotate in a flow. The rotation of 
spheres caused by shear forces has been exhaustively studied and has not been detailed here. Unlike the drag force which has elicited great interest from researchers, particle rotation and its associated damping dissipation have attracted little attention. Jeffery (1915) has studied the hydrodynamics accompanying the steady rotation of a body in an infinite fluid medium and developed equations and solutions for the flow field for different cases. The damping torque on a sphere as function of the spinning rate has not been calculated. He has, however, presented the effects of rotation for different shapes such as an ovary ellipsoid, planetary ellipsoid, circular disc, and two non-concentric spheres. Brenner (1964) theoretically studied the motion of propeller-like particles and developed the basic mathematical treatise for this class of problems. A more detailed treatise is provided by Besnard and Harlow (1986) where they studied the case of an elliptical disk in detail and have presented results for the relaxation times for linear and angular motion. Additionally, they also studied the influence of turbulence and proceeded to compute the dynamics of a jet laden with these particles. Torobin and Gauvin (1960) have presented a review on the effects of rotation, both top spin and screw motion, on particle drag. Their review indicates that top spin for spheres changes drag only marginally but has a more pronounced effect in reducing drag nn rylinders. On tho other hand, screw spin appears to have little, if any, effect on particle drag. It should be noted that the above conclusions are not supported by exhaustive data and indicate a need for more work in this area.

The foregoing discussion indicates the existence of a wealth of data, and its limitations, related to particle drag studies. Of particular. interest is the fact that drag data on nonspherical particles is scarce, and where present, does not include shape characterization or photographs of the particular particles studied. 


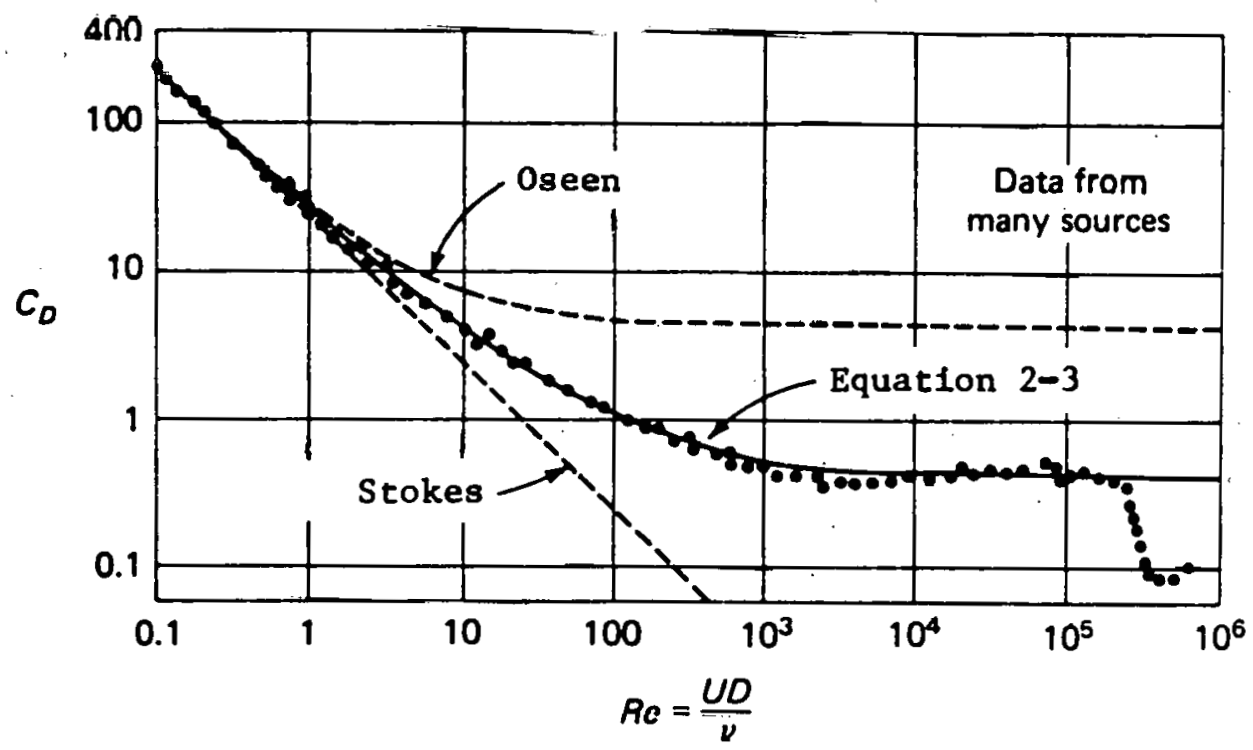

Figure 2.1. Comparison of Experiment, Theory, and Emperical Formulae for Drag Coefficient of a Sphere with Smooth Surface. (From White, 1974). 




Figure 2.2. Drag Coefficient vs. Reynolds Number from Pettyjohn and Christiansen (1948). Re1 is based on the Mass Equivalent Diameter; and $\mathrm{Cd}_{1}$ is based on the Projected Area of a Sphere of Equal Volume. Re2 is based on the Projected Area Equivalent Diameter for the most Stable Orientation of a Particle; and $\mathrm{Cd}_{2}$ is based on the Projected Area Normal to the Flow. 


\section{Chapter 3}

\section{EXPERIMBNTAL. APPARATUS}

This chapter gives a description of the experimental facilities used in the research which include an electrodynamic balance and several supporting systems. The device. was mounted on an optical table and comprised of the following major systems:

(ii) The Power Supply and Particle Imaging System, and,

(iii) The Laser Doppler Anemometry (LDA) System

Detailed description on each of these systems is given in Sections $3.2,3.3$, and 3.4 , respectively. The entire experimental facility was located in the laboratories of the U.S. Department of Energy, Morgantown Energy Technology Center.

\subsection{The Electrodynamic Balance}

Figure 3.1 shows a cross-section through the electrodynamic balance. It consisls of a pair of end elcctrodes (top and bottom) and a central (or ring) electrode mounted in a nonconducting housing. In order to suspend a particle, a D.C. potential was applied to the top and bottom electrodes, and an A.C. potential to the ring electrode. All the electrodes were conical in shape and made of brass. Other shapes, such as hyperboloids, have also been used (Davis, 1980, Maloney et al., 1985) because of the stronger field focussing resulting from this shape. For the subject application, conical shaped electrodes provided adequate field focussing at the balance center and given the ease of fabrication, were selected in the present design. Each end electrode was mounted in a plexiglas cap where it was held in place by nylon screws. The caps themselves were fixed to the housing by nylon screws. The top cap was not fixed rigidly to the housing but kept loose in urder to facilitatc removal during particle capture. When fully assembled, the electrodes were $25.4 \mathrm{~mm}$ apart. The ring electrode, $38 \mathrm{~mm}$ inside diameter, was mounted directly in the housing which was made of plexiglas, and held in place by nylon screws. All the screws used were made of nylon which provided both insulation against leakage and safety against accidental contact. Each end electrode had a hole $9.3 \mathrm{~mm}$ in diameter fur entry and exit of the air jet. The companion end cap was also provided with a concentric hole which was threaded for mounting pipe fittings. A wire connecting each end electrode to the DC power supply was passed through a third hole. The ring electrode had four tapered holes with a numerical aperture of $0.2\left(23^{\circ}\right.$ cone angle) at right angles to one another. Companion holes in the housing provided optical access to the balance center. One pair of opposite holes was used to view a suspended particle, and another hole enabled access for the Laser Doppler Anemometer (LDA) to make velocity measurements. All these view ports were covered with glass plates which were held in place by plexiglus covers and nylon screws. This design isolated the bulance interior from the surrounding air currents which were found to influence $a$ suspended particle. 
The balance was held in place by. three adjustable linkages which were fixed to an aluminium plate. The latter was bolted to an optical post which was mounted on an optical table. Throughout the experiments, the balance was mounted rigidly on the optical table. The optical table itself was equipped with pneumatic isolation legs which served two purposes, viz., (i) they provided insulation from miscellaneous laboratory vibrations, and (ii) they enabled accurate levelling of the table. A photograph showing the electrodynamic balance and components of the supporting systems is shown in Figure 3.2.

\subsection{Power Supply and Particle Imaging System}

A functional block diagram of the power supply and particle imaging system is shown in Figure 3.3. These systems serve two important functions in the successful operation of the electrodynamic balance. The power supply system generates the necessary AC and DC potentials for application to the electrodes, and the particle imaging system enables a particle to be stably suspended by controlling the DC voltage.

The AC power supply consists of a transformer and an amplificr which are excited by a signul generator, and is capable of operating in a frequency range of $10 \mathrm{~Hz}$ to $100 \mathrm{~Hz}$ with a maximum output voltage of 2,500 Volts (peak-to-peak). This voltage is applied to the ring electrode and provides adequate field strength to capture a charged particle. DC power for the end electrodes is drawn from a high voltage power supply and rectifier system. This DC voltage is applied to the ond electrodes via the balance control amplifier and the particle imaging system. The latter controls the DC voltage under automatic mode of operation, and also allows manual adjustment of the end electrode voltage.

The particle imaging system consists of a high resolution black and white video camera, CRT monitor, and a microprocessor-based feedback control system. The particle is back illuminated by a variable power light emitting diode (LED) which is fixed rigidly in one of the holes in the ring electrode. The resulting image is converted into a video signal by the video camera which is equipped with extension tubes to give a net magnification of about 100. The camera is mounted on a set of traversing mounts which enable accurate movement in three directions. This image is displayed on a CRT monitor and also recorded on video tapes via a video cassette recorder (VCR). The hardware also enables viewing of the videotapes for analysis purposes. Both the video camera and the CRT monitor are placed on their sides 80 as to give high resolution in the vertical direction (1024 pixels as against 512 in the horizontal direction).

The video signal is also fed to the microprocessor for image analysis. The microprocessor sets up ite own imuging area in the CRT which is about half the screen area, located in its center. For the current application this scanned area is sufficient for image analysis purposes. The camera was adjusted so that the image was located in the center of the scanned area and the microprocessor analyzes the pixel pattern to identify the particle image. The particle position can then be 
controlled either manually or automatically by adjusting the DC voltage. Under automatic mode, the image analysis algorithm "recognizes" vertical movement of the particle and sends a correction signal to the DC power supply via the balance control amplifier. The resulting increase or decrease in DC voltage to the end electrodes causes the particle to be restored to the balance center where it is stable. This automatic DC voltage adjustment was updated at a frequency of $15 \mathrm{~Hz}$ by the particle imaging system. The microprocessor also stores the pixel count and other image statistics in the memory which are accessed by an IBM Personal Computer (PC). Several controls provide flexibility in the operation of the imaging system. These include, threshold control for black-to-white transition in pixel color, gain of internal amplifier, manual variation of DC voltage, and adjustment of pixel count acquisition frequency. The hardware configuration allowed four sampling frequencies $(1.87 \mathrm{~Hz}, 3.75 \mathrm{~Hz}, 7.5 \mathrm{~Hz}$ and $15 \mathrm{~Hz})$ with a maximum sample size of 677 pixel counts. In addition to acquiring the pixel count, the PC is also configured to read the applied DO voltage via an $A / D$ converter.

\subsection{Air Supply System}

Figure 3.4 shows the air supply system tor the experimont. Compressed air from the station air supply system was used for the experiments, after passing it through filters and dryers in order to remove water and oil. Valve V1 provides isolation of the system from the high pressure supply at $1.034 \mathrm{MPa}(150$ psi) thereby enabling maintenance tasks downstream of the valve. The pressure regulator PR1 maintains constant pressure for use in the experiments. Air then passes through a heat exchanger with facility for oil circulation from a constant temperature oil bath. This process reduces fluctuations in the air temperalure and, hence, in its viscosity. The air flow is controlled by a needle valve, V2, which is then metered by a laminar flowmeter (LFM). A transducer connected across the LFM gives a digital output proportional to the pressure drop which is displayed on a readout unit and simultaneously accessed by the latroratory $\mathrm{PC}$ for recording and subsequent analysis. The air finally passes through an inlet jipe attached to the bottom of the electrodynamic balance. The top part of the inlet pipe fits into the bottom cap and the bottom electrode, and serves as the air jet nozzle. This pipe is held in place by an inlet pipe holder which is concentric with the inlet pipe and is rigidly bolted to the bottom electrode. A set of three screws enable adjustment of the inlet pipe relative to the holder and, hence, to the balance. This deaign enables reorientution of the jet in order to make it concentric with the vertical center line of the balance. Both, the inlet pipe and its holder, were made of plexiglas to provide adequate safety. For start-up purposes, il is esacntial to avoid a pressure surge and, hence, a system of on-off type valves, V3 and V4, was incorporated in the system. Valve $V 3$ vents to the atmosphere and V4 is in series with the main air flow.

In order to make jet velocity measurements with the LDA, the air was seeded with submicrun sized glass particles. The seeding chamber consists of a-steel vessel and a removable cover with two nozzle

connections for air inlet and outlet. Particles from the vessel are entrained in the flow and these serve as scattering sources for the LDA. 
The air was not seeded during drag measurements. All the piping up to the inlet pipe was made of stainless steel, except the connections to the seeding chamber which were made of Polyflo tubing. The piping was rigidly fixed to the optical table and grounded for additional safety. The straight section of the inlet pipe was $15 \mathrm{~cm}$ long, thereby providing a length/diameter ratio of 25, the inlet pipe inside diameter being $6 \mathrm{~mm}$. This straight portion after the final bend is adequate to overcome the bend effects on the fluid mechanics of the exiting jet. After entering the balance enclosure, the jet exits through holes in the top electrode and its cap.

\subsection{Laser Doppler Anemometer (LDA) System}

In order to obtain velocity and turbulence data for the air jet, a Laser Doppler Anemometer (LDA) system was used. The system consisted of a single-component fiber-optic probe manufactured by TSI, Inc.

Figure 3.5 shows a schematic of the LDA system. Monochromatic light is provided by a continuous wave, variable power Argon-ion laser which has two major emission lines, viz., Blue $(\lambda=488 \mathrm{~nm})$ and Green $(\lambda=514.5 \mathrm{~nm})$. The output beam from the laser was collimated and then paran through a colol sepurator. After separating the two beams, the green beam was blocked and the blue was used for the LDA. This blue beam was passed through a polarization rotator which enabled the polarization of the outgoing beam to be adjusted so that the direction was in the plane of the beam splitter. The beam splitter produced two beams of equal intensity spaced $50 \mathrm{~mm}$ apart. One beam was then frequency shifted in a Bragg cell (Acousto-Optic or A/O cell) by a fixed value of $40 \mathrm{MHz}$. In order to ensure equal optical paths, the unshifted beam was passed through a glass block.

These two beams were coupled into two separate optic fibers by a double input coupler which consists of two units, viz, a translating module and a coupling module. The translating module is used to provide gross adjustment in a plane normal to the two beams before they enter the coupling module. Two glass blocks of high optical quality, one for each beam, are used in this module and each block can be tilted by two adjusting screws to displace the beams. The coupler module provides fine adjustments to the two beams coming out of the translator and couples them into each fiber. It contains two plano concave lenses, one for each beam, each focusing one beam to the correct size necessary for coupling to the optical fiber. Each lens can be moved in three mutually perpendicular directions so that the beam is focused on the fiber tip. The transmitting fibers are single mode, polarization preserving and are connected to the junction box. At the junction box, a third fiber, viz., the receiving fiber, is grouped together with the two incoming transmitting fibers to form a three fiber bundle which is 10 meters long and ends in the probe.

The probe itself, see Figure 3.6, is cylindrical in shape with a diameter of $15 \mathrm{~mm}$ and a length of $100 \mathrm{~mm}$. Additional details of the probe are given in Table 3.1. The small size of the probe and long fiber cable provide excellent versatility in positioning the probe. 
Table 3-1

Salient Features of the Fiber Optic Probe

1. Probe dimensions

2. Working distance

3. Bean spacing

4. Beam diameter

5. Fringe spacing

6. Measuring volume diameter

'1. Measuring volume length

8. Nuniber of fringes
$15 \mathrm{~mm}$ dia. x $100 \mathrm{~mm}$ long

$60 \mathrm{~mm}$

$8 \mathrm{~mm}$

$0.35 \mathrm{~mm}$

$3.67 \mu \mathrm{m}$

$106 \mu \mathrm{m}$

$1.6 \mathrm{~mm}$

29

The fiber cable enters at one end of the prove after which the three individual fibers are separated. The two beams from the transmitting fibers end in collimating lenses and are focused by the transmitting lens to form the measuring volume. Light scattered by particles passing through the measuring volume is collected in backscatter mode by the same (transmitting) lens. This collimated light is focused on the end of the receiving fiber by the receiving lens, and led to a photomultiplier tube (PMT) which is equipped with an inbuilt variable gain amplifier. This combination of variable power laser and variable gain PMT enables operation of the LDA over a large range of operating conditions. Elcctrical output from the PMT was led to the Bragg cell power supply which contains a downmix circuit, The $40 \mathrm{MHz}$ shift in the signal can be changed to a value in the range of $2 \mathrm{KHz}$ to $10 \mathrm{MHz}$ by this downmix circuit thus increasing the sensitivity of the LDA to signals in a specific range of interest.

The signal was then fed to a counter-type signal processor before being acquired and stored on a PIP-11/23 computer. In the processor, the signal is amplified by a variable gain amplifier and then filtered by an amplitude discriminator which isolates signals from large sized particles. It is then passed through a set of low-limit and high-limit filters to remove low and high frequency noise. The signal is then checked for mlnimum number of valid cycles and accuracy of the burst periods by two logic circuits with adjustable settings. 'l'he slgual is thon sent to the timer module and, finally, to the data interface module. The former displays two numbers which are useful in monitoring the experiment. One is a voltage proportional to the doppler frequency and the other gives the dula rate, i.e. number of valid signals per second. The interface module converts the incoming signal into a set of three numbers, viz., number of cycles (N), time taken to cross $N$ cycles, and time between data, which are transferred to the computer by a DMA 
link. Software on the PDP computer analyzes this data and outputs velocity statistics (mean and turbulence) and also displays velocity histograms on the CRT.

\subsection{Particles}

- During the course of this research, experiments were conducted with both spherical and nonspherical particles. Commercially available microspheres of different diameters were used for both calibration of the imaging system and for drag measurements. These included glass microspheres of mean diameter $105 \mu \mathrm{m}$, and Polystyrene Latex (PSL) microspheres of mean diameters $136 \mu \mathrm{m}$ and $160 \mu \mathrm{m}$. The manufacturer's quoted standard deviation in the diameters of these spheres was $4.5 \mu \mathrm{m}$, $10.1 \mu \mathrm{m}$, and $6.9 \mu \mathrm{m}$, for spheres of diameters $105 \mu \mathrm{m}, 136 \mu \mathrm{m}$, and $160 \mu \mathrm{m}$, respectively. Nonspherical particles comprised pulverized coal (Montana Rosebud) and crushed oil shale (Colorado Mahogany). These particles were screened through 100 mesh and 150 mesh sieves to isolate particles in the size range from $105 \mu \mathrm{m}$ to $148 \mu \mathrm{m}$. This size range was selected because microspheres of this size were most easily captured and suspended in the electrodynamic balance.

\subsection{Dat.a Acquieition and Aublysts System}

This system comprised of two major and independent idata acquisition systems. The first system enabled data acquisition and analysis for the LDA and has been described in detail in Section 3.4 above. The second system utilized an IBM PC-AT for data acquisition from the electrodynamic balance, viz., DC voltage, LFM output voltage, and the image pixel count. This data was analyzed on the PC itself and stored on disks. It was subsequently transferred to a VAX 11/750 computer for further analysis. Details of this system are given below.

Pixel count from the particle imaging system was down-loaded from the imaging system microprocessor to the PC and stored in a file. This data was then input to another program which computed the mean pixel count. The mean pixel count was calibrated against the sphere diameter and this correlation was subsequently used for obtaining the area equivalent diameter $\left(d_{e}\right)$ for nonspherical particles. The projected area and, hence, the mean diameter for the spheres was correlated to the pixel count by the relation:

$$
\begin{aligned}
& A=k_{1}^{\prime} \cdot P+k_{2}^{\prime} \\
& d^{2}=k_{1} \cdot P+k_{2}
\end{aligned}
$$

The correlation in equation $3-2$ was used in subsequent programs to calculate the area equivalent diameter, $d_{e}$, for nonspherical particles. In order to obtain drag data, the inputs required are the jet velocity (obtained from the LFM read out) and the balance voltage. Pairs of this data were acquired by $A / D$ converters which were activated by a common switch. A calibration of the LFM output and jet velocity (from LDA measurements) was developed (see Section 4.4 for details) and this 
together with the balance DC voltage, $\mathrm{V}_{\mathrm{dc}}$, was used to calculate the drag coefficient and Reynolds number, details of which are given in Section 4.6 .

The data, comprised of the drag coefficient, $C_{d}$, and Reynolds number, Re, was stored on a hard disk and backed up on floppy disks for 'further analysis.' It was subsequently transferred to the central DEC-8650 computer system where SAS programs were: developed to analyze and plot the results.

$\therefore$ 

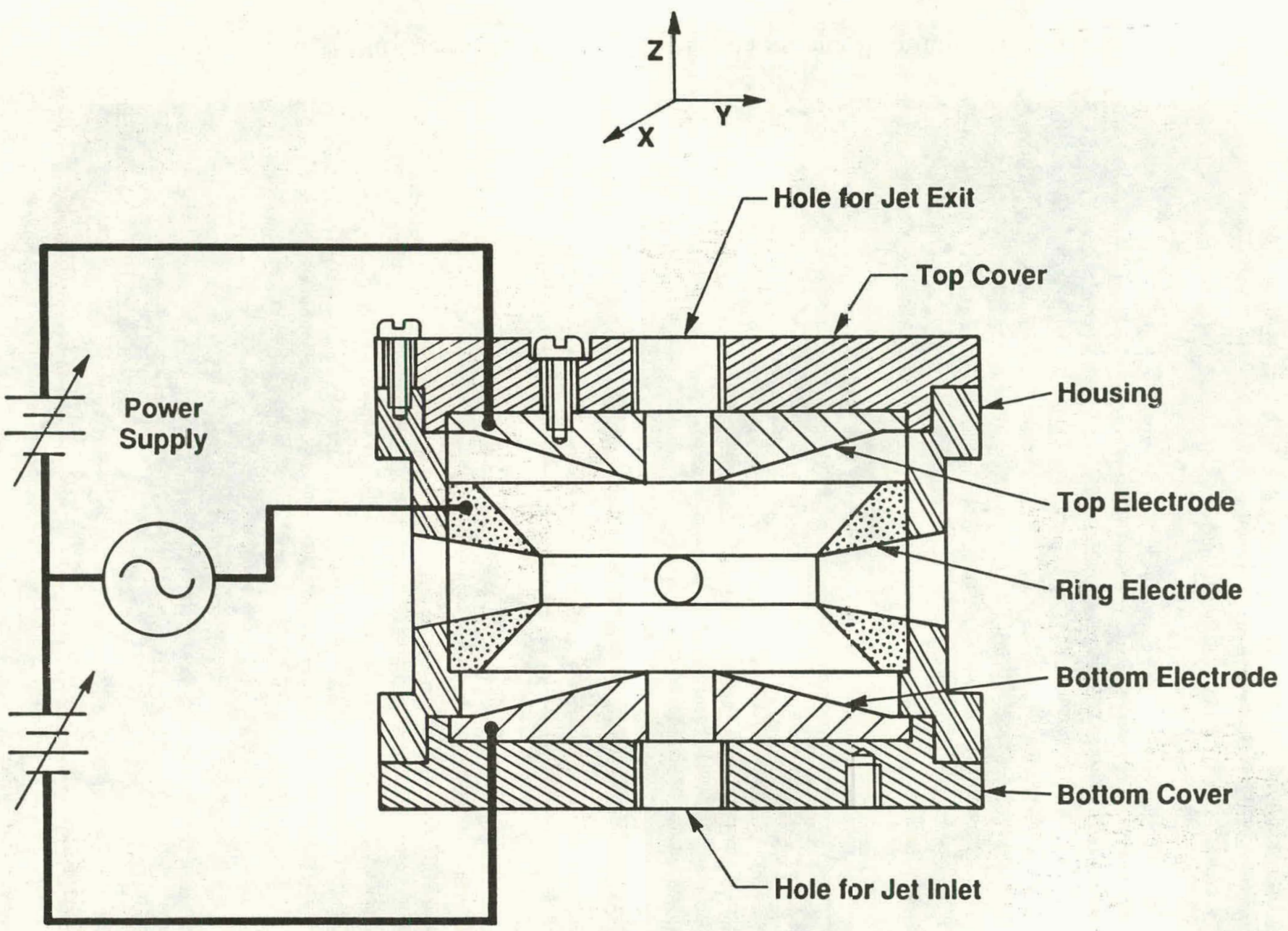

Figure 3.1. Cross-sectional View of the Electrodynamic Balance. 


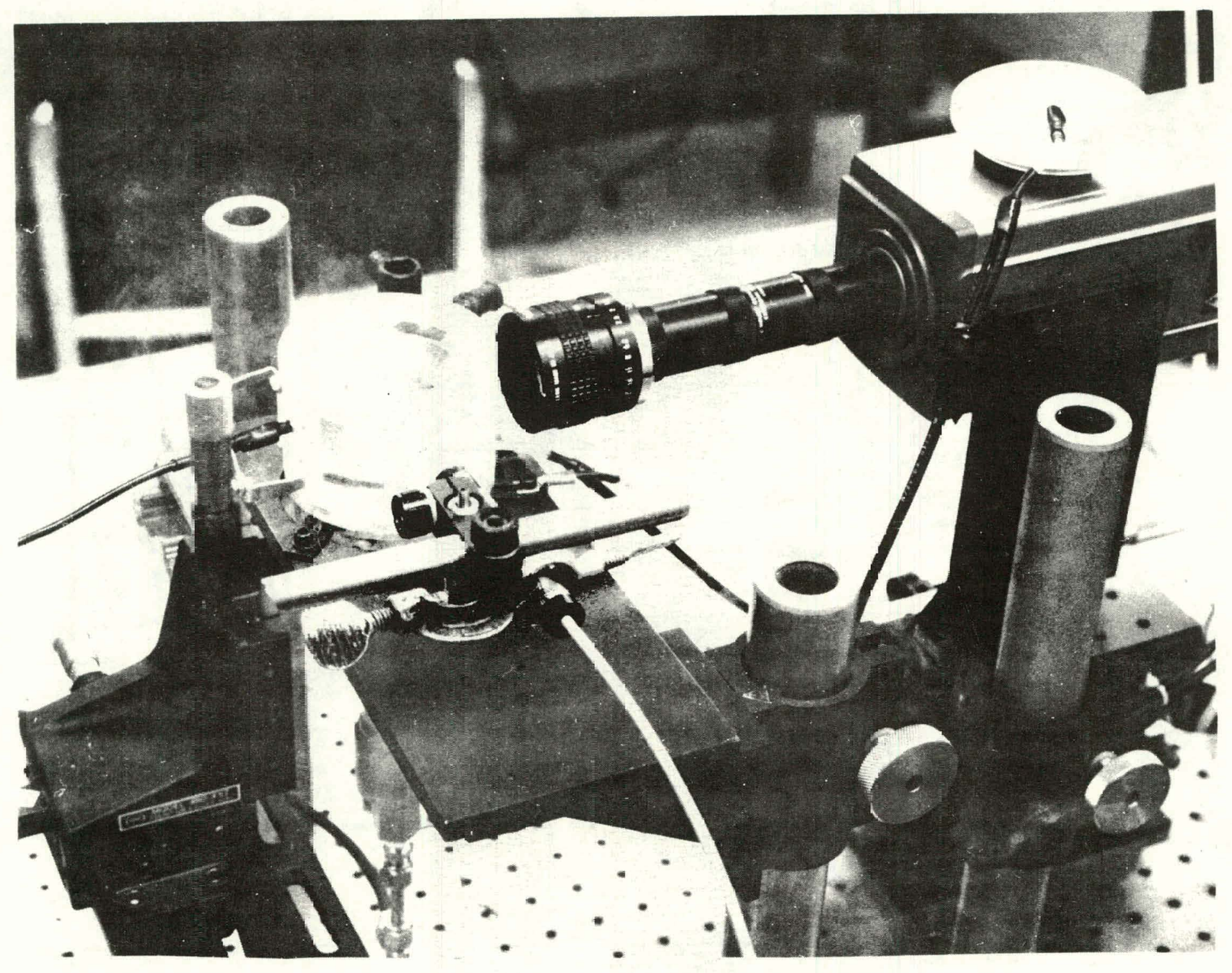

Figure 3.2. Photograph of the Electrodynaimc Balance Facility. 


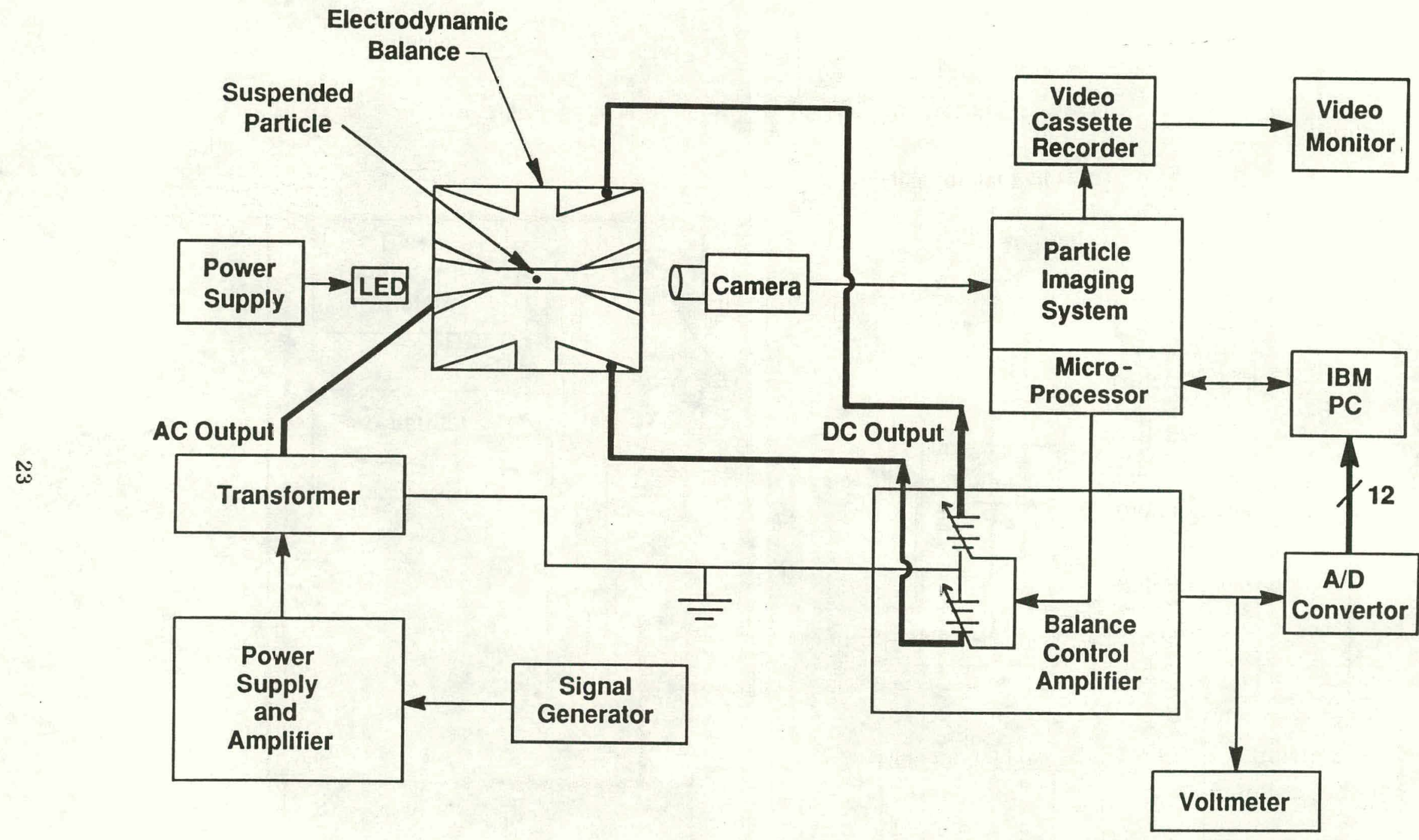

Figure 3.3. Schematic Diagram of the Power Supply and Particle Imaging System. 
Compressed Air (Filtered and Dried)



Figure 5.4. Schematic Diagram of the Air Supply System. 


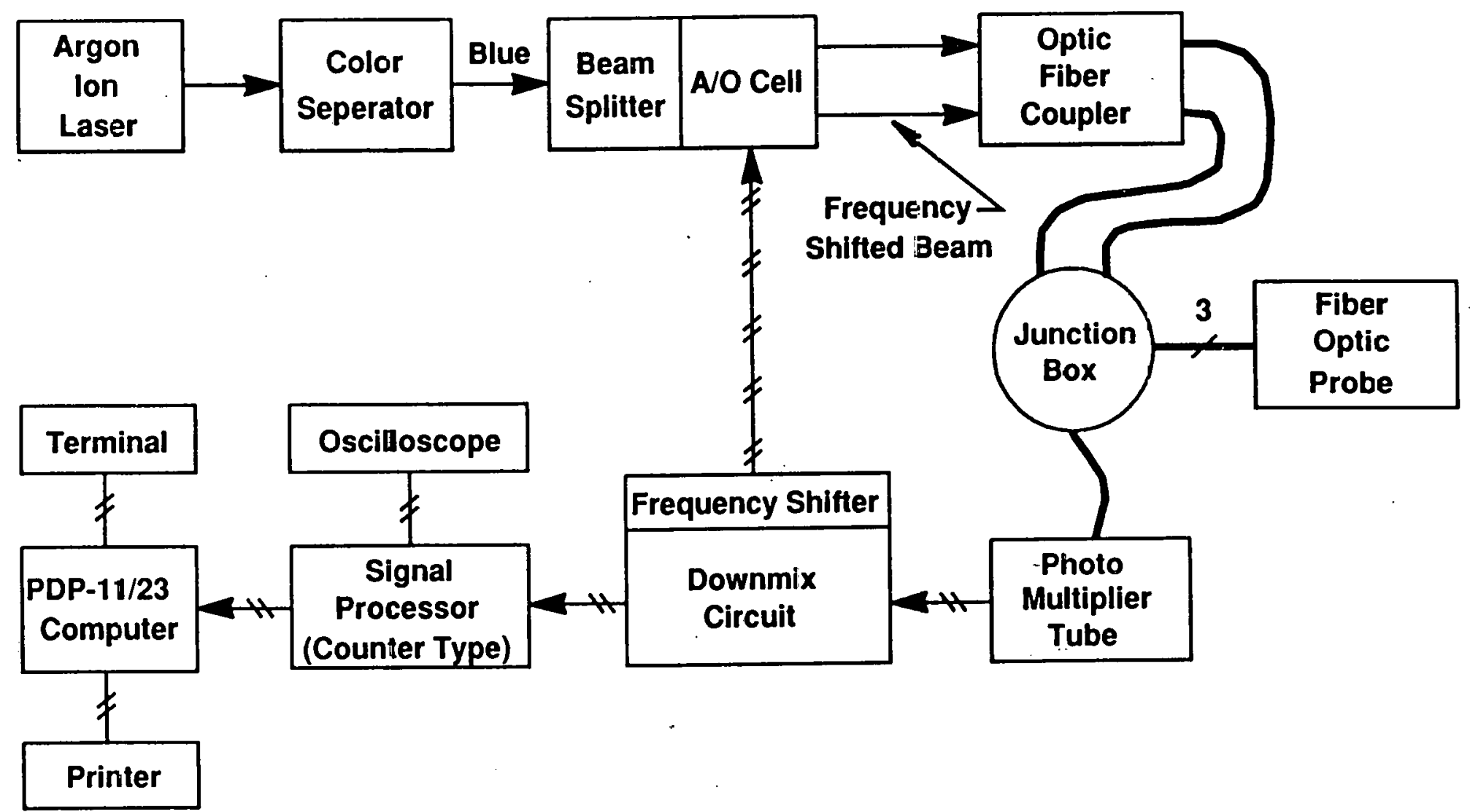

Figure 3.5. Schematic Diagram of the Lager Dopfler Anemometer System. 




Figure 3:6. Schematic Diagram of the Fiber Optic Probe. 


\section{Chapter 4}

\section{EXPERIMENTAL PROCEDURES}

This chapter describes the experimental procedures followed in conducting the experiments. Details are presented on the general procedures, equipment qualification, and data acquisition and analysis.

\subsection{Particle Preparation}

The experiments were conducted with spherical and nonspherical particles. Commercially available spherical particles were procured with mean diameters of $105 \mu \mathrm{m}$ (glass), and $136 \mu \mathrm{m}$ and $160 \mu \mathrm{m}$ (Polystyrene Latex, PSL). Scanning electron microscope (SEM) photographs of these particles are shown in Figures 4.1, 4.2, and 4.3 for $105 \mu \mathrm{m}, 136 \mu \mathrm{m}$ and $160 \mu \mathrm{m}$ diameter spheres, respectively. As can be seen, these particles are spherical in shape. The manufacturer's quoted standard deviation for these samples were $4.5 \mu \mathrm{m}, 10.1 \mu \mathrm{m}$, and $6.9 \mu \mathrm{m}$ for spheres of diameter $105 \mu \mathrm{m}, 136 \mu \mathrm{m}$, and $160 \mu \mathrm{m}$, respectively.

Nonspherical particles comprised coal (Montana Rosebud) and oil shale (Colorado Mahogany) in the size range from $105 \mu \mathrm{m}$ to $148 \mu \mathrm{m}$, corresponding to a mesh size of 150 and 100 respectively. The sizes available on station at METC were sieved to obtain particles of desired size. Figures 4.4 and 4.5 show SEM photographs of the coal and oil shale samples, respectively. These figures show that the coal is chunky in shape (less than about $20 \%$ variations in the three major dimensions) while the oil shale is flake-like. All the particles were stored in plastic bottles for subsequent use.

\subsection{Particle Suspension Method}

In order to suspend a particle in the electrodynamic balance, two conditions need to be satisfied, viz., (i) a charged particle must be introduced into the balance, and (ii) an electric field capable of capturing the charged particle must be established in the balance. Based on the experience of Maloney et al.(1985), it was observed that the AC field alone is enough to first capture a charged particle. In order to visually observe the suspended particle the LED and video camera were first powered up and a small object (tiny screw) was suspended at the balance center by a wire. A combination of extension tubes and magnifying lenses were then attached to the camera to obtain a magnification of about 100 on the CRT with the focus at the balance center. The final combination used included a $40 \mathrm{~mm}$ focal length lens with $120 \mathrm{~mm}$ extension tubes. In order to capture a particle, the DC potential was set to zero; the signal generator was adjusted to a frequency in the range of $35 \mathrm{~Hz}$ to $45 \mathrm{~Hz}$ with a peak-to-peak amplitude of about 8 Volts (corresponding to 1,600 Volts at the balance); and the top cover (with the top electrode) was removed.

In order to charge the particles, the bottle containing the particles was shaken vigorously. Some particles became charged by this process and adhered to the cap. The cap was then unscrewed, held over the 
open balance and hit sharply causing some of the charged particles to fall into the balance. The prevailing AC field would catch one or more particles which could be seen on the video terminal. At this time, the top cover was replaced and the DC potential was applied which lifted the particle(s) to the balance center. In the event that a single particle was caught, it would oscillate vertically at off-center positions and only at the balance center would it be perfectly stable. If several particles were caught, a situation not entirely uncommon, then they would oscillate vertically with the positions forming the corners of a polygon in the horizontal plane. Under this condition, the field AC frequency was momentarily reduced causing some of the particles to fall down to the balance bottom. This procedure was repeated, as required, until only one particle was left in the balance. Finally, the DC voltage was adjusted to bring this single particle to the balance center where it would remain stably suspended for long time periods. A photograph of the image of a suspended $160 \mu \mathrm{m}$ diameter sphere on the video terminal is shown in Figure 4.6.

The focusing of the electric field kept the particle along the center line of the balance. At off-center vertical pusilions, the particle would oscillate in a vertical line. The particle would be perfectly stable only at the balance center at which point, the upward electric force from the DC potential would be equal to the weight of the particle.

\subsection{Balance Level Adjustments}

After suspending a particle stably, the DC voltage was slightly changed causing the particle to oscillate vertically at an off-center vertical position. Sometimes, the oscillations would be inclined to the vertical as seen on the terminal. This observation was attributed to the fact that the vertical centerline of the balance was not true with the gravitational vertical. Since the balance was rigidly fixed to the optical table, this defect could be corrected only by adjusting the table mounts. Each of the four pncumatic isolation/adjustment mounts were pressurized until the particle oscillation was observed to be perfectly vertical. This process was repeated prior to the start of an experimental run to ensure that the balance vertical line (and hence the vertical centerline of the electric field) was true with the gravitational vertical.

\subsection{Jet Calibration}

In order to obtain accurate drag data it is important to calibrate the jet. Towards this end, the jet velocity profile needs to be accurately known. Further, making center line velocity measurements during drag data acquisition is a time consuming task and, hence, it was decided to calibrate the LFM output against the centerline velocity with the $A C$ and DC fields turned off. Further, it was also observed that a particle laden jet over a suspended particle resulted in seed particles attaching themselves to the suspended particle. It is also possible that the jet calibration with the AC and DC fields powered would influence the motion of the seed particles. It was, therefore, necessary to calibrate the LFM output in terms of the jet centerline velocity with the electric field turned off. Since the electrodynamic balance stably captures a 
charged particle at its center, it was imperative to make jet velocity measurements in a horizontal plane through the center. Thus, these measurements were about 1.4 diameters downstream of the jet exit nozzle.

Prior to performing velocity measurements, it was necessary to locate the measuring volume at the balance center. For this purpose, the LDA was energized after clamping the probe to the three axis translating mount so that the beams intersected in a vertical plane with the fringe movement being downwards, i.e. against the jet flow. The measuring volume was then adjusted, by the three micrometer screws, to bring it approximately near the balance center. For this purpose one of the access holes in the ring electrode was used (Figure 3.2). A $160 \mu \mathrm{m}$ PSL sphere was then suspended in the balance and the three axes translation stage was adjusted to make the measuring volume coincident with the sphere. Under this condition, the sphere was brightly illuminated by both beams and this could be seen on the CRT. This adjustment confirmed that the measuring volume was coincident with the balance center and, hence, with the vertical centerline of the jet. The system was then geared up for making LDA measurements.

The electric fields were then turned off and a small amount (about $50 \mathrm{gm}$ ) of submicron sized lens grinding glass was put in the seeding chamber. The air flow was started and after checking the system for any leaks, the flow was seeded by shaking the seeding chamber. This caused some of the submicron glass powder to be entrained in the flow and serve as scattering sources for LDA measurements. Streamwise velocity measurements were made at the jet center and then at regular intervals of $0.5 \mathrm{~mm}$ in each of the two transverse radial directions, $\mathrm{X}$ and $Y$ in Figure 3.1. The jet flow was set at a typical value for this purpose and the velocity, mean and turbulence, were acquired and analyzed on the PDP-11 computer. The velocity histograms were displayed on the terminal and the Doppler bursts were continuously monitored on a oscilloscope. The first set of measurements showed that the jet velocity profile was asymmetric about the center line. This result was unacceptable and necessitated readjustment of the inlet pipe. After a couple of iterations with pipe adjustments, the velocity profiles were observed to be symmetric about the jet centerline, refer Figure 4.7. These profiles also show that for suspended particles up to $200 \mu \mathrm{m}$ in diameter, the flow field can be considered to be uniform for about five diameters around the particle. A suspended particle can, therefore, be considered to be in a uniform flow field which can be characterized by the jet centerline velocity.

The laminar flow meter (LFM) output was then calibrated against the jet centerline velocity, as measured by the LDA. This calibration was performed up to the full capacity of the air system, i.e. needle valve V2 in fully open position. The calibration result is given in Figure 4.8 and shows a cubic fit which was performed on the data:

$$
\mathrm{U}=\mathrm{C}_{0}+\mathrm{C}_{1} \cdot \mathrm{V}+\mathrm{C}_{2} \cdot \mathrm{V}^{2}+\mathrm{C}_{3} \cdot \mathrm{V}^{3}
$$


where, $U$ is the jet centerline velocity in $\mathrm{m} / \mathrm{s} ; \mathrm{V}$ is the LFM output in Volts; and, $\mathrm{C}_{0}$ thru $\mathrm{C}_{3}$ are constants. The calibration fit yielded the following values:

$$
\begin{aligned}
& C_{0}=-0.0346 \\
& C_{1}=+0.1029 \\
& C_{2}=+8.5766 \times 10^{-3}, \text { and } \\
& C_{3}=-5.165 \times 10^{-4}
\end{aligned}
$$

The calibration was performed for jet velocities up to $1.64 \mathrm{~m} / \mathrm{s}$ and the measured turbulence intensity was less than $5 \%$. With this calibration in place, the air flow rate and, hence, the desired centerline velocity could be achieved by selecting the corresponding value on the LFM readout and adjusting control valve V2 (Figure 3.4). This flow calibration and characterization eliminatco the need for l.DA use at each point during drag measurements. Centerline velocity variations near the balance center could not be peiformed bocause nf I.DA beam interference with the access holes in the central electrode.

\section{4:5 Imaging System Calibration}

The imaging system was calibrated to convert the pixel count from the video image to the diameter (for spherical particles) or to an area equivalent diameter (for nonspherical particles).

\subsubsection{Optimization of Sygtem Settings}

In order to obtain a reliable and accurate correlation, several variables in the hardware needed to be optimized. These were (a) LED power supply voltage; (b) balance cuntrol amplifier gain; (c) video threshold level; and (d) background illumination. In order to evaluste and optimize the above variables, a $160 \mu \mathrm{m}$ I'SL ophor war suspended in the balance and the pixel count obtained under various combinations of the above variables. The imaging system would acquire, and then transfer to the PC, a set of lip to 677 pixel counts. These counts would be stored in a file on the disk drive for further analysis. A sepurate program would then be activated to read 100 valuco and calnulate the mean pixel count for that particular set. It was observed that the first 100 points were sufficient to give an average for the whole set and it was used as a parameter in comparing the effects of the four factors listed above.

\section{a. LED Power Supply}

The LED was powered by a variable voltage DC power supply unit. which could be used to vary the intensity of the emitted light. The voltage was varied from 8 Volts to 12 Volts and the pixol count was observed to decrease when the other parameters were constant. A supply voltage of 10 Volts was, therefore, selected as an optimum value for further studies. 


\section{b. Balance Control Amplifier Gain}

The gain on the balance control amplifier can be varied by a knob on the front panel. Effects of this parameter on the pixel count were studied and an optimum value of 665 on the dial was selected for all experiments.

\section{c. Video Threshold Level}

Transition of the video picture pixels from black to white, and vice versa, is governed by a variable setting which can be adjusted manually. Each pixel is illuminated on the screen by 256 shades of grey ranging from black to white. The value at which the change of color is identified can be changed manually by a knob on the front panel of the particle imaging system. As can be seen from Figure 4.6, the video picture appears black on a white background. Thus, increasing the threshold and, hence, a darker shade of grey, would increase the pixel count of the picture. The sensitivity of the pixel count to threshold setting was found to be substantial and it was also seen to adversely affect the response of the imaging system. An optimum value of 40 was selected and the knob locked at that value for the duration of the exporiments.

\section{d. Background Illumination}

The optical table was located inside a closed laboratory building with no windows. As such, the imaging system was not affected by variations in sunlight. Within the room itself, the apparatus was located under a fume hood equipped with fluoroscent lights in addition to those in the room. It was found that with the hood lights turned on, the pixel count would decrease because of greater background illumination of the particle. It was, therefore, decided to switch off these lights throughout the experiments.

\subsubsection{Imaging System Calibration}

With the above adjustments in place the imaging system was then ready for calibration. In general, the projected area of a particle can be correlated to the pixel count by a linear relation, such as:

$$
A=k_{1}^{\prime} P+k_{2}^{\prime}
$$

where, $A$ is the projected area; $P$ is the pixel count; and, $k_{1}$ and $k_{2}$ are constants. The above relation can also be expressed as:

$$
\begin{array}{ll}
d^{2}=k_{1} P+k_{2} & \text { (spherical particles) } \\
d_{e}^{2}=k_{1} P+k_{2} & \text { (nonspherical particles) }
\end{array}
$$

The calibration constants, $k_{2}$ and $k_{2}$, were obtained by suspending twenty spheres each of diameter $105 \mu \mathrm{m}, 136 \mu \mathrm{m}$, and $160 \mu \mathrm{m}$ and recording their pixel counts. It was necessary to suspend a large 
number of spheres of each size due to variations in the manufacturer's quoted nominal diameter. In each case, a sphere was suspended and 100 values of the pixel count were taken at a frequency of $15 \mathrm{~Hz}$. These counts were then averaged and stored in a file. This procedure was repeated for twenty spheres of each of the three sizes, and the mean of these twenty measurements was taken as the mean for the nominal diameter. Finally, a linear fit was performed between the nominal diameter and the pixel count. The calibration yielded the following values for equation $4-4 \mathrm{~b}$ to yield the diameter, $d$, in micrometers.

$$
\begin{aligned}
& k_{1}=42.94, \text { and } \\
& k_{2}=1897
\end{aligned}
$$

During the experiments, the images were recorded on video tapes for future analysis with a frame grabber.

\subsection{Drag Measurements}

Experiments to measure drag coefficient against Reynolds number were conducted for spherienl and nonspherical particles. The procedure for both of these was the same and is described below. Experiments will spheres were performed to qualify the apparatus against published data in the literature.

\subsubsection{Data Acquisition}

In order to obtain drag data, a particle was first suspended in the balance. During this process valve V4 was, closed and V3 opened, and the particle was tracked by the imaging system in automatic mode. The imaging system was then used to obtain 100 samples of the pixel count which were subsequently averaged by another program on the PC. The main data acquisition program was started and the pixel count was input to it. Using the calibration equations $4-4 b$ and $4-5 a, b$, the program computed a diameter ( $d$ or $d_{e}$ ) for tho particle. This procedure would give the diameter of a sphere and an area equivalent diameter for a nonspherical particle. The latter was a good representative dimension for coal particles which were chunky with the three maximum dimensions within $20 \%$ of one another. This representation would, however, not work satisfactorily for oil shale particle which were flake-like in shape. Since the flakes oriented vertically in the balance, the viewing direction would significantly affect the pixel count, in most cases by a factor of as much as two. These particles were, therefure, rotated slowly (about 8 seconds/revolution) by starting the air jet and 100 pixel counts were obtained for about two revolutions with a data acquisition frequency of $7.5 \mathrm{~Hz}$. The area equivalent diameter $\left(\mathrm{d}_{c}\right)$ was computed from the mean of this pixel data. This value was then utilized for all subsequent computations, viz drag coefficient and Reynolds number. Details of these calculations, which were executed in FORTRAN, are given below in Section 4.6.2.

The first data point, with no flow, was used to calculate the balance constant. (See Section 4.6 .2 for details). The particle imaging system was then commissioned and the jet started. In order to avoid the 
starting surge valves V3 and V4 (Figure 3.4) were used in tandem. The needle valve, V2, was cracked opened and then valve V4 was slowly opened. The bypass valve, V3 was then slowly closed enabling all the flow to pass through the balance. The jet would push the particle upwards but the imaging system would bring it back to the balance center. The air flow was set to a desired value and a control switch was pressed to activate recording of the balance DC voltage and LFM output on the PC. Using these input data, the software program, on the PC, described in Section 4.6.2, would calculate and display the corresponding drag coefficient and Reynolds number on the screen. The needle valve was further opened and another pair of data points obtained. This process was repeated until the balance DC voltage was zero, indicating that the particle was suspended only by the drag on it. Under this condition, the jet velocity would be equal to the terminal velocity of the particle. The jet velocity was further increased and additional data points were taken until the balance voltage reached its starting value but with opposite polarity. This condition indicated that the jet velocity was twice the particle terminal velocity. Data acquisition was continued until either the air supply system or the DC power supply system reached their full capacity. The flow was then reduced, by control valve $V 2$, and data taken at regular intervals until the jet flow was zern. Not all the particles could be tested for the full capacity of the system. Instabilities, particularly for coal and oil shale, limited the experimental data range and this aspect is discussed in detail in Chapter 5 . Typically, about 40 data poinls were taken for spheres, 25 for coal and 10 to 15 for oil shale particles. All the data was stored on a disk for future use. This data was also transferred to the central VAX cluster where SAS routines were used to analyze and plot the data.

\subsubsection{Data Analysis Procedure}

Inputs to the main data acquisition and analysis program include LFM readout, balance DC voltage, pixel count for the particle image and ambient temperature. To reduce uncertainities in the measurement the LFM and DC voltage were each sampled 500 times for each data point and the mean taken for calculation purposes. The diameter, or area equivalent diameter, was calculated using equations 4-4b, 4-5a, and 4-5b. Similarly, using equations 4-1 and 4-2, the LFM readout was converted into a velocity. The particle Reynolds number was then computed using the relation:

$$
\begin{aligned}
& R e=\frac{U \cdot d}{\nu}, \text { or } \\
& R e=\frac{U \cdot d_{e}}{y}
\end{aligned}
$$

The kinematic viscosity of air, $\nu$ (in $\mathrm{m}^{2} / \mathrm{s}$ ) was calculated from the air temperature, $\mathrm{T}$ (in Kelvin) using the following relation:

$$
\nu=(0.092 \mathrm{~T}-11.876) \times 10^{-6}
$$


The drag coefficient, $C_{d}$, is defined as:

$$
C_{d}=\frac{F_{D}}{\frac{i}{2} \rho_{Q} U^{2} \cdot A}
$$

Here, $F_{D}$ is the drag force on the particle at air velocity $U$ and $A$ is the projected area in the direction of the flow. The projected area, A, was calculated by the following relations:

$$
\begin{aligned}
& A=\frac{\pi d^{2}}{4}, \text { or } \\
& A=\frac{\pi d_{e^{2}}}{4}
\end{aligned}
$$

The density of air, $\rho_{a}$, was calculated using the relation

$$
p_{u}=2.638-0.00397 \mathrm{~T}
$$

where, $\mathrm{T}$ is in Kelvin and $\rho_{\mathrm{a}}$ in $\mathrm{kg} / \mathrm{m}^{3}$.

In the presence of a jet the forces on a suspended particle can be expressed as in Figure 4-9. In general, the force balance on a suspended particle can be written in terms of the particle weight, $W$ (=mg); the electrostatic force $F_{E}$; and, the drag force $F_{D}$ as:

$$
w=F_{D}+F_{E}
$$

At velocities in excess of the terminal velocity, $v_{t}$, the electric force reverses direction and, hence, $F_{E}$ changes sign. $F E$ can also be expressed as:

$$
F_{E}=q \cdot K_{B}^{\prime} \cdot V_{d c}
$$

where, $\mathrm{q}$ is the charge on the particle; $\mathrm{K}_{\mathrm{B}}$ the balance constant, and $V_{\text {dc }}$ the balance DC voltage. Equation 4-12 also shows that the clectrostatic force is independent of the applied AC polential or its frequency. This condition is true at the balance center where the particle is stable and is influenced by the DC field only. At zero air velocity,

$$
\begin{aligned}
W & =F_{E} \\
& =q \cdot K_{B}^{\prime} \cdot v_{d c}, 0
\end{aligned}
$$

Assuming the charge on the particle to remain constant, a condition which was true in the experiments, a modified balance constant for the particle can be obtained as: 


$$
K_{B}=q \cdot K_{B}^{\prime}=\frac{w}{V_{d c, 0}}
$$

where,

$$
\mathrm{W}=\mathrm{mg}
$$

For a sphere

$$
\mathrm{m}=\frac{\pi \cdot \mathrm{d}^{3}}{6} \cdot \rho
$$

For nonspherical particles, the mass was calculated as:

$$
\mathrm{m}=\frac{\pi \cdot \mathrm{d}_{\text {e }}^{9}}{6} \cdot \rho
$$

Uncertainities resulting from using $d_{e}$ in calculating the area and mass of nonspherical particles are discussed in detail in Chapter 6. The

\begin{tabular}{|c|c|c|}
\hline & Particle & Density, $\rho,\left(\mathrm{kg} / \mathrm{m}^{3}\right)$ \\
\hline & $\begin{array}{l}105 \mu \mathrm{m} \text { Glass spheres } \\
136 \mu \mathrm{m} \text { PSL spheres } \\
160 \mu \mathrm{m} \text { PSL spheres } \\
\text { Coal (Montana Rosebud) } \\
\text { Oil Shale (Colorado Mahogany) }\end{array}$ & $\begin{array}{l}2,450^{*} \\
1,050^{*} \\
1,050^{*} \\
1,200^{*} \\
2,000^{* *}\end{array}$ \\
\hline$* *$ & $\begin{array}{l}\text { Quoted by manufacturer. } \\
\text { Measurements done at METC. }\end{array}$ & \\
\hline
\end{tabular}
material densities for the various partioles aro given in Table 4-1.

\section{Table 4-1}

Densities of Test Particles

At a given velocity, $U$, the electric force was calculated as follows:

$F_{E}=K_{B} \cdot V_{d c}$

where, $\mathrm{K}_{\mathrm{B}}$ is obtained from equation 4-14.

Finally, the drag coefficient was calculated as:

$\mathrm{C}_{\mathrm{d}}=\frac{\mathrm{mg}-\mathrm{K}_{\mathrm{B}} \cdot \mathrm{V}_{\mathrm{dc}}}{\frac{1}{2} \rho_{\mathrm{Q}} \mathrm{U}^{2} \cdot \mathrm{A}}$

The above procedure was incorporated in interactive FORTRAN 
programs based on the PC. A typical set of drag data for a particle would take about 15 minutes and the constant $\mathrm{h}_{\mathrm{B}}$ was calculated for each individual particle.

The behavior of particles in the presence of the jet was recorded on video tapes. Some particles exibited very interesting dynamics. Occasionally a coal or oil shale particle would shift radially in the jet but video pictures indicate this movement to be no greater than a couple of diameters. Given the jet velocity profile, this lateral movement is considered insignificant and is not likely to affect the drag data. Some of the particles, especially oil shale, were observed to rotate about the jet axis. Video tapes of these particles were replayed in slow motion and the particle rotation velocity was measured as function of the jet velocity. Some particles would be unstable and oscillate as the velocity was increased at which point data acquisition was terminated.

\subsection{Experimental Uncertainities}

The uncertainty in DC voltage measurement are less than $\pm 1 \%$, and that in jet centerline velocity measurement 19 less than $\pm 5 \%$. Varintiono in the pixel count output from the imaging system result in an uncertainity of $\pm 2 \%$ in diameter/area equivalent diameter. The total uncertainties in drag coefficient and Reynolds number calculations together with uncertainties in drag data interprelation due to the irregular shape of coal and oil shale particles are discussed in detail in Chapter 6. The above uncertainities indicate the maximum variations (error bands) in the measured values of each parameter. 


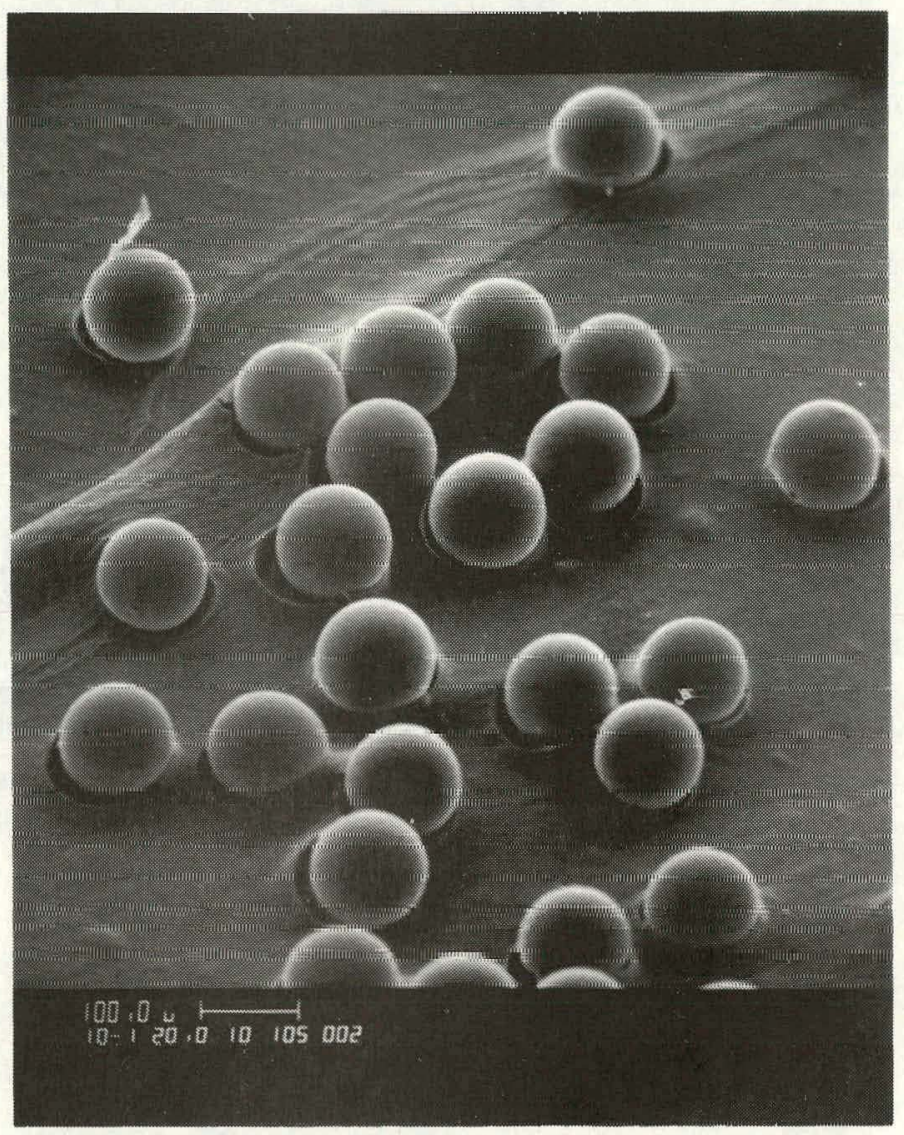

Figure 4.1. SEM Photograph of $105 \mu \mathrm{m}$ Diameter Glass Spheres. 


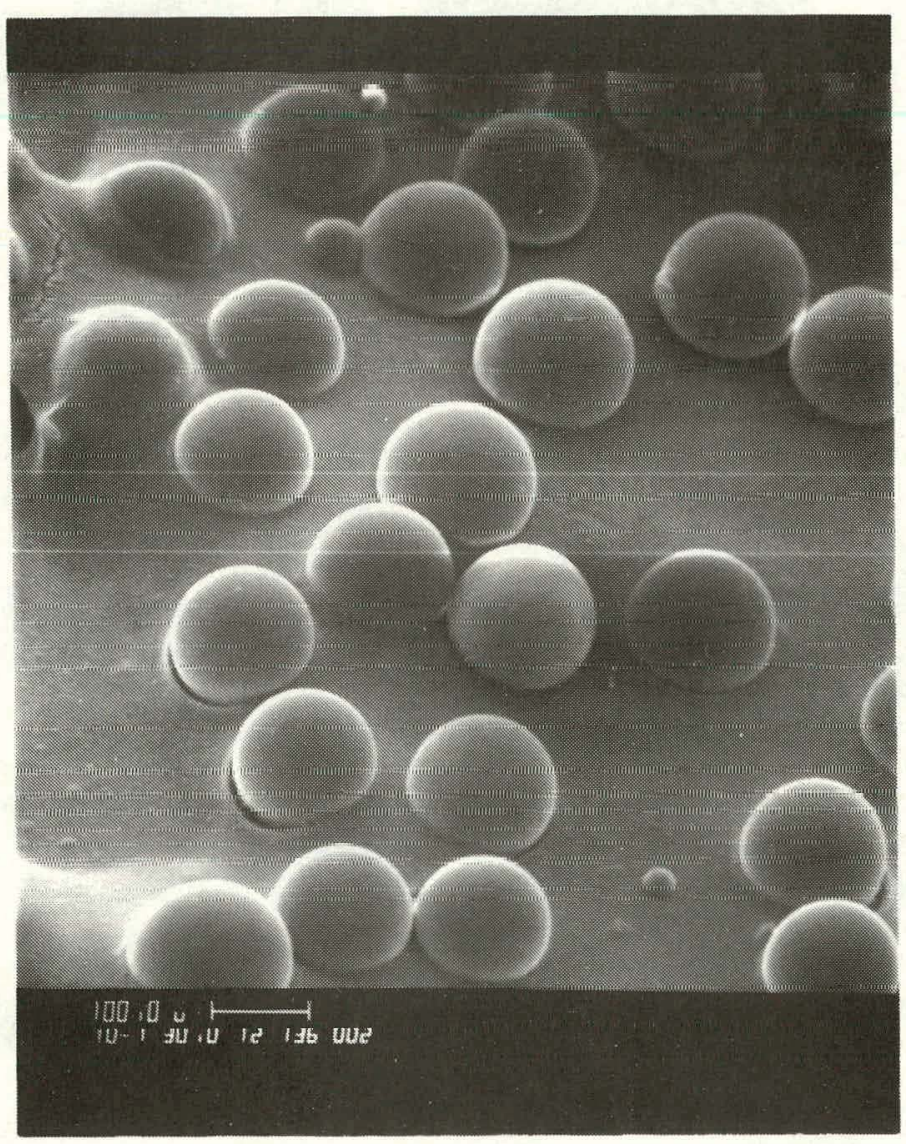

Figure 4.2. SEM Photograph of $136 \mu \mathrm{m}$ Diameter PSL Spheres. 


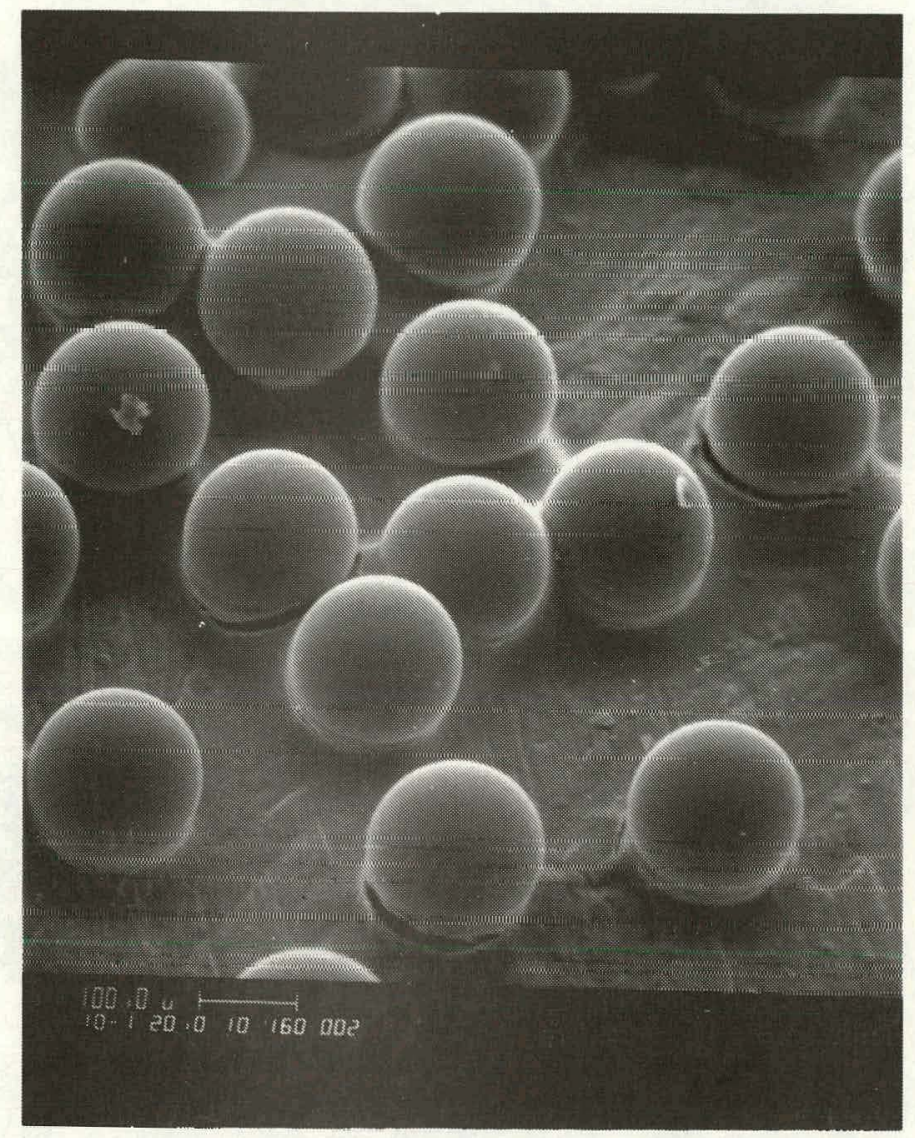

Figure 4.3. SEM Photograph of $160 \mu \mathrm{m}$ Diameter PSL Spheres. 


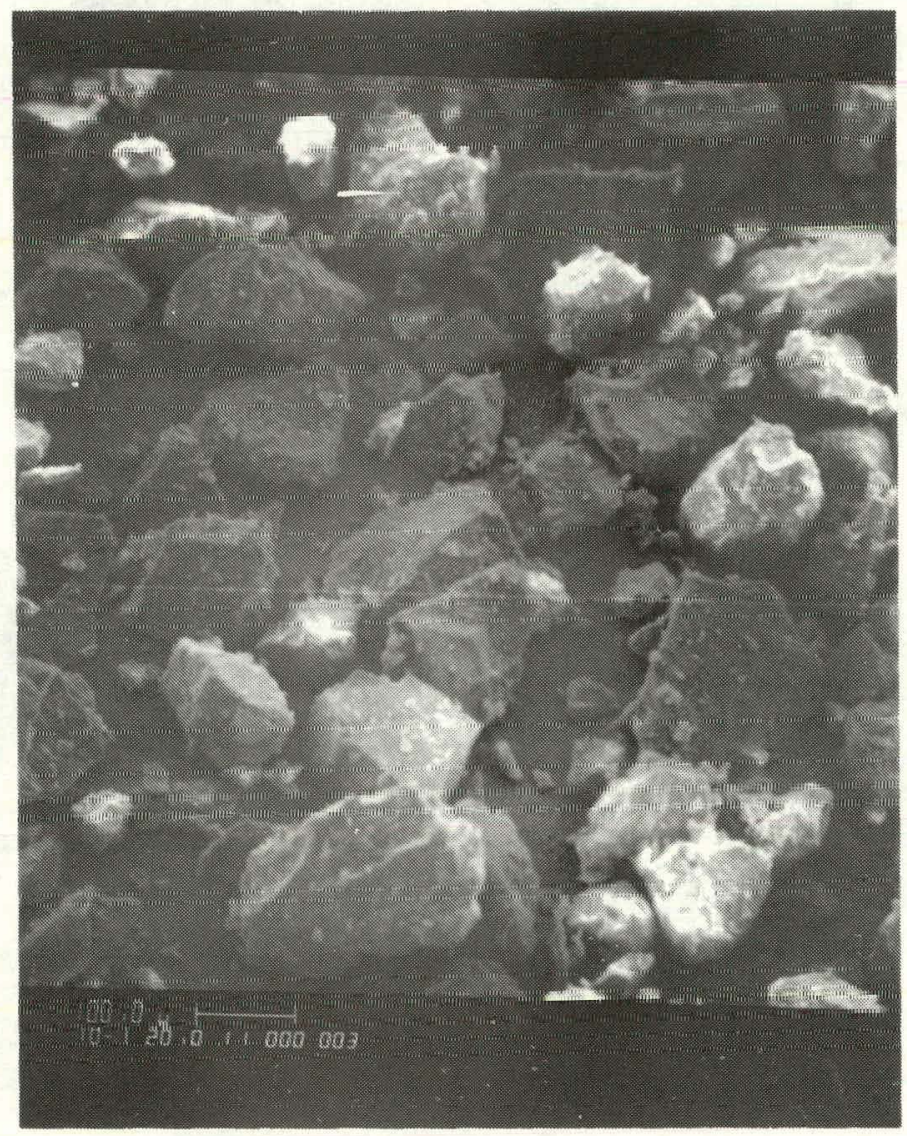

Figure 4.4. SEM Photograph of Montana Rosebud Coal Particles in the Size Range from $105 \mu \mathrm{m}$ to $148 \mu \mathrm{m}$. 


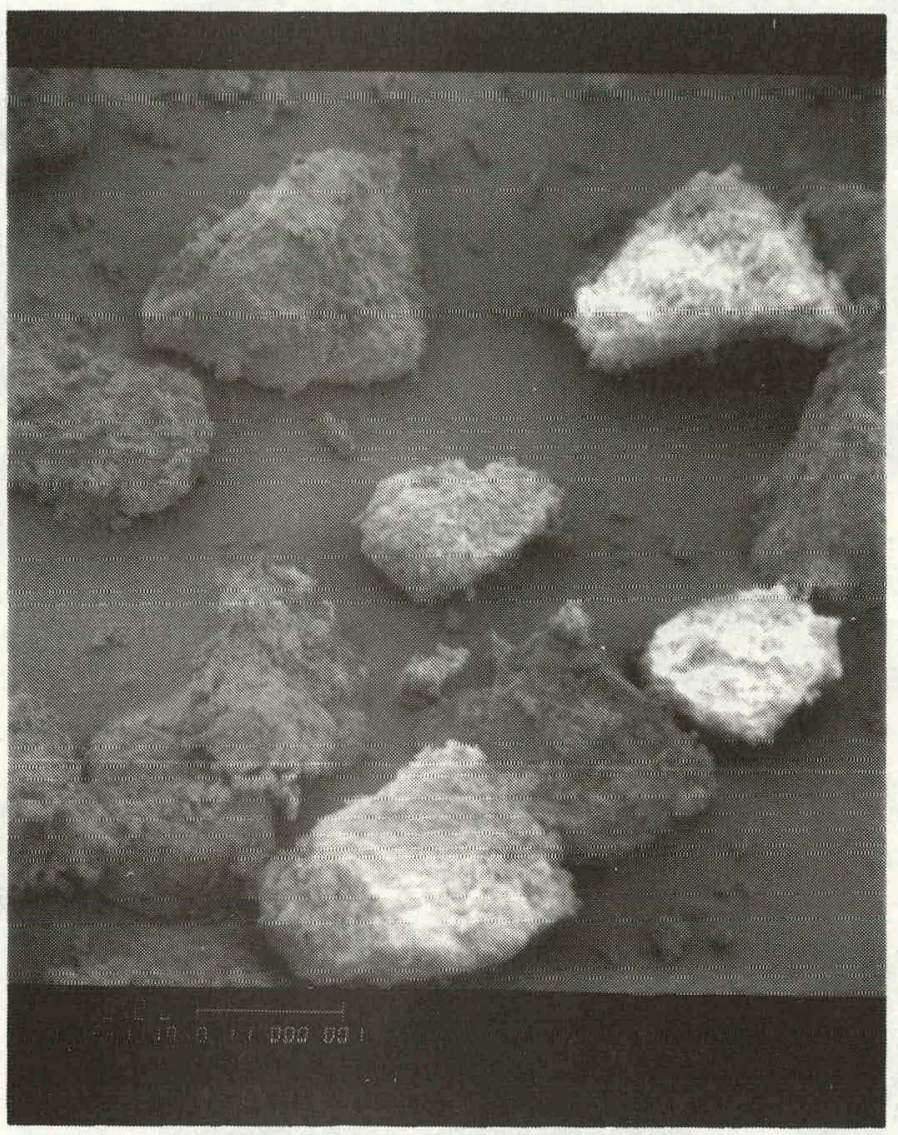

Figure 4.5. SEM Photograph of Colorado Mahogany Oil Shale Particles in the Size Range from $105 \mu \mathrm{m}$ to $148 \mu \mathrm{m}$. 


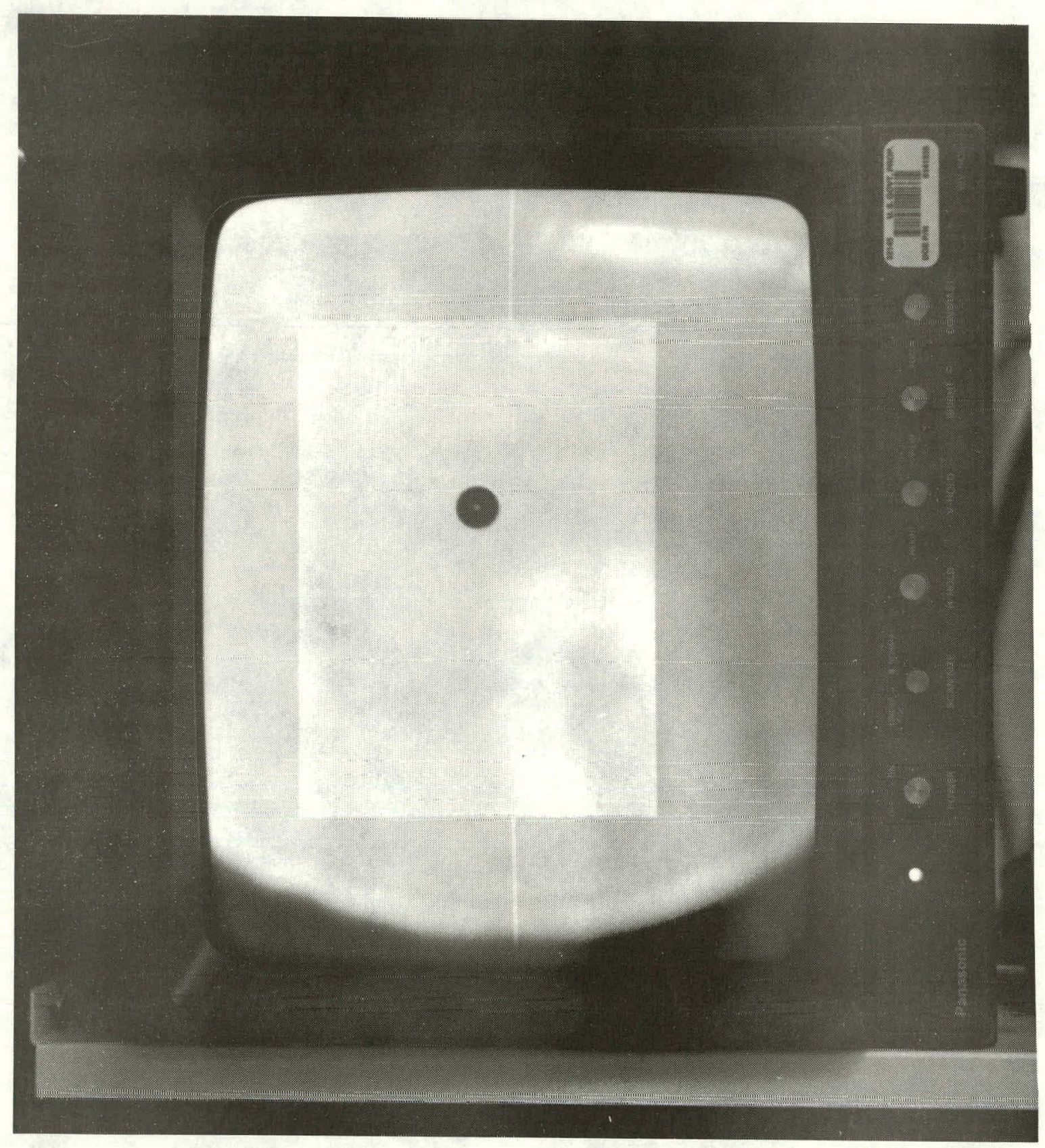

Figure 4.6. Photograph of a $160 \mu \mathrm{m}$ Diameter PSL Sphere suspended in the Electrodynamic Balance as seen on the Video Monitor. 


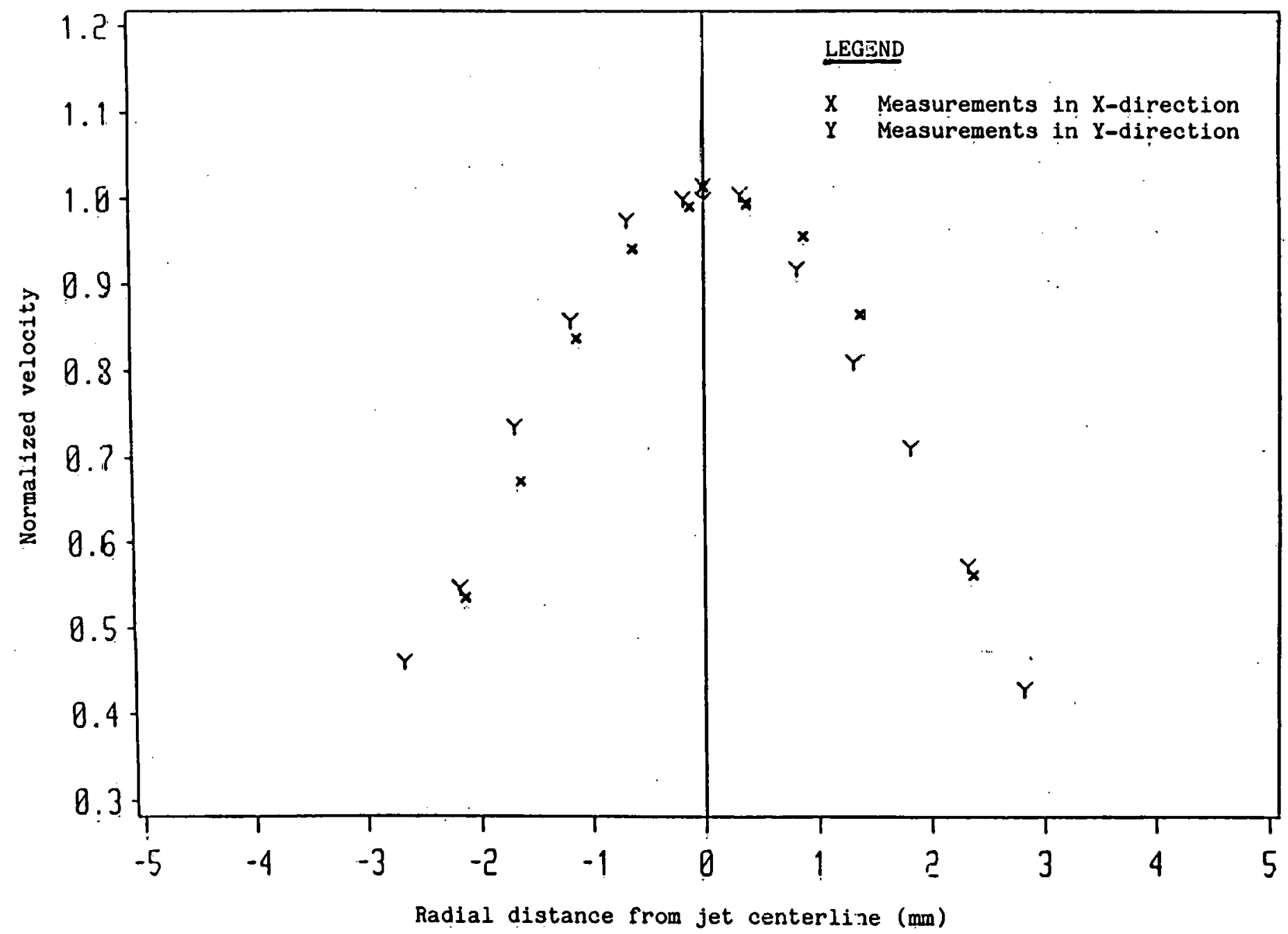

Figure 4.7. Jet Velocity Profiles. 


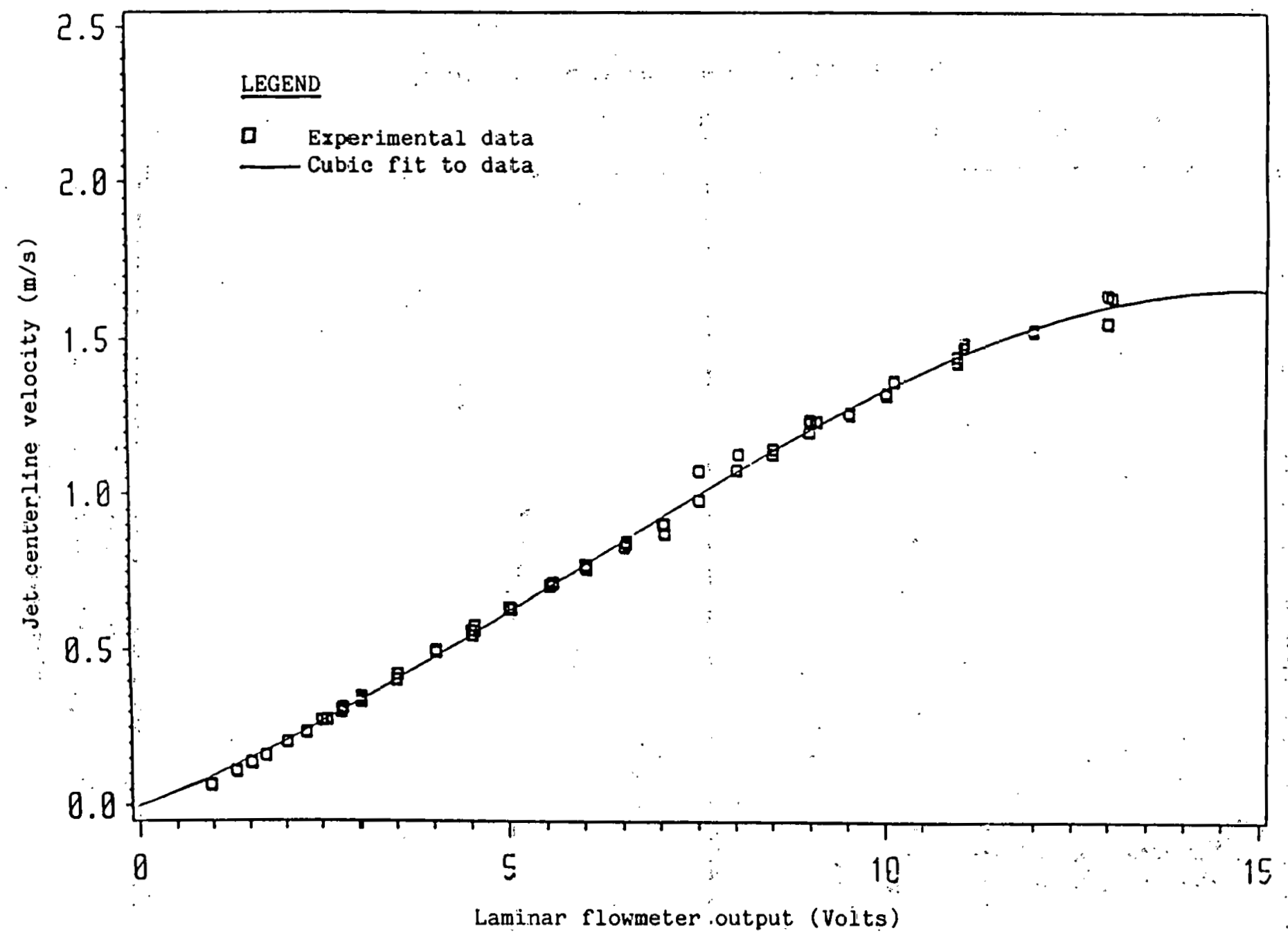

Figure 4.8. Calibration Curve for the Laminar Flowneter. 


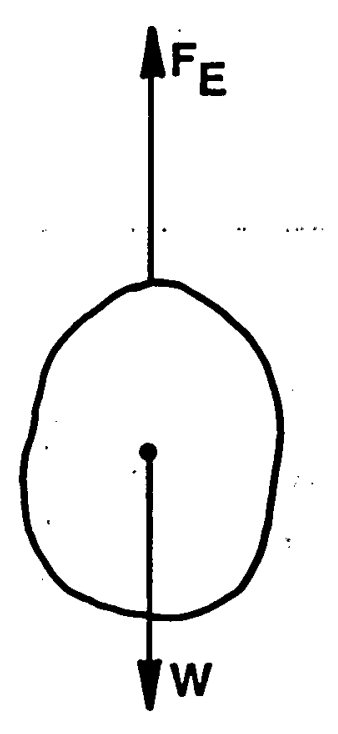

(a) No Jet Flow.

$\mathbf{W}=\boldsymbol{F}_{\mathbf{E}}$

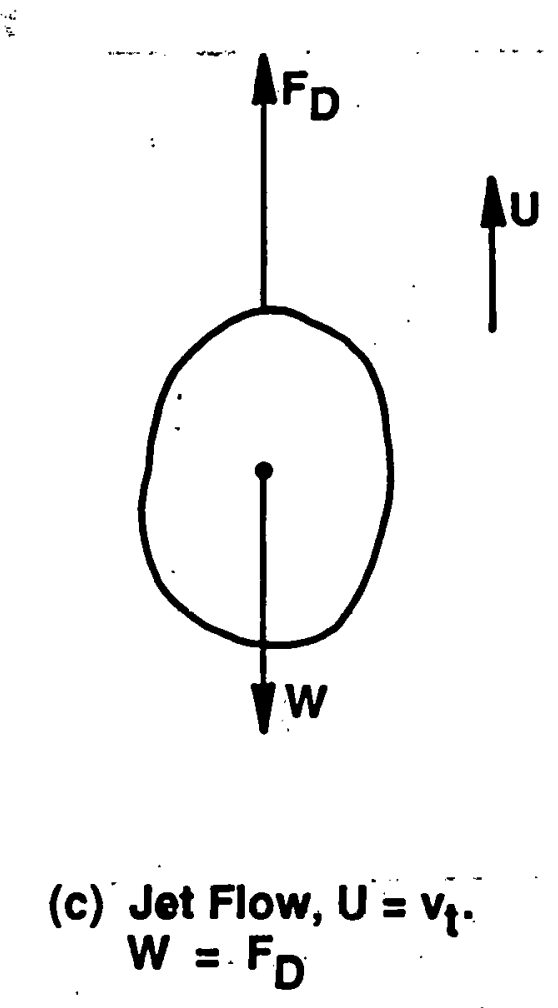

(c) Jet Flow, $U=v_{t}$.

$\mathbf{W}=\mathbf{F}_{\mathbf{D}}$

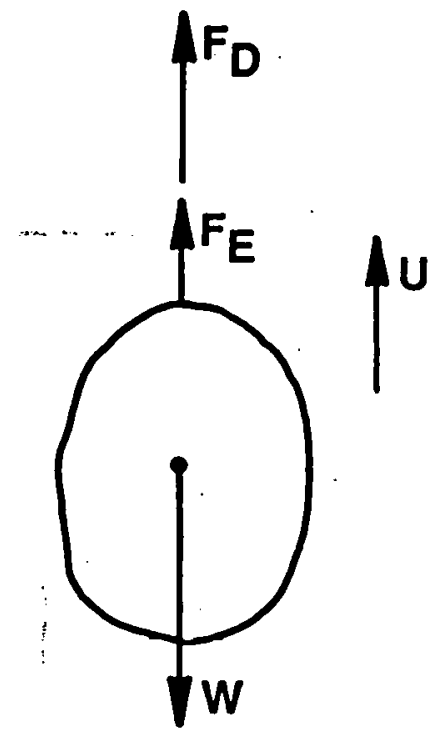

(b) Jet Flow, $U<V_{t}$ : $\mathbf{W}=\boldsymbol{F}_{\mathbf{E}}+\boldsymbol{F}_{\mathbf{D}}$

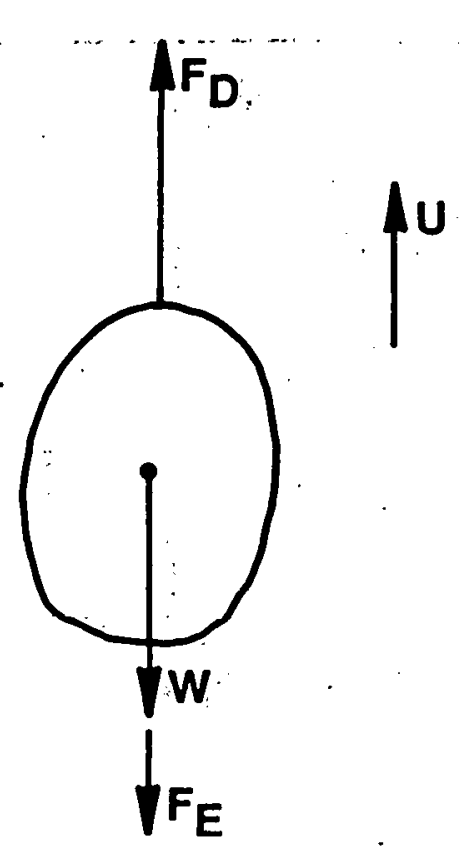
Figure 4.9. Forces on a Particle suspended in an Electrodynamic 


\section{Chapter 5}

\section{RESULTS}

The results obtained from the experiments are described in three sections, viz., (i) drag characteristics of spherical particles, (ii) drag characteristics of nonspherical (irregular) particles, and (iii) rotational characteristics of nonspherical particles.

\subsection{Drag Characteristics of Spherical Particles}

As described earlier, ten spheres of each of three diameters were studied for drag characteristics. These results are presented in Figures $5.1,5.2$, and 5.3 for spheres of diameters $105 \mu \mathrm{m}, 136 \mu \mathrm{m}$, and $160 \mu \mathrm{m}$, respectively. In all these Figures, the drag coefficient has been plotted as a function of Reynolds number on a log-log scale. Also shown on these figures is a curve for the standard drag relation for a ophere (White, 1974):

$$
C_{d}=\frac{24}{R e}+\frac{6}{1+R e^{0.5}}+0.4
$$

which is valid for Reynolds number up to 200,000 .

Figures 5.1(a) and 5.1(b), each show the data obtained for five different glass spheres indicated by as many symbols, and the data set for each sphere has been numbered sequentially from S105-1 thru S105-10. The data indicates some scatter at Reynolds numbers less than 0.5. At Reynolds numbers greater than about 1 , the scatter is substantially lēsis and data from all the particles overlay one another very well. Due to the limitations of the systems, these tests could be conducted up to a Reynolds number of about 8.2. The sensitivity of the LFM to sinull flow rates restricted the minimum Reynolds number to 0.2 . Over this range the drag, coefficient decreases from a high of 91.6 to a low of 5.7 which is more than one order of magnitude decrease. It can be seen that the data follows a linear trend for a significant portion but is offset from the standard drag curve.

Figures $5.2(a)$ and $5.2(b)$ present similar data for len spheres, S136-1 thru S136-10, for $136 \mu \mathrm{m}$ diameter spheres. "For this size, the Reynolds number range varied from 0.2 to 8.9 over which range the drag coefficient decreased from about 110.9 to 5.2. Here, too, the scatter in the data is greater at Reynolds number less than about 0.8 . At the higher end, however, the uncertainty is much less and all the points collapse to a single curve. As was observed for $105 \mu \mathrm{m}$ diameter spheres, here, too, the data is offset from the standard drag curve.

The drag data : for ten $160 \mu \mathrm{m}$ diameter spheres, S160-1 thru s160-10, is presented in Figures 5.3(a) and 5.3(b), and exhibits characteristics similar to those for $105 \mu \mathrm{m}$ and $136 \mu \mathrm{m}$ diameter spheres. The Reynolds number range studied for these spheres is from 0.2 to 12.3, over which range the drag coefficient decreases from 94 to 4.2 . As in the previous cases, the data exhibits a linear trend with a fixed 
offset from the standard curve on a log-log scale.

\subsection{Drag Characteristics of Coal Particles}

Drag data for thirteen coal particles are presented in Figures $5.4(\mathrm{a}), 5.4(\mathrm{~b})$, and $5.4(\mathrm{c})$. The data obtained shows a Reynolds number variation from 0.1 to 10 , based on the area equivalent diameter. In each of these figures, the standard curve for a sphere is also shown for comparison purposes.

For clarity purposes the data has been presented in three figures with five particles each in Figures 5.4 (a) (particles no. C-1 thru C-5) and $5.4(\mathrm{~b})$ (particles no. C-6 thru C-10), and three in Figure $5.4(\mathrm{c})$ (particles no. C-11 thru C-13). The three particles for which drag data is presented in Figure 5.4(c) were captured and photographed by a scanning electron microscope (SEM). These photographs, for particles no. $\mathrm{C}-11, \mathrm{C}-12$, and $\mathrm{C}-13$ are presented in Figures $5.5(\mathrm{a}), 5.5(\mathrm{~b})$, and $5.5(\mathrm{c})$, respectively. The arrow on each of these figures shows the direction of orientation of the suspended particle which was obtained from the video recordings of the particle dynamics. This direction of orientation is collinear with the balance vertical centerline whlch is ulso collinear with the gravitational vertical and with the jet. The maximum jet velocity and, hence, the Reynolds number range, studied for each particle was dictated by its stability. It was observed that some particles were more unstable than others, and restricted drag data to balance voltage variations ranging from $31 \%$ to $202 \%$ of the initial balance voltage; where, $100 \%$ balance voltage change indicates jet velocity equal to the particle terminal velocity. Details about the particle dynamics are discussed separately in Section 5.4 below.

The data in Figures $5.4(\mathrm{a}), 5.4(\mathrm{~b})$, and $5.4(\mathrm{c})$ shows that for the most part, the coal particles exhibit a similar behavior. On the log-log graph these data show a linear trend which is very similar to that for a sphere. The curves are, however, offset from each other, and from the standard curve for spheres by varying amounts. The slopes are, however, almost the same. As in the case of spheres, here, too, the uncertainty is highest at Reynolds numbers less than 0.5. In general, the drag coefficient appears to be greater than that for a sphere of comparable size.

\subsection{Drag Characteristics of Oil Shale Particles}

The drag characteristics for thirteen oil shale particles are presented in Figures $5.6(\mathrm{a}), 5.6(\mathrm{~b})$, and $5.6(\mathrm{c})$. As with coal, here, too, the particles were first studied for drag characteristics and these results are presented in Figures 5.6(a) (particles no. OS-1 thru OS-5) and 5.6(b) (parlicles no. OS 6 thru OS-10) for five particles each. Subsequently, three more particles were studied, Figure 5.6(c), and these were captured and photographed by a SFM. These photographs are shown in Figures $5.7(\mathrm{a}), 5.7(\mathrm{~b})$, and $5.7(\mathrm{c})$ for particles OS-11, OS-12, and OS-13, respectively, and indicate that each particle was flake-like in shape. The arrow in these photographs indicates the axis of urientation of a particle when suspended in the electrodynamic balance 
which was obtained from video recordings of the particle motion.

The data obtained covers a Reynolds number range from 0.2 to 4.0, with the upper limit being dictated by the particle stability. This enabled data acquisition for balance voltage variations ranging from $34 \%$ to $100 \%$ of the initial balance voltage. Only one particle was stable until the terminal velocity was achieved, and all the particles exhibited significant rotation. Details of the particle rotation are discussed separately in Section 5.4 below.

On a log-log scale, the data for each particle exhibits a linear trend with the slope varying marginally from the standard curve for a sphere. The data is, however, offset from the standard curve by varying amounts and the drag on one particle (OS-13) is substantially higher than that exhibited by the other particles.

\subsection{Rotational Characteristics of Coal and Oil Shale Particles}

During the drag experiments it. was nhoerved that all tho coal and oil shale particles rotated in the presence of the air jet. The angular spin vector was in the same direction as the jet. As the jet velocity was increased, some particles moved to off-center radial positions but continued to rotate with the same spin vector direction. This off-center movement was observed to be up to two particle widths (about $400 \mu \mathrm{m}$ ). Further increase in velocity caused the particle to oscillate in a vertical direction, in addition to the already present rotation. This condition was interpreted as the onset of instabilities and provided the upper limit for drag data acquisition. Motion of all the particles were recorded on video tapes for subsequent analysis and attempts were also made to measure thls particle spin velocity by using an LDA.

While conducting the experiments, it was observed that the AC field frequency affected the stability of a suspended particle. The ability to stably suspend a spherical particle without any jet flow was greatly influenced by the AC frequency. Nonspherical particles also exhibited this behavior but were also observed to rotate or oscillate even without the jet flow. However, at a high enough frequency (greater than $70 \mathrm{~Hz}$ ), all the particles achieved a stable orientation without in any way affecting the balance DC voltage. This observation suggested that the AC frequency could bias the rotation of a particle in the presence of the air jet but would not have any effect on the drag characteristics. The effects of $\mathrm{AC}$ field frequency on the rotation of one oil shale particle are presented in Figure 5.8. The effect of AC frequency was studied at two jet velocities, $4.7 \mathrm{~cm} / \mathrm{s}$ and $7.6 \mathrm{~cm} / \mathrm{s}$. Both these velocitice caused slow and steady rotation of the particle over the range of AC frequencies studied, viz., $30 \mathrm{~Hz}$ to $70 \mathrm{~Hz}$. Below $30 \mathrm{~Hz}$ the particle was unstable exhibiting large vertical oscillations. Frequencies in excess of $70 \mathrm{~Hz}$ prevented any rotation of the particle. The particle motion was recorded on video tapes which were subsequently replayed in slow motion to measure the angular velocity. The data shows that for a jet velocity of $4.7 \mathrm{~cm} / \mathrm{s}$, the particle rotation speed varied from zero to a maximum of $50 \mathrm{rpm}$, the maxima occurring at $41 \mathrm{~Hz}$. A similar behavior is seen at a jet velocity of $7.6 \mathrm{~cm} / \mathrm{s}$. In this case the rotation speed peaks 
at $86 \mathrm{rpm}$, corresponding to a frequency of $35 \mathrm{~Hz}$.

The above data shows that the angular velocity of a particle in an electrodynamic balance is strongly influenced by the AC field frequency. It will, therefore, not be possible to obtain quantitative data on single particle rotation using an electrodynamic balance. At best, the data on rotation can give some qualitative information on particle dynamics. The rotational characteristics for three coal particles, viz., C-11, C-12, and $\mathrm{C}-13$, were obtained at fixed $\mathrm{AC}$ field frequencies of $33.6 \mathrm{~Hz}, 35 \mathrm{~Hz}$, and $54.7 \mathrm{~Hz}$, respectively, and these are presented in Figure 5.9. Similar data for three oil shale particles, viz., OS-11, OS-12, and OS-13, were obtained at fixed AC field frequencies of $43.3 \mathrm{~Hz}, 40.9 \mathrm{~Hz}$, and $55.6 \mathrm{~Hz}$, respectively, and these are presented in Figure 5.10. In general, the rotational speed is observed to increase with increasing jet velocity at a constant AC field frequency.

A detailed discussion on these results is given in the next chapter. 




Figure 5.1(a). Drag Coefficient v8. Reynolds Number for Five Glass Microspheres of Diameter $1.05 \mu \mathrm{m}$. 


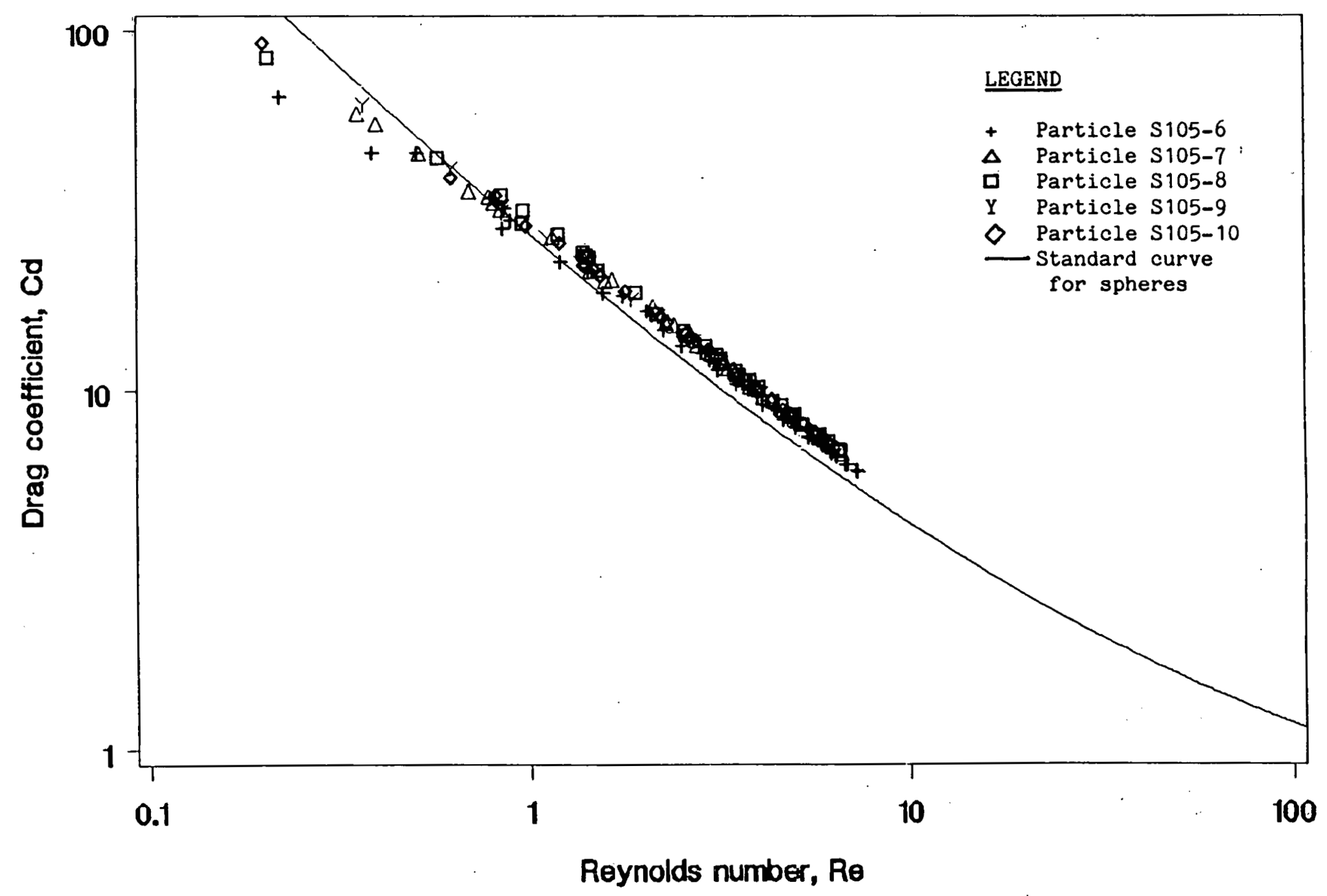

Figure 5.1(b). Drag Coefficient vs. Reynolds Number for Five Glass Microspheres of Diameter $105 \mu \mathrm{m}$. 


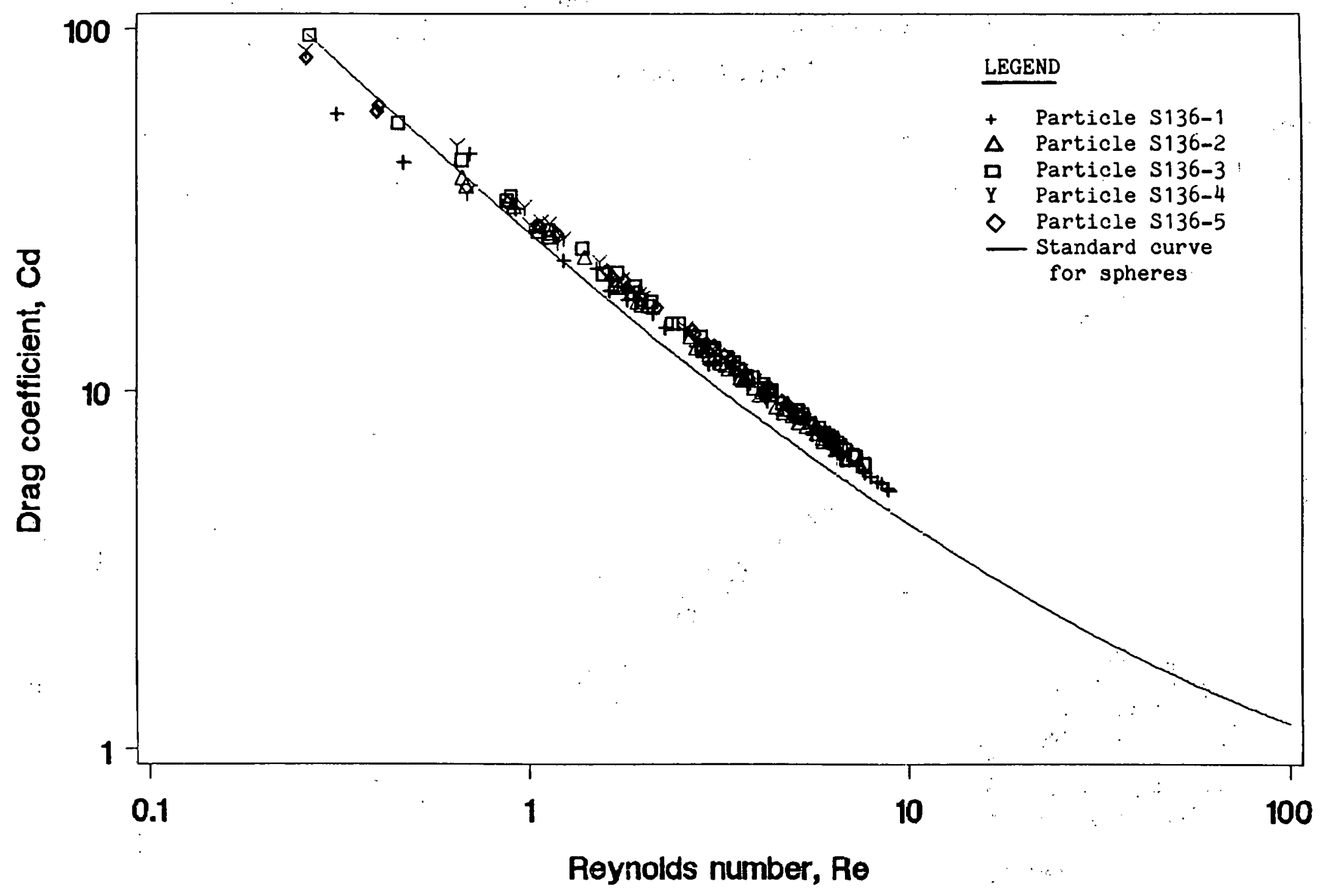

Figure 5.2(a). Drag Coeff-cient vs. Reynolds Number for Five PSL Microspheres of Diameter $136 \mu \mathrm{m}$. 


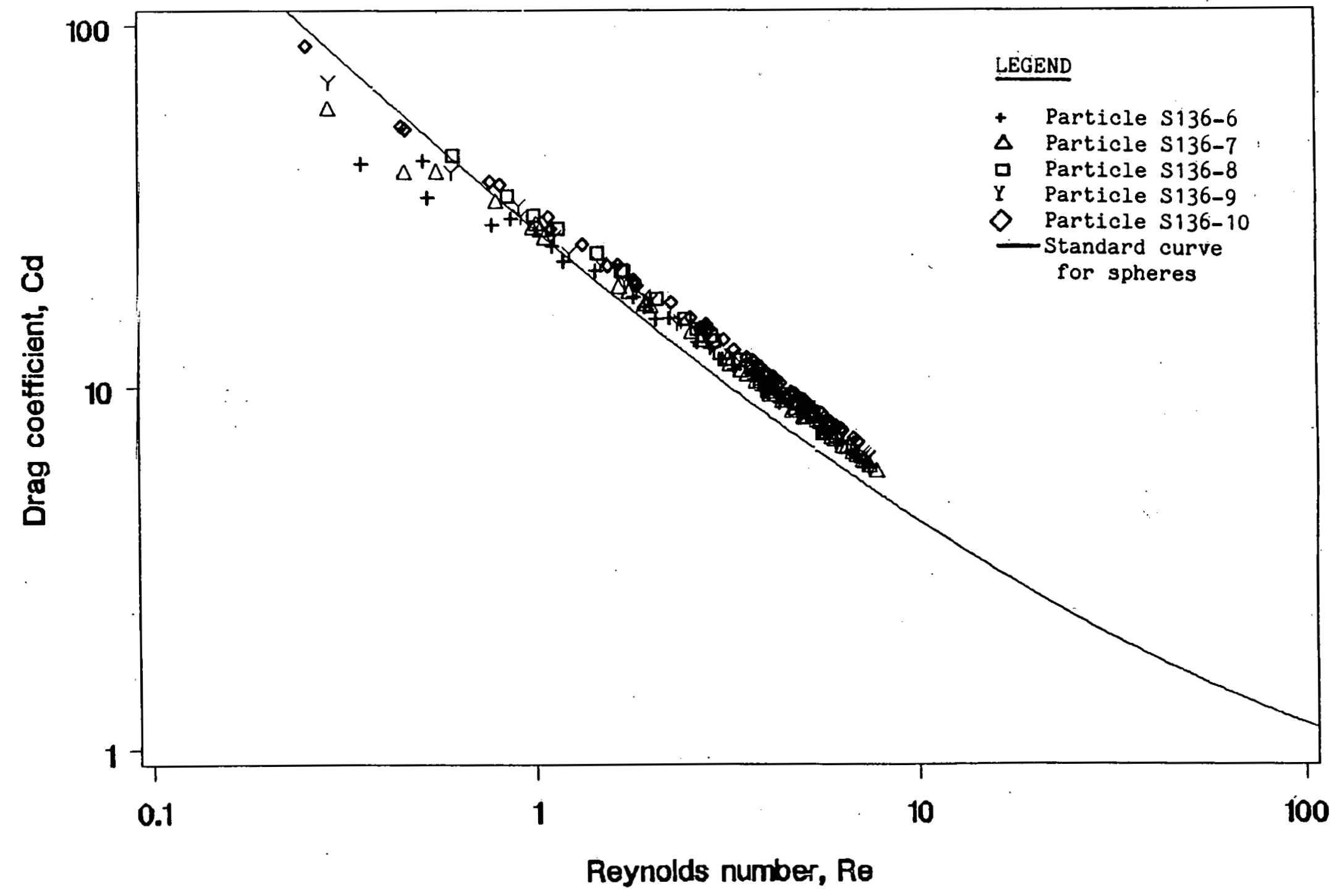

Figure 5.2(b). Drag Coefficient v8. Reynolds Numjer for Five PSL Microspheres of Diameter $136 \mu \mathrm{m}$. 




Figure 5.3(a). Drag Coefficient vs. Reynolds Number for Five PSL Microspheres of Diameter $160 \mu \mathrm{m}$. 


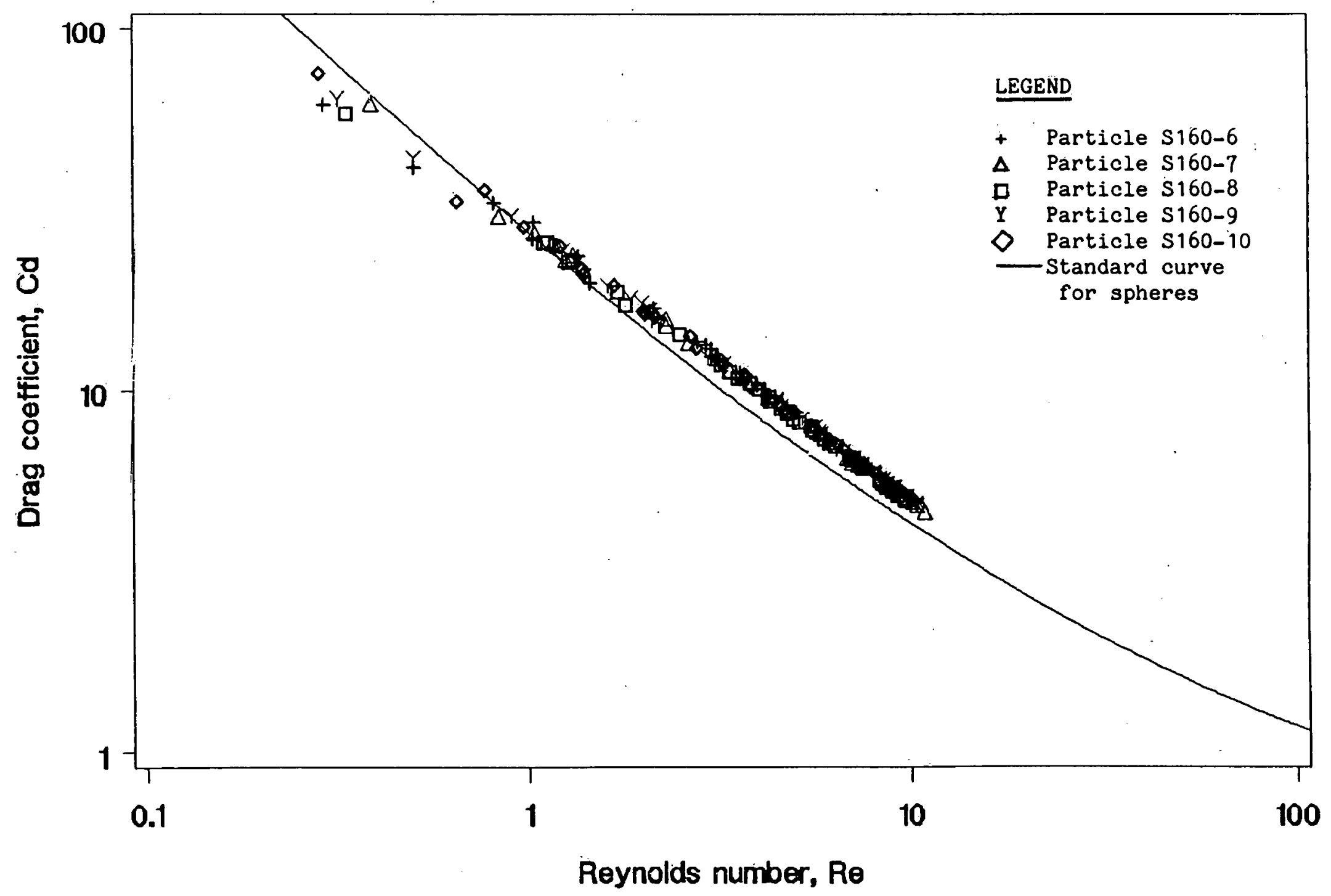

Figure 5.3(b). Drag Coefficient v8. Reynolds Number for Five PSL Microspheres of Diameter $160 \mu \mathrm{m}$. 


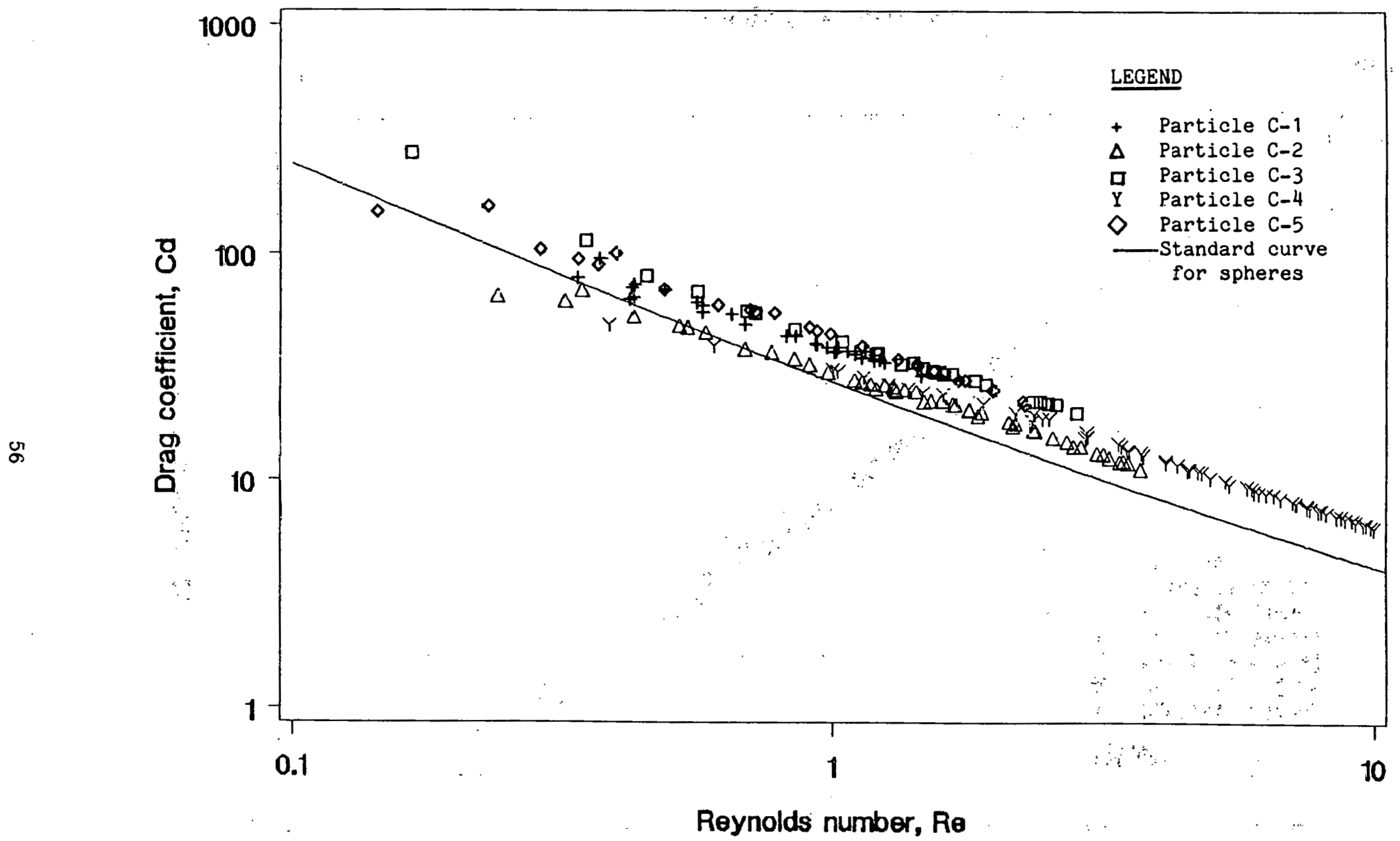

Figure 5.4(a). Drag Coef:-cient vg. Reynolds Number for Five Coal Particles. 


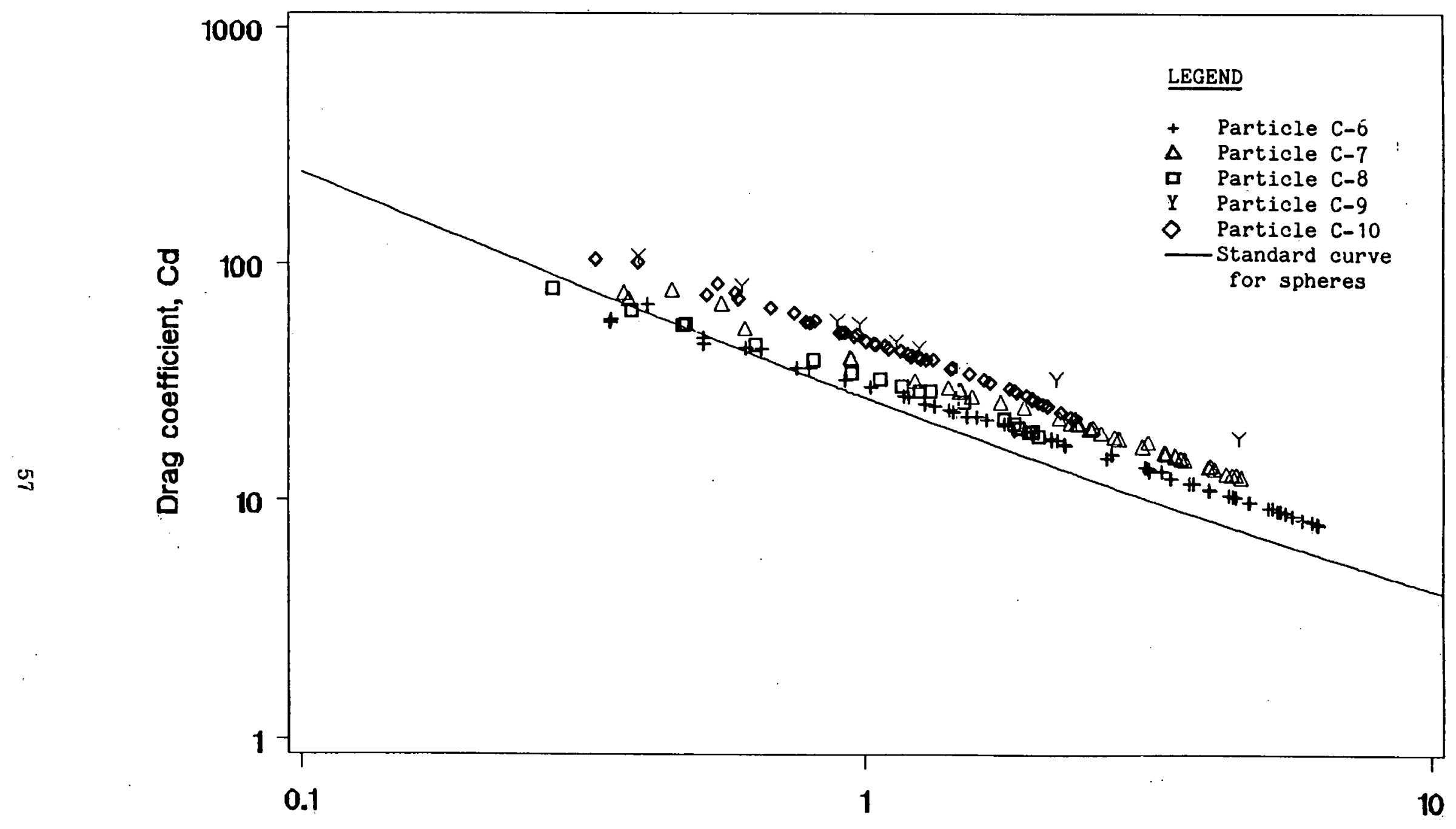

Reynolds number, Re

Figure 5.4(b). Drag Coefficient vs. Reynolds N 


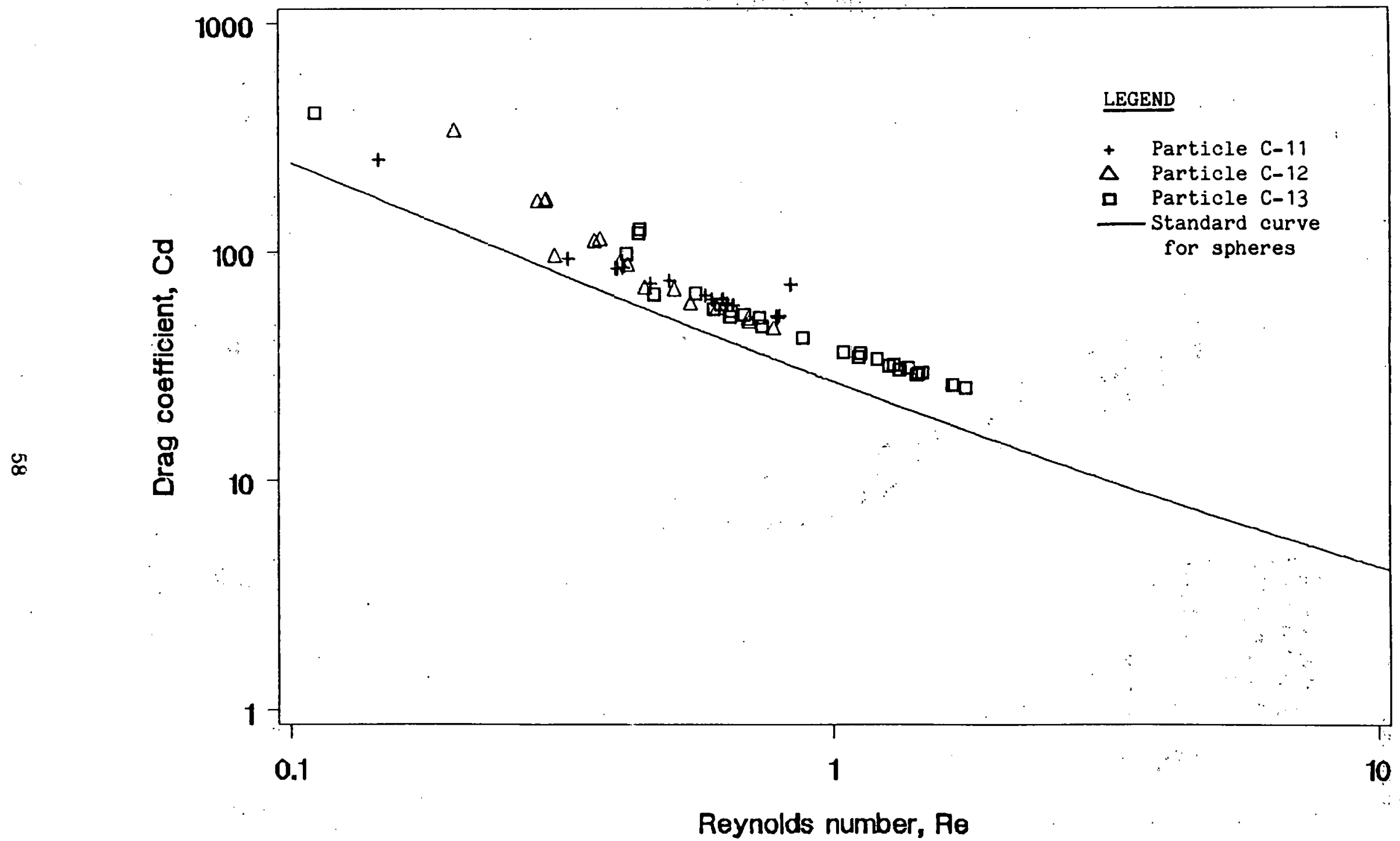

Figure 5.4(c). Drag Coefficient vs. Reynolds Number fcr Three Coal Particles. 




Figure 5.5(a). SEM Photograph of Coal Particle no. C-11. The Drag Characteristics of this Particle are shown in Figure 5.4(c), and the Arrow shows the Approximate Orientation of the Jet. 


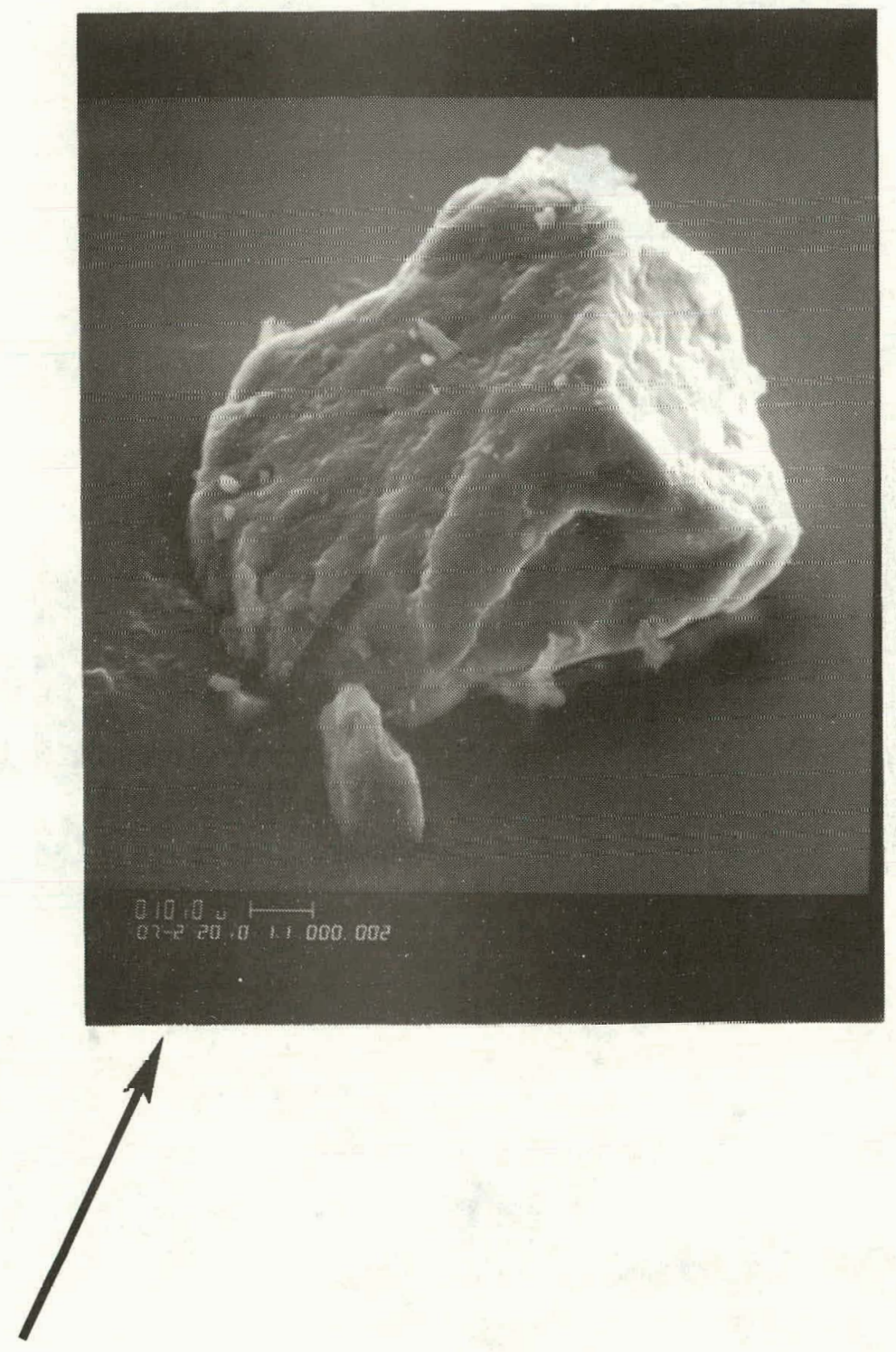

Figure 5.5(b). SEM Photograph of Coal Particle no. C-12. The Drag Characteristics of this Particle are shown in Figure $5.4(\mathrm{c})$, and the Arrow shows the Approximate Orientation of the Jet. 


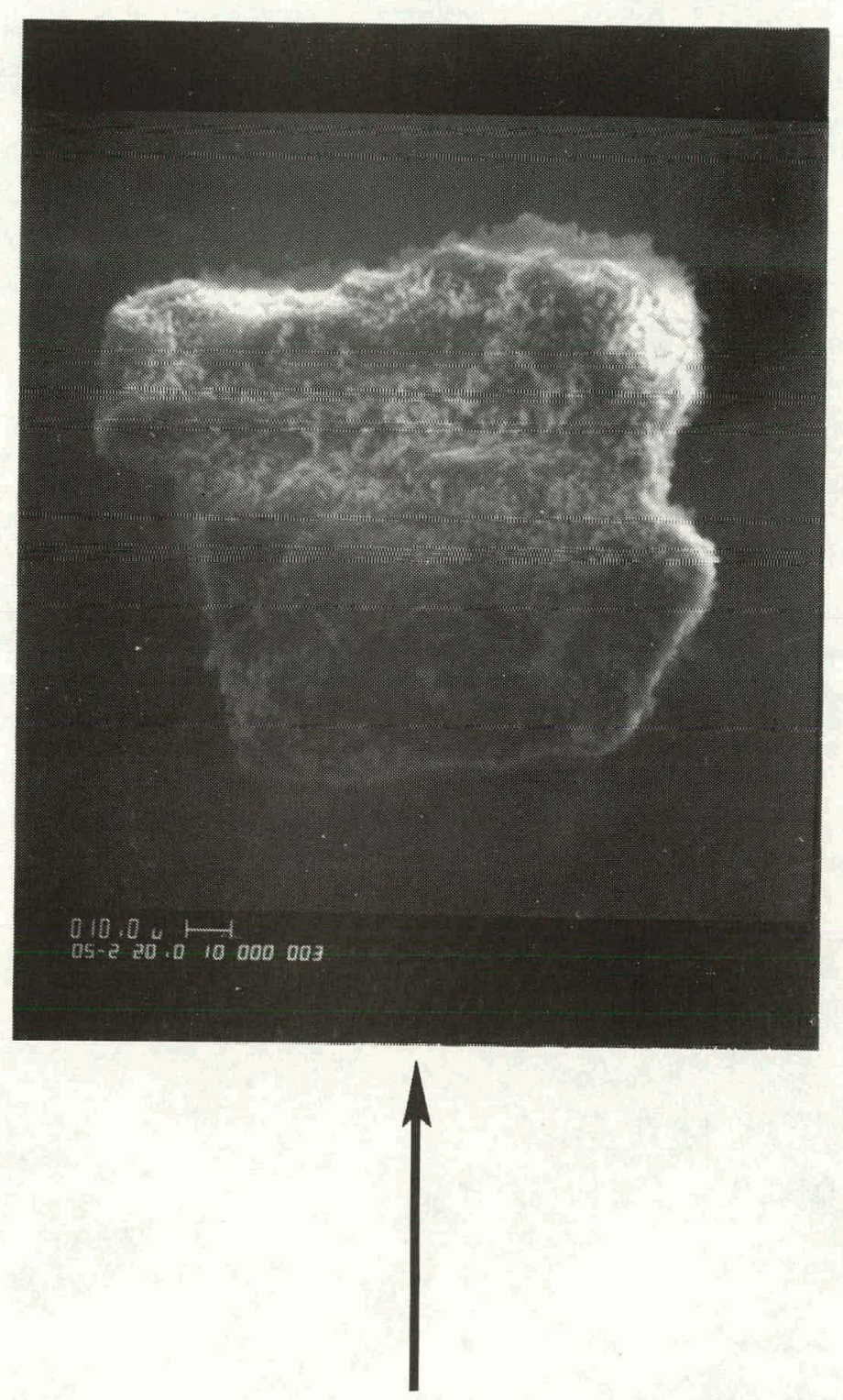

Figure 5.5(c). SEM Photograph of Coal Particle no. C-13. The Drag Characteristics of this Particle are shown in Figure 5.4(c), and the Arrow shows the Approximate Orientation of the Jet. 


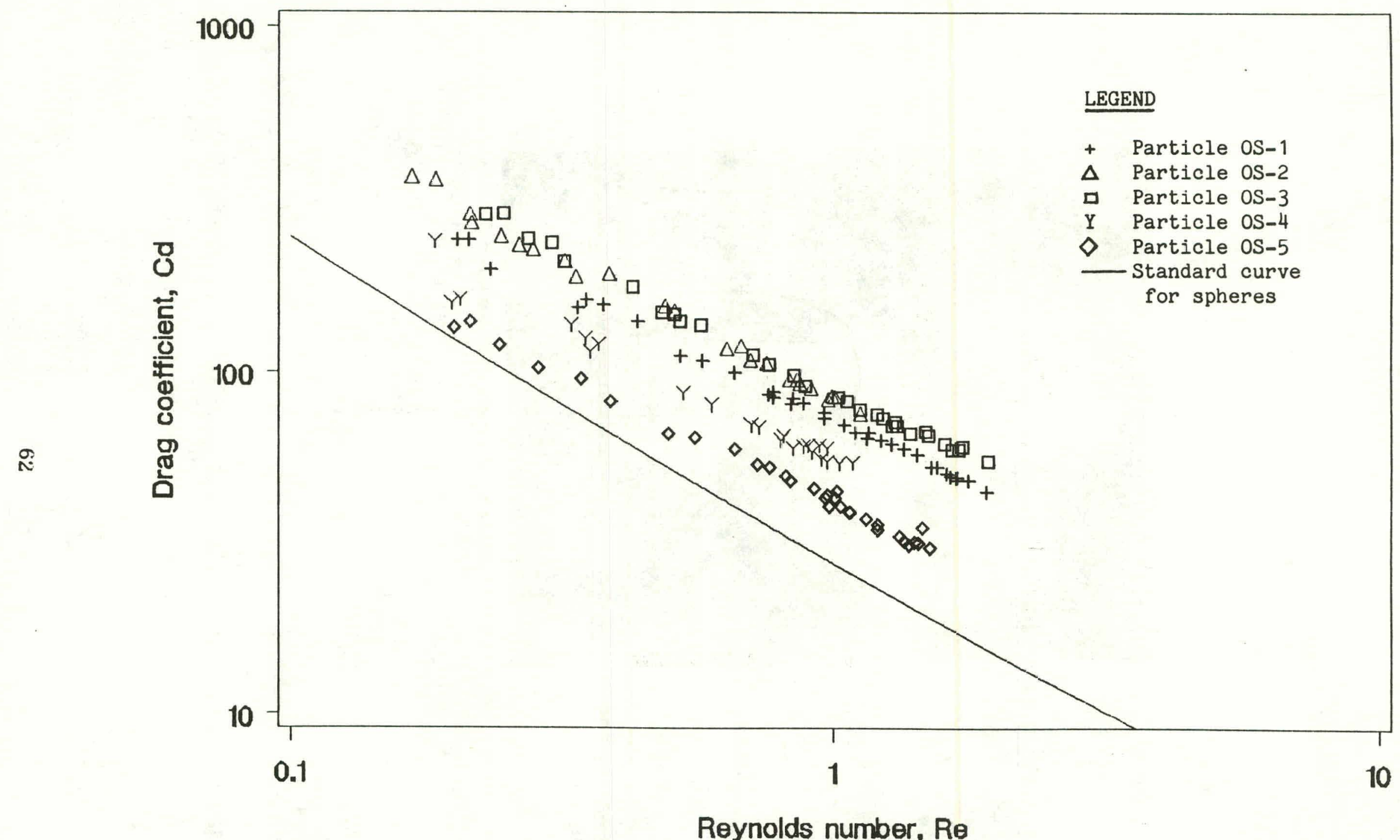

Figure 5.6(a). Drag Coefficient vs. Reynolds Number for Five Oil Shale Particles. 


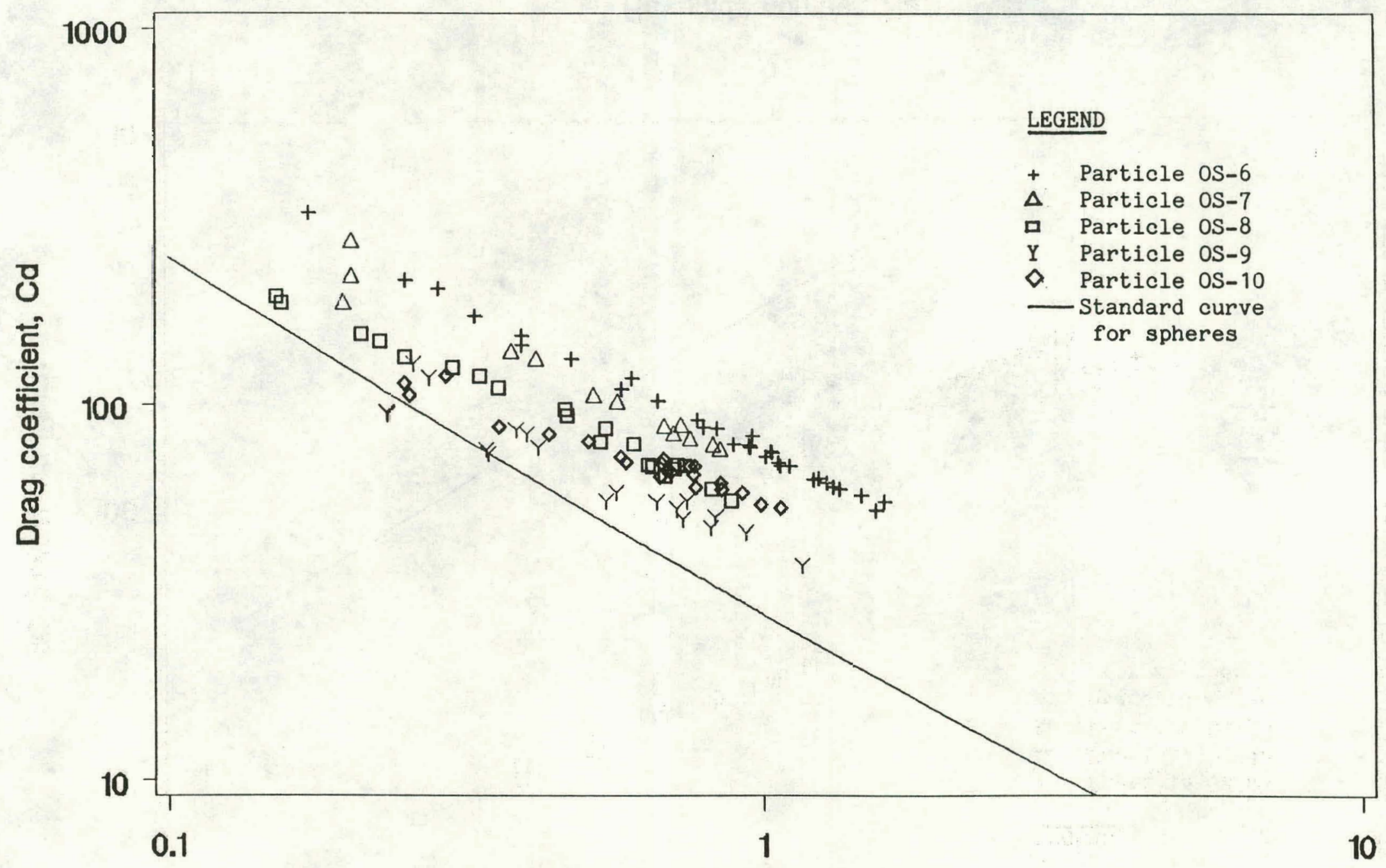

Reynolds number, Re

Figure 5.6(b). Drag Coefficient vs. Reynolds Number for Five Oil Shale Particles. 




Reynolds number, Re

Figure 5.5(c). Drag Coefficient vs. Reynolds Number for Three Oil Shale Particles. 


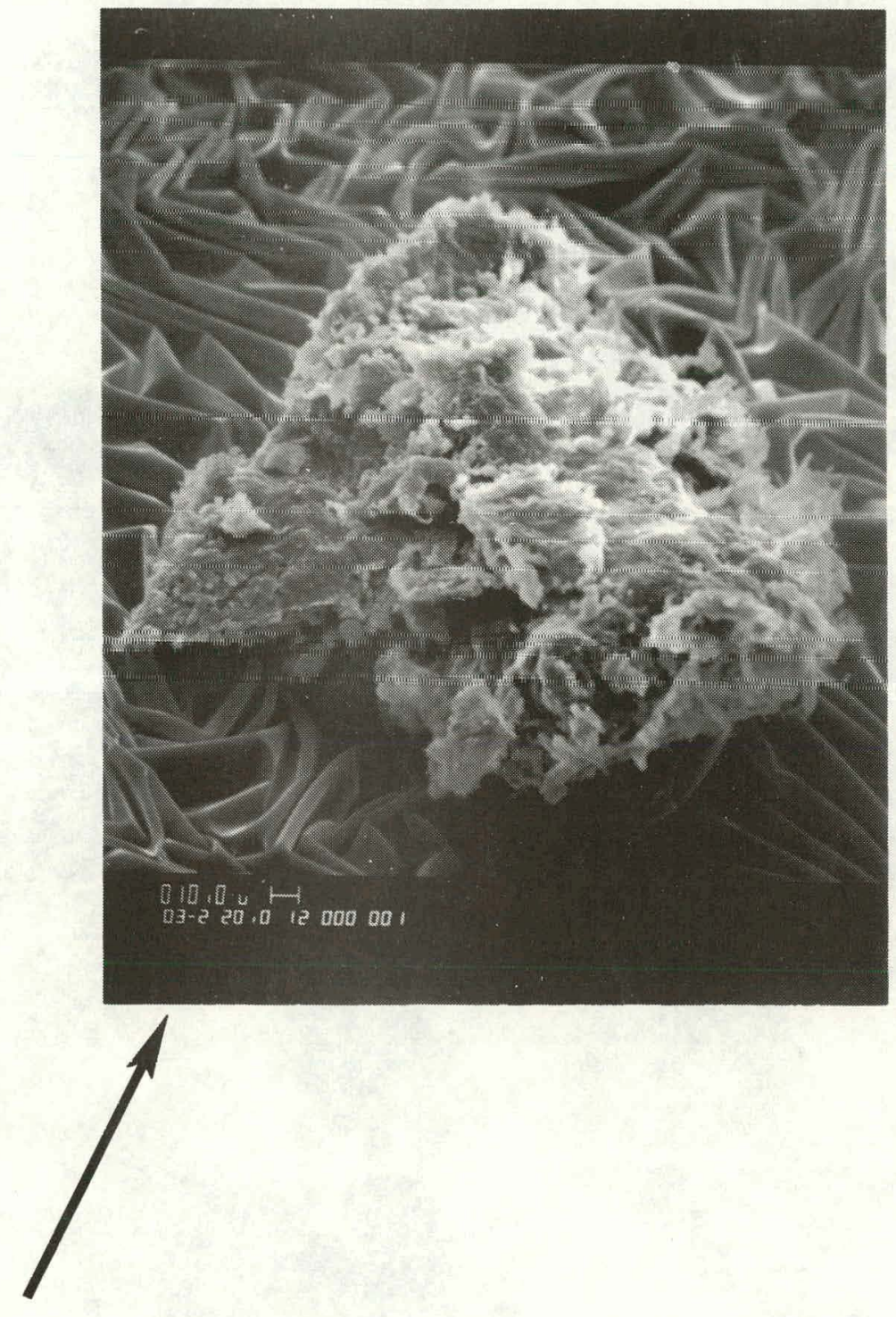

Figure 5.7(a). SEM Photograph of Oil Shale Particle no. OS-11. The Drag Characteristics of this Particle are shown in Figure 5.6(c), and the Arrow shows the Approximate Orientation of the Jet. 


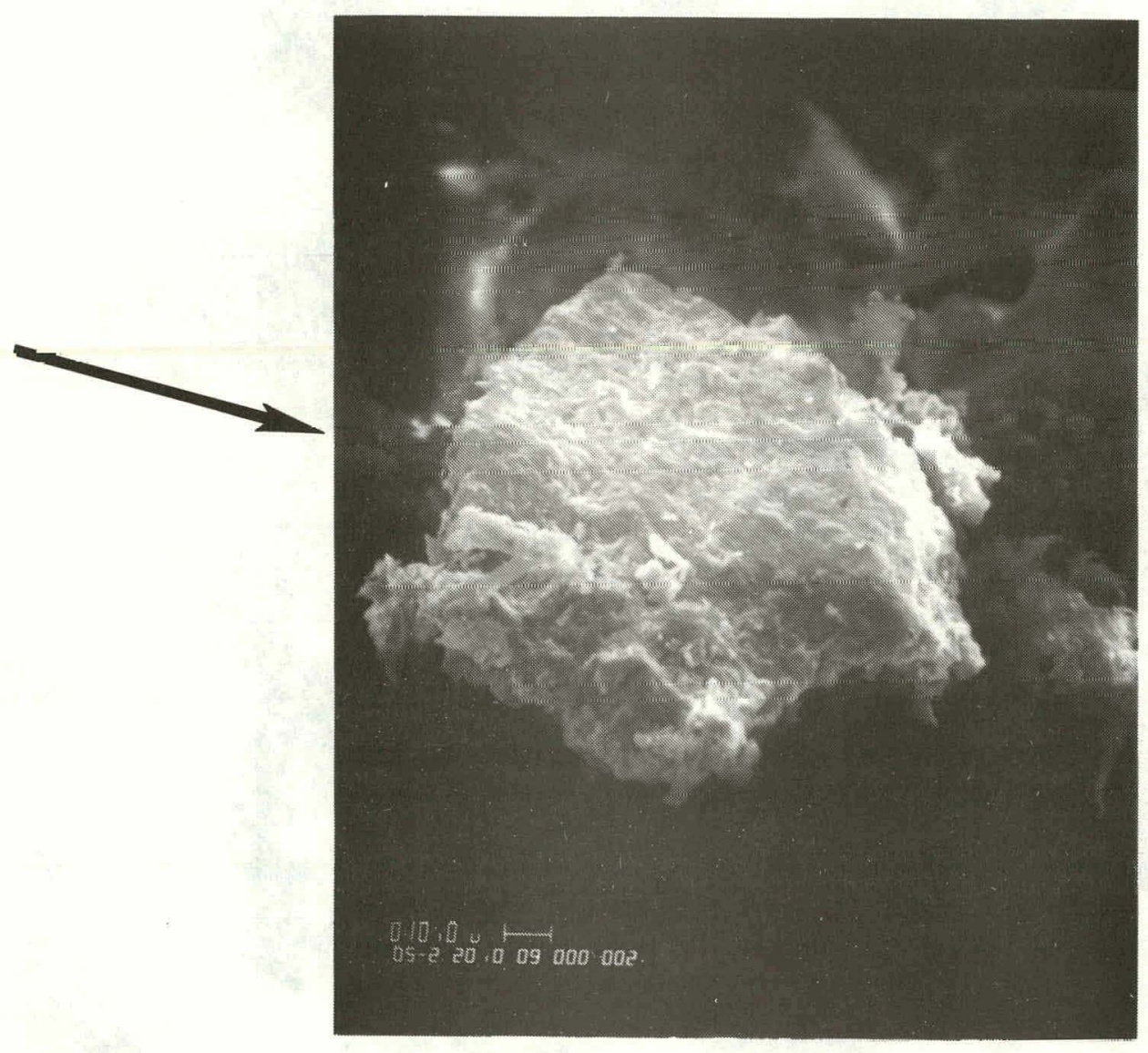

Figure 5.7(b). SEM Photograph of Oil Shale Particle no. OS-12. The Drag Characteristics of this Particle are shown in Figure $5.6(\mathrm{c})$, and the Arrow shows the Approximate Orientation of the Jet. 


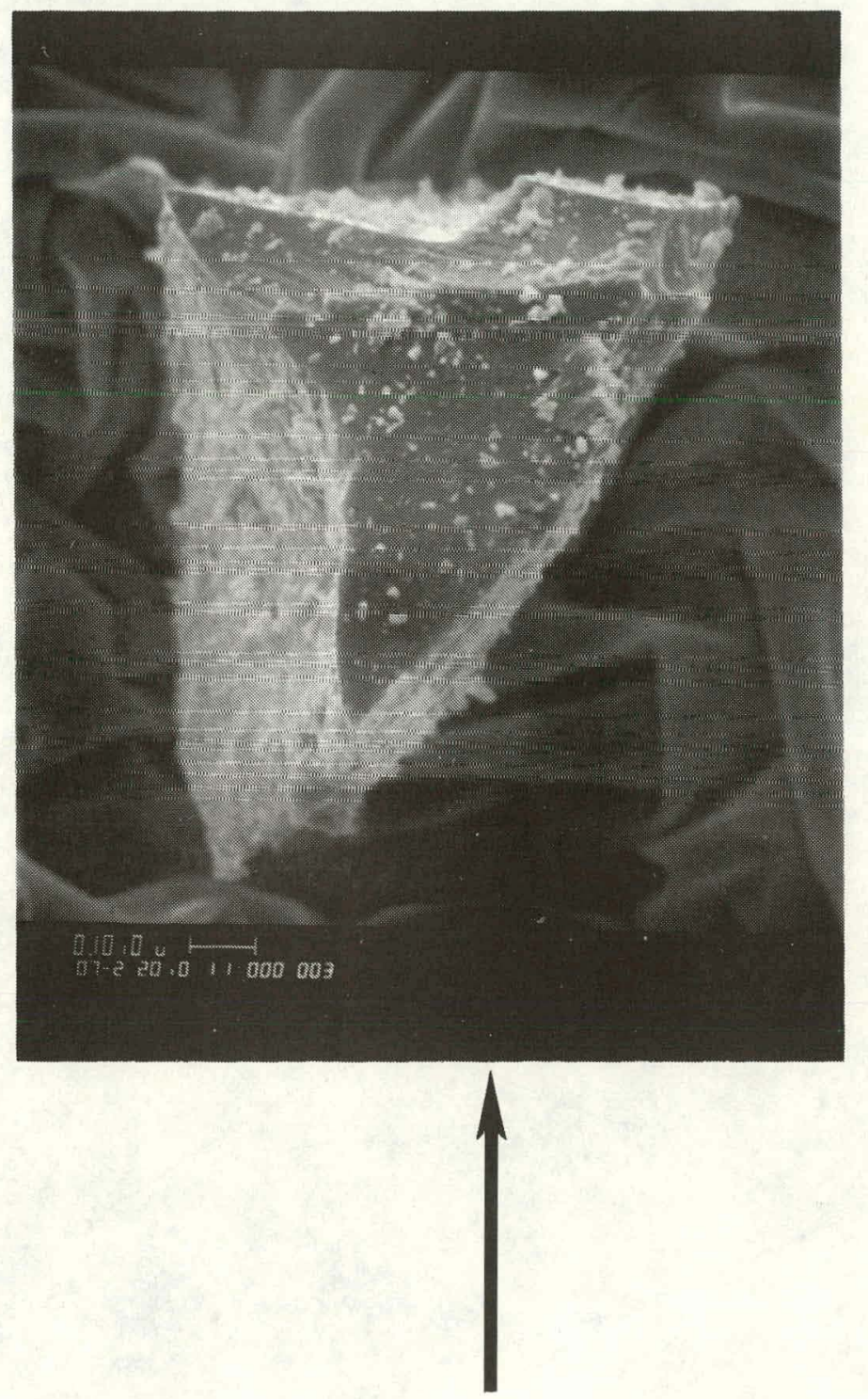

Figure 5.7(c). SEM Photograph of Oil Shale Particle no. OS-13. The Drag Characteristics of this Particle are shown in Figure 5.6(c), and the Arrow shows the Approximate Orientation of the Jet. 




Figure 5.8. Effects of AC Field Frequency on the Rotation of an Oil Shale Particle at Two Jet Velocities. 


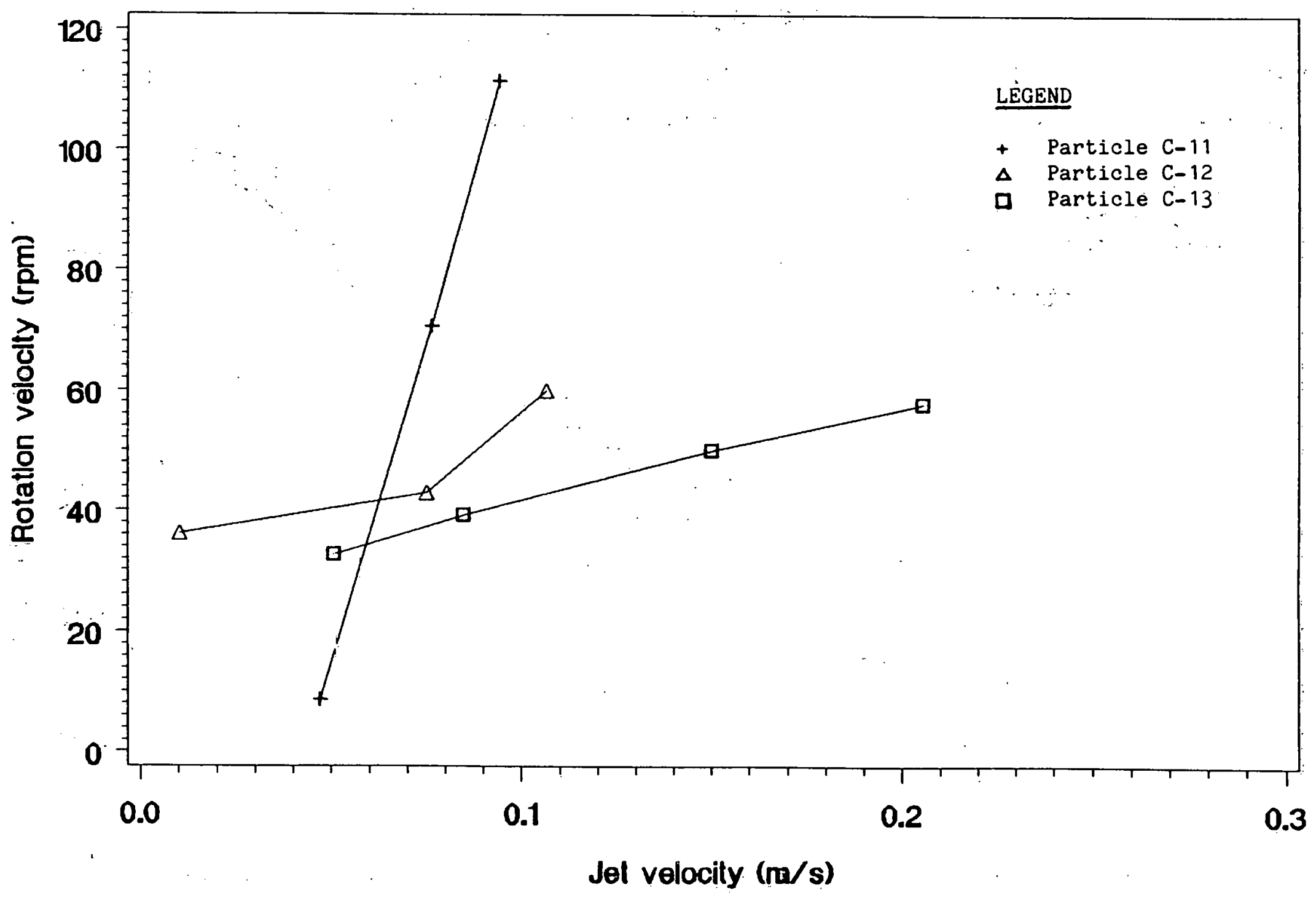

Figure 5.9. Rotational Characteristics of Three Coal Particles. 


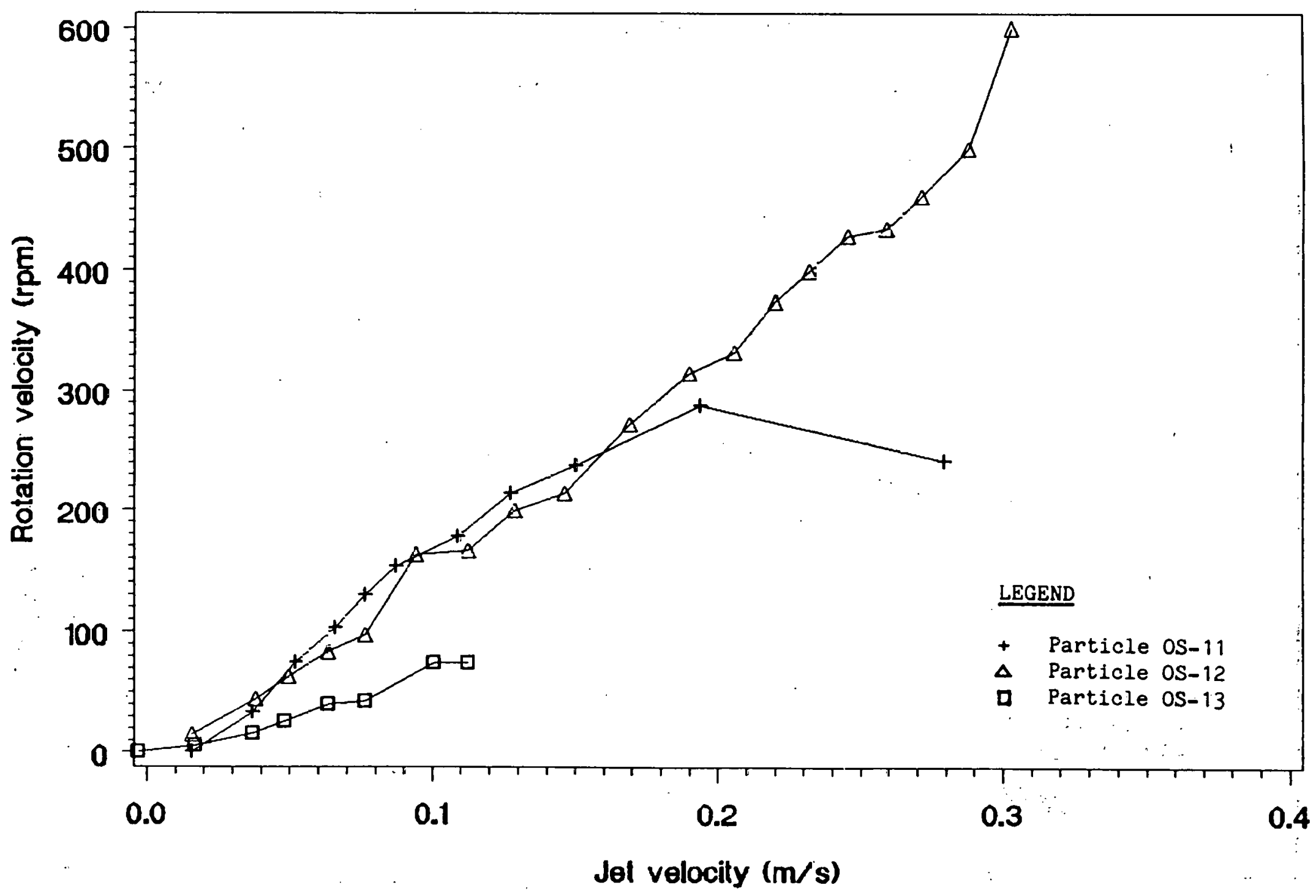

Figure 5.10. Rotational Characteristics of Three Oi: Shale Particles. 


\section{Chapter. 6}

\section{DISCUSSION}

The experimental data presented in the previous chapter shows some very interesting behavior which is discussed in detail below.

\subsection{Drag Characteristics of Spherical Particles}

The drag data for all the $105 \mu \mathrm{m}, 136 \mu \mathrm{m}$, and $160 \mu \mathrm{m}$ diameter spheres is presented in Figures $6.1,6.2$, and 6.3 , respectively. The data shows a linear variation of drag coefficient with Reynolds number, on a log-log scale. The companion theoretical fit proposed by white (1974) is shown by the solid line and represents the equation:

$$
C_{d}=\frac{24}{\operatorname{Re}}+\frac{6}{1+R e^{0.5}}+0.4
$$

which is generally accepted up to Reynolds numbers of 200,000 with an uncertainty of $\pm 10 \%$. A power law regression of the form given below was performed on these data sets.

$$
C_{d}=K \cdot R e^{n}
$$

where $K$ and $n$ are constants. For Stokes flow, $K=24$ and $n=-1$ which gives the classic relation:

$$
C_{d}=\frac{24}{R e}
$$

This above relation is valid for Reynolds numbers much less than unity and, hence, cannot be used for comparison with the present data which includes Reynolds numbers up to 13. The power law fit of the form 6-2 offers a simple way of comparing data in the region studied. For the three sets of data for spheres, the values obtained from this regression are presented in Table 6-1 below.

$$
\text { Table 6-1 }
$$

Power Law Regression on Data for Spheres

\begin{tabular}{ccc}
\hline Sphere dianeter $(\mu \mathrm{m})$ & $\mathrm{K}$ & $\mathbf{n}$ \\
\hline 105 & 26.98 & -0.739 \\
136 & 30.06 & -0.777 \\
160 & 28.17 & -0.758 \\
\hline
\end{tabular}

The mean values for the three sizes of spheres gives $K=28.40$ and $n=-0.758$. Over the same Reynolds number range, a power law fit to the data from equation $6-1$ gives $K=28.42$ and $n=-0.848$. The above 
fit shows a variation of $5 \%$ between equation $6-1$ and its corresponding power law regression,

$$
C_{d}=28.42 \operatorname{Re}^{-0.848}
$$

Further, the regression on the experimental data varies from equation 6-1, with the experimental data overestimating the drag coefficient by about $20 \%$. This variation does not appear to be random but systematic in nature and is about the same for the three different sized spheres. In order to isolate possible causes for this uncertainty, it is necessary to critically examine the experimental setup and the calculation procedure for the drag coefficient and Reynolds number given by equations 4-18 and 4-6 in Chapter 4, respectively.

The Reynolds number in the present study is based on the sphere diameter and is calculated using equation 4-6 (Chapter 4) which is reproduced below.

$$
\operatorname{Re}=\frac{U \cdot d}{\nu}
$$

As described in Chapter 4, uncertainty in measuring the sphere diameter, $d$, is less than $\pm 2 \%$ and that for $U$ is $\pm 5 \%$. Therefore, the total uncertainty in Reynolds number calculation is about $\pm 5.3 \%$ (See Appendix I) and, hence, cannot fully explain the variations in experimental data from the standard correlation for spheres. The drag coefficient was calculated from equation 4-18 (Chapter 4) which is given below.

$$
c_{d}=\frac{m g-K_{B} \cdot v_{d c}}{\frac{1}{2} \rho_{a} U^{2} \cdot A}
$$

whare,

$$
\begin{aligned}
& \mathrm{m}=\frac{\pi \mathrm{d}^{3}}{6} \cdot \rho \\
& \mathrm{A}=\frac{\pi \mathrm{d}^{2}}{4}, \text { aud } \\
& \mathrm{K}_{\mathrm{B}}=\frac{\mathrm{mg}}{\mathrm{V}_{\mathrm{dc}, 0}}
\end{aligned}
$$

Equations 6-7a thru 6-7c together with 6-6 gives:

$$
\mathrm{C}_{\mathrm{d}}=\frac{4}{3} \cdot \frac{\rho}{\rho_{\mathbf{a}}} \cdot \frac{\mathrm{dg}}{\mathrm{U}^{2}}\left[1-\frac{\mathrm{V}_{\mathrm{dc}}}{\mathrm{V}_{\mathrm{dc}, 0}}\right]
$$

Uncertainities in $d, U$, and $V_{d c}$ together account for about $\pm 8.6 \%$ in the drag coefficient using equation 6-6. However, if equation $6-\overline{8}$ were to be used to calculate the drag coefficient, then the uncertainty would be $\pm 7.3 \%$. Details of these calculations are given in Appendix I. The 
combined uncertainties in both the Reynolds number and the drag coefficient adequately explain the observed variation of the data from the standard curve. Uncertainties at low Reynolds number are attributed to higher uncertainties in both, the flow and balance DC voltage measurements; changes in which were small enough to be dwarfed by the experimental uncertainties. The above uncertainty analysis provides quantitative information on random variations in the experimental data. However, the variation from the standard correlation appears to be systematic rather than entirely random. Some possible explanations for this variation are given here.

A consistent overestimation of the drag coefficient could be caused by a higher than true value of the sphere density, $\rho$. In the case of PSL spheres, the manufacturer's quoted density is $1,050 \mathrm{~kg} / \mathrm{m}^{3}$ which is slightly greater than the density of water. It was observed that these spheres would settle in water without floating. Thus, the density overestimation cannot be more than 5\% and it is not possible to adequately explain the observed variation in the data.

Another systematic error could be attributed to the jet velocity calibration. If all the seed particles for LDA measurements are not less than $2 \mu \mathrm{m}$ in size, then the larger particles will slip relative to the fluid flow. The resulting velocity measurement would underestimate the jet velocity. From equation 6-5 it can be seen that this error in jet calibration would underestimate the Reynolds number while equation 6-8 indicates that the drag coefficient would be overestimated. For instunce, if the jet calibration underestimates the true velocity by $5 \%$, then the true Reynolds number would be $5 \%$ greater than the measured value and the true drag coefficient would be about $10 \%$ less than the measured value. The combined effect of these changes would result in data with less variations from the standard correlation.

Finally, it is also possible that suspended spheres were subjected to a flow with some three dimensionalities as well as some unsteadiness. The finite size of the jet does not produce a true two-dimensional flow and could, therefore, affect the drag data. From the data available in literature, it appears that turbulence (or unsteadiness) effects could result in reduced drag coefficient, especially at high Reynolds numbers.

Within the experimental uncertainties, the experimental set-up centered around the electrodynamic balance provides a reliable and accurate method for estimating the drag coefficient of a single particle. In the present study, the higher limit on particle Reynolds number was limited to about 13 and reliable data on the lower limit was obtained until about 0.2 . Engineering applications encompass a wide range of Reynolds numbers and, as such, it will be worthwhile to examine the limits of the electrodynamic balance set-up for studying drag characteristics at Reynolds numbers less than 0.2 and greater than 13.

Lower Reynolds numbers can be achieved by either reducing the size of the particles or by reducing the jet centerline velocity. At low flows (centerline velocity less than $1 \mathrm{~cm} / \mathrm{s}$ ) the uncertainities in the jet calibration increase substantially. DC voltage changes for low velocities 
are also small, of the order of $10 \mathrm{mV}$, which increase the uncertainty in the measurements of both the drag coefficient and the Reynolds number. Reducing the size of the spheres is a possibility and it is estimated that spheres as small as $50 \mu \mathrm{m}$ in diameter can be successfully used with the present set-up. The lower limit on the size of spheres is dictated by accuracies of the imaging and sizing system. For small particle sizes (less than $30 \mu \mathrm{m}$ ), the present set-up results in optical aberrations which cause non-linearities in the area equivalent diameter measurements. An alternate method could employ particle sizing by light scattering measurements, Davis et al. (1987). Their technique enables study of spheres as small as $0.5 \mu \mathrm{m}$ in diameter and Reynolds numbers as low as 0.001 .

The higher limit for drag measurements will be dictated by turbulence resulting from a high velocity jet flow. In the present case this criteria would enable jet diameter Reynolds numbers of up to about 2,000 corresponding to a jet velocity of about $5.3 \mathrm{~m} / \mathrm{s}$ (jet nozzle diameler $=6 \mathrm{~mm}$ ). The corresponding particle diameter Reynolds number is about 69 for a sphere of diameter $200 \mu \mathrm{m}$, which can be considerod to be in a uniform flow. Experiments at higher Reynolds numbers would induce the effects of turbulence on drug which ennnot be isolater individually. In the present study, turbulence or long term unsteadiness in the jet, as measured by the LDA were limited to $5 \%$ and would not have an adverse effect on the drag measurements. The apparatus can, however, be modified to study the effects of turbulence or imposed unsteadiness by modifying the air flow system. The capacity of the air flow system in the present set up allowed data acquisition at air velocities greater than twice the terminal velocity of the particle. This aspect will, therefore, not limit the air velocity at 'which drag information can be obtained.

From the above discussion it appears that only a limited range of Reynolds numbers can be studied using the present electrodynamic halance. Modification of the balance to suspend larger particles and a larger jet could increase the upper linit by a factor of about four. However, in order to obtain reliable data it is necessary that the velocity profile in the vicinity of the particle be uniform for at least ten diameters around the particle. This important condition could severely limit the upper range of Reynolds numbers studied.

\subsection{Drag Characteristics of Coal Particles}

The drag characteristics for all the coal particles are shuwn in Figure 6.4. The linear relationship between drag coefficient and Reynolds number on a log-log scale for each individual particle suggests that a power law relationship can be used lu correlate the two. A power law fit, equation 6-2, was performed and the values for each particle are presented in Tuble $6-2$.

The mean values for all the thirteen coal particles are $K=38.88$, and $n=-0.815$. Over the same range of Reynolds number, the power law fit to the data from the standard correlation for a sphere (equation 6-1) gives values of $K=28.77$ and $n=-0.867$. A power law fit to the 
Table 6-2

Power Law Regression on Data for Coal Particles

\begin{tabular}{ccc}
\hline Coal particle no. & $\mathrm{K}$ & $\mathrm{n}$ \\
\hline C-1 & 38.94 & -0.710 \\
C-2 & 30.10 & -0.698 \\
C-3 & 45.00 & -0.857 \\
C-4 & 31.89 & -0.694 \\
C-5 & 42.59 & -0.757 \\
C-6 & 30.68 & -0.719 \\
C-7 & 39.23 & -0.732 \\
C-8 & 32.90 & -0.721 \\
C-9 & 54.61 & -0.716 \\
C-10 & 47.23 & -0.820 \\
C-11 & 43.49 & -0.808 \\
C-12 & 28.64 & -1.372 \\
C-13 & 40.19 & -0.991 \\
\hline
\end{tabular}

data for all thirteen particles was also performed and it yielded values of $\mathrm{K}=41.15$ and $\mathrm{n}=-0.875$.

Figure 6-4 shows that data for coal is limited to Reynolds numbers. less than 10. As in the case of spheres, the uncertainty in drag. measurement is highest at the lower end of Reynolds number range. All these paticles were irregular and chunky in shape with no general isometry. Further, the three major dimensions were observed to be within approximately $20 \%$ of one another. Video images of each particle in two orthogonal directions, as viewed by the camera, indicated mean aspect ratios between 0.84 and 1.05 .

Drag data on some coal particles were obtained at air velocities greater than the particle terminal velocity; however, for some particles it was limited to $40 \%$ of the terminal velocity. This upper limit is attributed to instabilities in the particle motion. In general, the drag force vector is not parallel to the jet direction because of the nonspherical shape of the particles, Brenner (1964) and Torobin and Gauvin (1960). This total force can be expressed as the vector sum of two forces, viz., a drag force which is collinear with the jet flow and, a transverse lift force. At very low air velocities, the horizontal stabilizing force in the electrodynamic balance is able to balance the transverse drag and thereby keeps the particle at the balance center. As the air velocity increases, the horizontal force in the balance is smaller in magnitude than the lift force and, consequently, the particle is pushed radially outwards. However, because the particle remained in a horiznntal plane bisecting the electrodynamic balance, it did not oscillate vertically but remained still. Further increase in the air velocity resulted in particle rotation with accompanying vertical oscillations.

Some particles exhibited pure spinning molion at low air velocities. 
In general, irregular shaped particles can be expected to spin in a flow, Brenner (1960). In this particular application the electrostatic force would restrain the particle spin to a direction about the vertical centerline and, hence, about the jet direction. The rotational velocity was observed to increase with jet velocity which subsequently led to transverse instabilities, thereby limiting drag data acquisition. However, it is interesting to note that high $\mathrm{AC}$ field frequencies (greater than 70 Hz.) completely inhibited particle rotation without influencing the DC voltage and, hence, the drag coefficient.

An important parameter affecting the drag characteristics is the characteristic dimension used in the calculations, $d_{e}$, the area equivalent diameter. From the procedure given in Chapter 4, the scheme for the drag coefficient computation can be written as:

$$
\mathrm{C}_{\mathrm{d}}=\frac{4}{3} \cdot \frac{\rho}{\rho_{\mathbf{a}}} \cdot \frac{\mathrm{d}_{\mathrm{e}} \cdot \mathrm{g}}{\mathrm{U}^{2}}\left[1-\frac{\mathrm{V}_{\mathrm{dc}}}{\mathrm{V}_{\mathrm{dc}, 0}}\right]
$$

Two assumptions used to arrive at this relation need critical evaluation for nonspherical particles. First, the area equivalent diameter was used to calculate the mass of the particle and, sucund, it was also used to calculate the projected area in the direction of the jet. As stated earlier, orthogonal projections of the particle image showed coal particles to be chunky and the three major dimensions to be almost equal. Thus, $d_{e}$, as obtained in these experiments is a fairly accurate representation of the particle mass as well as its projected area as seen by the jet. Other parameters being constant, the choice of the characteristic dimension will have a linear effect on both the drag coefficient and Reynolds number.

The rigorous experimental procedure for measuring the drag coefficient of a particle would require explicit measurements of the particle mass and projected area in the jet direction. On the basis of this information, the drag coefficient can be calculated as follows:

$$
\begin{aligned}
\mathrm{C}_{\mathrm{d}} & =\frac{\mathrm{mg}-\mathrm{K}_{\mathrm{B}} \cdot \mathrm{V}_{\mathrm{dc}}}{\frac{1}{2} \rho_{\mathrm{a}} \mathrm{U}^{2} \cdot \mathrm{A}_{\mathrm{p}}} \\
& =\frac{2 \mathrm{mg}}{\rho_{\mathrm{a}} \mathrm{U}^{2} \mathrm{~A}_{\mathrm{p}}}\left[1-\frac{V_{\mathrm{dc}}}{\mathrm{V}_{\mathrm{dc}, 0}}\right]
\end{aligned}
$$

This computational procedure does away altogether with the necessity for calculating an area equivalent diameter for computing the drag coefficient. In the present setup, it was not possible to measure the mass of each individual particle. Attempts to obtain the projected area in the direction of the jet were made by assembling an optical setup comprised of a mirror, two lenses and a high resolution video camera to view the particle from the balance top. Back illumination of the particle was provided by an optic fiber bundle which directed the light from a lamp to the bottom of the air inlet pipe. This arrangement resulted in increased magnification but the video image showed increased fuzziness in demarcating the image border. The latter aspect 
would introduce substantial uncertainities in the calibration of the imaging system and, hence, was not pursued further.

Calculation of Reynolds number, however, requires a characteristic dimension for the particle. For a chunky particle like coal, such a dimension based on the projected area will vary by $20 \%$ depending upon the viewing direction. From a hydrodynamic viewpoint, the surface area equivalent diameter, i.e. diameter of a sphere having the same surface area as that of the particle, would be preferrable. A technique for this area measurement, for each particle, was not available and, hence, not used.

The results for all the thirteen particles show that the drag on coal particles is greater. than that for spheres by up to 40\%. Similar increase in the drag coefficient of irregular particles have been reported by Pettyjohn and Christiansen (1948) and Kamiwano et al. (1984). Neither of them have offered an explanation into the physics of this aspect. It is possible, especially at high Reynolds numbers, that shape and surface imperfections would cause eddy shedding thus increasing the total dissipation. This process is shown schematically in Figure 6.5. Given this hypothesis, it is then possible that drag would be increased both by the surfare roughnoon and also by shape irregularities. This aspect is further discussed in detail in Section 6.4 below.

\subsection{Drag Characteristics of Oil Shale Particles}

Drag data for thirteen oil shale particles is presented in Figure 6.6 and a power law fit (equation 6-2) was performed on each data set. Results from this regression are given in Table 6-3 for each particle.

Table 6-3

Power Law Regression on Data for Oil Shale Particles

\begin{tabular}{ccc}
\hline $\begin{array}{c}\text { Oil shale } \\
\text { particle no. }\end{array}$ & $\mathrm{K}$ & $\mathrm{n}$ \\
\hline OS-1 & 72.13 & -0.744 \\
OS-2 & 83.45 & -0.806 \\
OS-3 & 87.11 & -0.791 \\
OS-4 & 55.16 & -0.748 \\
OS-5 & 41.24 & -0.752 \\
OS-6 & 73.97 & -0.780 \\
OS-7 & 66.30 & -0.754 \\
US-8 & 52.79 & -0.692 \\
OS-9 & 41.87 & -0.653 \\
OS-10 & 54.72 & -0.518 \\
OS-11 & 66.19 & -0.364 \\
OS-12 & 77.48 & -0.728 \\
OS-13 & 270.38 & -0.655 \\
\hline
\end{tabular}


Table 6-3 shows that particle OS-13 exhibits an unusually large value for $K$ which can be attributed to its shape and size. If this value is excluded, then the mean value of $K$ for twelve particles is $64.37(80.22$ for all thirteen particles). Similarly, particle. OS-11 exhibits a significantly small value for the exponent, $n$. If this value is excluded, then the mean value of the exponent, $n$, is $-0.718 \cdot(-0.691$. for all thirteen particles).

As in the case of coal particles, oil shale particles too exhibited instability in the presence of the jet. These instabilities were accentuated by the shape difference between coal and oil shale; the latter being distinctly flake-like. This aspect limited drag data acquisition to about $40 \%$ to $60 \%$ of the particle terminal velocity and data for only one particle (OS-1) was acquired up to its terminal velocity.

In general, all the oil shale particles oriented themselves vertically in the electrodynamic balance and thus indicated a preferred orientation relative to the jet. The preferred orientation and, also, the absence of a clearly defined characteristic dimension for a flake could rcoult in substantial variations in the drag data interpretation. This aspect is discussed below in greater detall.

As described earlier, the drag coefficient for a particle was computed using equations 6-6 and 6-7. The area equivalent diameter, $d_{e}$, was obtained by averaging the projected area as the particle rotated at a slow and steady rate (Section 4.6.1, Chapter 4). Figure 6.7(a) shows the sketch of a typical oil shale particle as viewed in two mutually perpendicular directions. In this case the jet velocity, as also the direction of suspension of the particle, is in the z-direction. These projected images can be characterized by the three largest dimensions, viz., $w, h$, and $t$; with the maximum and minimum projected areas being $A_{1}$ and $A_{2}$. As in the case of coal, for oil shale, too, two parameters need to be determined accurately to obtain the drug coefficient, viz., particle mass and the projected area in the jet direction. Due to hardware limitations, explained in the previous section, the third orthogonal view could not be obtained which would have provided the projected area in the jet direction. In the absence of this information, the projected area was estimated from the available data by obtaining a mean projected arca,

$$
A_{p}=\frac{A_{1}+A_{2}}{2}
$$

The area equivalent diameter, $d_{e}$, was then calculated using the following equation:

$$
d_{e}=\left[\frac{4 A_{p}}{\pi}\right]^{0.5}
$$

and the mass and projected area of the particle were calculated from the following relations: 


$$
\begin{aligned}
\mathrm{m} & =\frac{\pi \mathrm{d}_{\mathrm{e}}^{3}}{6} \cdot \rho \\
\mathrm{A}_{\mathrm{p}} & =\frac{\pi \mathrm{d}_{e^{2}}}{4}
\end{aligned}
$$

Finally, the Reynolds number was calculated using $d_{e}$ as the characteristic dimension,

$$
\operatorname{Re}=\frac{\mathrm{U} \cdot \mathrm{d}_{\mathbf{e}}}{\nu}
$$

Given the irregular shape of the particles it is not possible to evaluate the uncertainities explicitly. The above technique requires both the mass and the projected area of the particle to calculate the uncertainities involved. However, these uncertainities can be estimated by assigning well defined shapes to the particle. Presented below are two analyses to evaluate the uncertainties inherent in the above process; first, assuming the flake to be rectangular in shape with a uniform thickness; and second, for an ellipsoidal flake. The three major dimensions for all the flakes are assumed to be similar to that for a typical oil shale particle. Measurements made from the video images of all the oil shale particles indicated the following relationships between the three major dimenaions:

$$
\begin{aligned}
& \frac{w}{h}=1.2 \\
& \frac{t}{h}=0.5
\end{aligned}
$$

\subsubsection{Rectangular Flake Model}

If the suspended flake were to be rectangular in shape then the experimental set-up would give the following values for projected areas, mean projected area and the area equivalent diameter:

$$
\begin{aligned}
& A_{1}^{\prime}=w h=1.2 h^{2} \\
& A_{2}^{\prime}=t h=0.5 h^{2} \\
& A_{p}^{\prime}=0.85 h^{2} \\
& d_{e}^{\prime}=1.04 h
\end{aligned}
$$

where, the primed symbols indicate values for the rectangular shape as the optical system would have measured. The drag coefficient can now be estimated using the above relations with equations 6-9 to give

$$
\mathrm{C}_{\mathrm{d}}^{\prime}=1.39\left[\frac{\rho}{\rho_{\mathbf{a}}} \frac{\mathrm{gh}}{\mathrm{U}^{2}}\left(1-\frac{\mathrm{V}_{\mathrm{dc}}}{\mathrm{V}_{\mathrm{dc}, 0}}\right)\right]
$$


Similarly using equation 6-13, the Reynolds number can be obtained as follows:

$$
\mathrm{Re}^{\prime}=1.04 \frac{\mathrm{Uh}}{\mathrm{v}}
$$

However, if the true values for mass and projected area were to be used, the result would be as follows:

$$
\begin{aligned}
& m_{t}=0.6 \mathrm{~h}^{3} \cdot \rho \\
& A_{p, t}=0.6 \mathrm{~h}^{2}
\end{aligned}
$$

Substituting these values in equation 6-10, the drag coefficient can be expressed aș:

$$
\mathrm{C}_{\mathrm{d}, \mathrm{t}}=2\left[\frac{\rho}{\rho_{\mathrm{a}}} \frac{\mathrm{gh}}{\mathrm{U}^{2}}\left(1-\frac{\mathrm{V}_{\mathrm{d} a}}{\mathrm{~V}_{\mathrm{dc}, \mathrm{O}}}\right)\right]
$$

Therefore,

$$
\begin{aligned}
& \frac{\mathrm{C}_{d}^{\prime}}{C_{d, t}}=0.69 \text {, or } \\
& C_{d, t}=1.44 \mathrm{C}_{d}^{\prime}
\end{aligned}
$$

The above relation shows that for the same experimental data, the measured drag coefficient would be about $31 \%$ less than the true value. The true value of the drag coefficient would, therefore, be $44 \%$ greater than the measured value. In order to calculate the Reynolds number a characteristic dimension is required. Of the several criteria put forward (Beddow, 1980), the one appropriate in this sludy is the diameter of a circle with the same area as the projected area in the direction of the flow. For the rectangular shape, the area equivalent diameter from equation $6-19$ is:

$$
\mathrm{d}_{\mathbf{e}}=0.87 \mathrm{~h}
$$

This value for the area equivalent diameter gives

$$
\begin{aligned}
& R e_{1}=0.87 \frac{\mathrm{Uh}}{\nu}, \text { and } \\
& \frac{\mathrm{Re}^{\prime}}{\operatorname{Re}}=1.19, \mathrm{Ui} \\
& R e_{1}=0.84 \mathrm{Re}^{\prime}
\end{aligned}
$$

The true Reynolds number would, therefore, be $1.6 \%$ less than the measured value. Using a mass equivalent diameter, which has also been proposed by several investigators, the Reynolds number is calculated as: 


$$
\begin{aligned}
& R e_{2}=1.05 \frac{U h}{\nu} \\
& \frac{R e^{\prime}}{R e_{2}}=0.99, \text { or } \\
& R e_{2}=1.01 R^{\prime}
\end{aligned}
$$

This choice of characteristic dimension would result in Reynolds number which is almost the same as the experimentally determined value. On the basis of the above, the experimentally obtained value of Reynolds number can be considered to be a good estimator for drag coefficient correlation. Each of these effects are shown in Figure 6.8 for a typical particle (particle OS-12). In general then, the experimental values obtained provide a lower limit for the drag coefficient-Reynolds number relationship.

\subsubsection{Ellipsoidal Flake Model}

In this treatment of particle shape, the flake is assumed to be ellipsoidal in all three views, with the three largest dimensions forming the three major axes of the ellipsoid. From the observations of several flukes, the most probable orientation of the ellipsoidal flake would be with its largest axes along the vertical, Figure 6.7(c).

The projected areas and the area. equivalent diameter, as would be obtained from the experimental set-up are as follows:

$$
\begin{aligned}
& A_{1}^{\prime}=0.94 h^{2} \\
& A_{2}^{\prime}=0.39 h^{2} \\
& A_{p}^{\prime}=0.67 \mathrm{~h} \\
& d_{e}^{\prime}=0.92 \mathrm{~h}
\end{aligned}
$$

Using equation 6-9, the drag coefficient can be formulated as:

$$
\begin{aligned}
& C_{d}^{\prime}=1.23\left[\frac{\rho}{\rho_{\mathbf{a}}} \frac{g h}{U^{2}}\left(1-\frac{V_{d c}}{V_{d c}, 0}\right)\right] \\
& \operatorname{Re}^{\prime}=0.92 \frac{U_{h}}{\nu}
\end{aligned}
$$

The exact calculations for the mass and projected area for an ellipsoid are given below:

$$
\begin{aligned}
& m_{t}=0.31 \mathrm{~h}^{3} \cdot \rho \\
& A_{p, t}=0.47 \mathrm{~h}^{2}
\end{aligned}
$$

The drag coefficient can now be estimated by equation $6-10$, as follows: 


$$
C_{d, t}=1.33\left[\frac{\rho}{\rho_{\mathrm{a}}} \frac{g h}{U^{2}}\left(1-\frac{V_{d c}}{V_{d c, 0}}\right)\right]
$$

therefore,

$$
\begin{aligned}
& \frac{c_{d}^{\prime}}{c_{d, t}}=0.93, \text { or } \\
& c_{d, t}=1.08 c_{d}^{\prime}
\end{aligned}
$$

The above relation shows that for the same data, the true drag coefficient will be $8 \%$ greater than the measured value.

Using the criteria described in Section 6.3.1, the Reynolds number based on the projected area equivalent diameter in the direction of the jet is as follows, equation $6-12 \mathrm{a}$ and $6-30 \mathrm{~b}$ :

$$
\begin{aligned}
& \mathrm{He}_{1}=0.77 \frac{\mathrm{Uh}}{\nu} \\
& \frac{R e^{\prime}}{R e_{1}}=1.19, \text { or } \\
& R e_{1}=0.84 \mathrm{Re}^{\prime}
\end{aligned}
$$

The Reynolds number based on mass equivalent diameter is calculated from equation 6-30a as follows:

$$
\begin{aligned}
& R e_{2}=0.84 \frac{\mathrm{Uh}}{\nu} \\
& \frac{R e^{\prime}}{R e_{2}}=1.09, \text { or } \\
& R e_{2}=0.91 \mathrm{Re}^{\prime}
\end{aligned}
$$

The effects of these computational changes on drag characteristics are shown in Figure 6.9 for the same particle, OS-12. In general, this assumption of ellipsoidal shape also indicates that the experimental data provides a lower limit un the drag characteristics of a particle.

\subsubsection{Effect of Shape on Drag Characteristics}

Figures 6.8 and 6.9 show the effects of shape on the drag characteristics of oil shale particles. In the models explained above in Sections 6.3.1 and 6.3.2, it has been assumed that the experimentally obtained drag data for an oil shale particle would nut vary aignificantly if the particle were to be rectangular or ellipsoidal. Given the video pictures of the particles, it can be said that the latter model would be a more accurate representation of the flake. The two models, never the less, provide some interesting insight into particle drag characteristics.

For a rectangular flake, Figure 6.8 indicates that changes in the 
drag characteristics could be significant depending on the characteristic dimension and the computation procedures used. For a given particle-fluid combination, the Reynolds number based on mass equivalent diameter will result in a different curve than that based on projected area equivalent diameter. It appears, then, that the drag curve has to be characteristic dimension specific. Further, no universal curve can be obtained for a nonspherical particle.

The ellipsoidal shape model, Figure 6.9, does not change the drag curve by a significant amount. With about $10 \%$ uncertainty, the drag coefficient-Reynolds number dependence is independent of the characteristic dimension and the computation procedure used.

It should be noted that, the relative orientation of the particle with the flow will, in general, change the dimension based on projected area. It will, however, not change the characteristic dimension of mass equivalent diameter. If the latter criterion were to be used, then, the drag data will have to include a family of curves, each curve representing a particular orientation of a particle relative to the mean flow. For practical purposes, it will be useful to have a universally accepted dimension for calculating the Reynolds number. An appropriate dimension for fluid mechanics applications will be the hydraulic diameter which is the diameter of a sphoro cqual lu lie wetted area (area in contact with the fluid) of the particle. Such a calculation will be relatively simple for well defined shapes but will be rather complex for nonspherical particles with rough surfaces such as, coal and oil shale.

Finally, it should be noted that the data obtained includes any influence of particle rotation on drag characteristics. As stated earlier, a high AC frequency would completely inhibit particle rotation without influencing the balance DC voltage. This observation suggests that the drag coefficient is not affected by particle rotation in a direction collinear with the mean flow direction. Data from these experiments is, therefore, a true indicator of the drag characteristics of the nonspherical particles studied.

\subsection{Particle Rotation}

On the basis of their experiments, Pettyjohn and Christiansen (1948), and other investigators have reported that particles entrained in a fluid flow are likely to rotate. Theoretical credence to their observation is provided by Brenner (1964) and others who report that, in general, a nonspherical particle will experience a drag force and a torque. If the particle is not bound in any way then it is likely to rotate also. In general, the direction of rotation may not be parallel to the direction of the mean flow. In the present case, the irregular particles, both coal and oil shale, were observed to rotate about an axis which was collinear with the jet flow direction. This preferred direction can be attributed to the balance of two forces viz., the particle weight and the electrodynamic force.

As can be seen from Figures 5.9 and 5.10, an increase in the jet. velocity causes the rotation velocity to increase for both coal and oil 
shale. In general, the oil shale particles exhibited higher rotation velocities than coal particles, an observation which can be attributed to the flake-like shape of oil shale. This data is, however, overshadowed by Figure 5.8 which indicates that the rotation velocity is dependent on the AC field frequency also, in addition to the jet velocity. This observation suggests that unlike the electrodynamic force on the particle which is independent of the AC frequency, the electrodynamic torque on the particle is AC field dependent. Such a situation is likely due to the finite size' of the electric field null point at the balance center which could interact asymmetrically with the particle charge. It is also possible that the charge on the particle may not be concentrated at one point on the particle but actually be distributed over its surface. A combination of charge distribution and a finite sized null point could influence the particle rotation dynamics. For this reason, particle rotation characteristics cannot be quantitatively studied with an electrodynaimc balance. A correlation between the rotation velocity and the jet velocity has, therfore, not been offered. However, in general, it appears that the particle rotation velocity wlll inciease with increasing alip velocity belween the particle and the mess flow. A frcc falling particle under the influence of gravity is likely to rotate at a constant velocity once it achieves its terminal velocity, Pettyjohn and Christiansen (1948).

Figure 6.10 illustrates aspects of particle stability in the balance more clearly. In order for the particle to be stable, it is necessary that the line of action of these two forces coincide. This condition is shown in Figure 6.10(a) and it dictates the orientation of the particle under static conditions. A situtation where the line of action of these two forces is not the same is shown in Figure $6.10(\mathrm{~b})$. Under this condition, the particle will experience a net moment which will bring it into static equilibrium, as shown in Figure $6.10(\mathrm{c})$. This condition restricts the particle rotation to a direction which is same as the jet flow. As stated earlier, the rotation velocity increused with increasing jet velorit.y until the onset of instabilities when violent horizontal and vertical oscillatory motion would set in. Data acquisition was terminated when this condition was oluserved.

Attempts were also made to measure the rotation of the particle by the LDA system. Until now, no experimerits have been conducted to ineasure the rotation of a particle with an LDA. The ability of an electrodynamic balance to stably suspend a rotating particle was exploited to test the ability of a one-component fiber optic LDA to measure the particle rotation speed. In this case, the particle itself would provide several light scattering sources from its surface. Figure 6.11 shows a schematic of this technique where the point farthest from the rotational axis, $P$, would correspond to the highest velocity $\left(v_{\max }\right)$ which could be obtained from the $L D A$ velocity histogram. The radial distance between $P$ and the rotation axis, $R_{\max }$, can be determined from video images of the particle and the rotation velocity, $\omega$, could then be obtained using:

$$
\omega=\frac{v_{\max }}{\mathrm{k}_{\max }}
$$


Finally, this rotation can be cross-checked against measurements from video recordings of the particle motion.

The technique described above was tested successfully for one particle but was not critically analyzed. As described earlier, the particle rotation speed is itself subject to the influence of the AC field frequency and, consequently, provides little information of practical significance related to particle aerodynamics. Further, experiments using the above technique could provide useful information on particle rotation induced errors in two-phase flow measurements. 




Figure 6.1. Drag Data for Ten Spheres of Diameter $105 \mu \mathrm{m}$. 


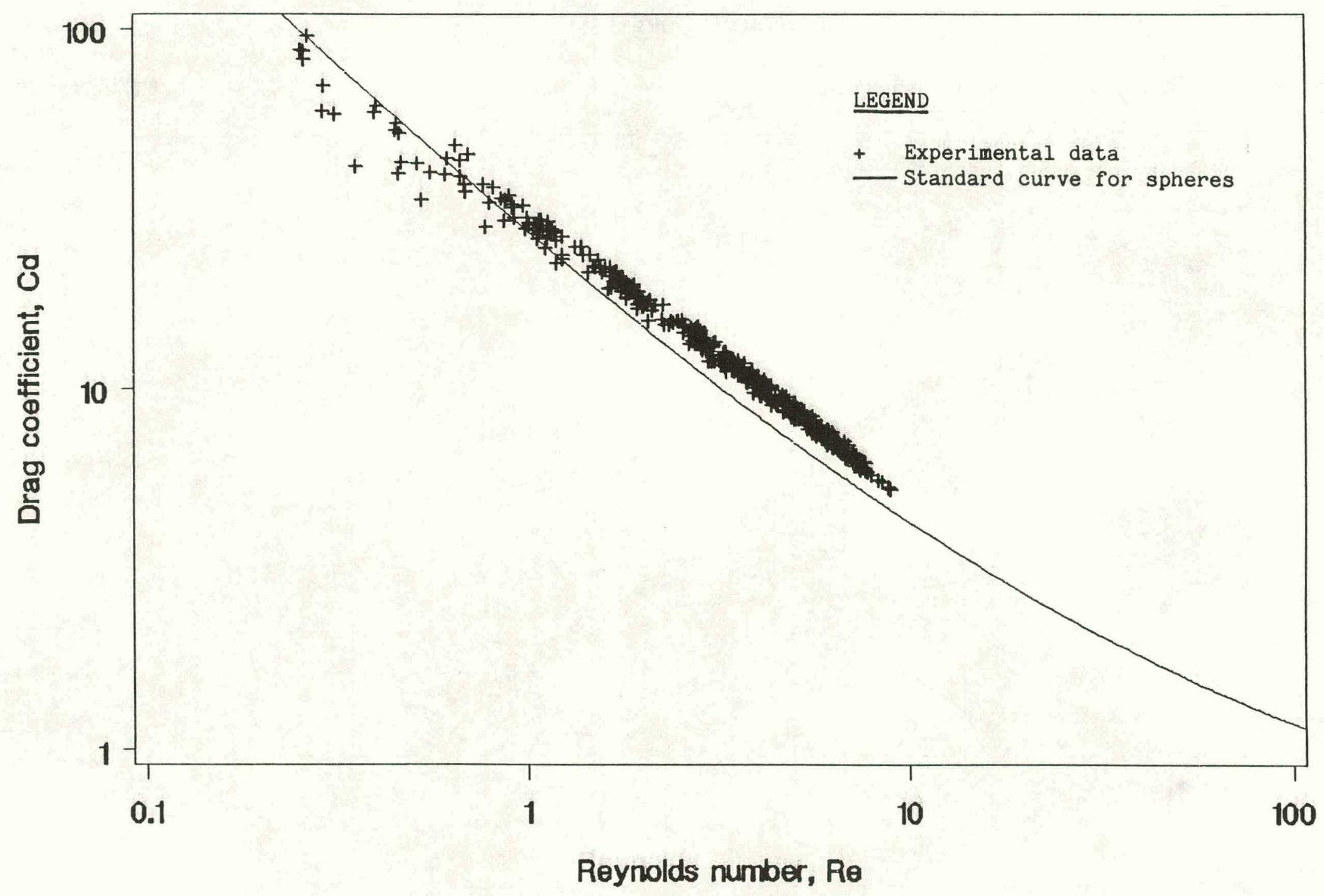

Figure 6.2. Drag Data for Ten Spheres of Diameter $136 \mu \mathrm{m}$. 


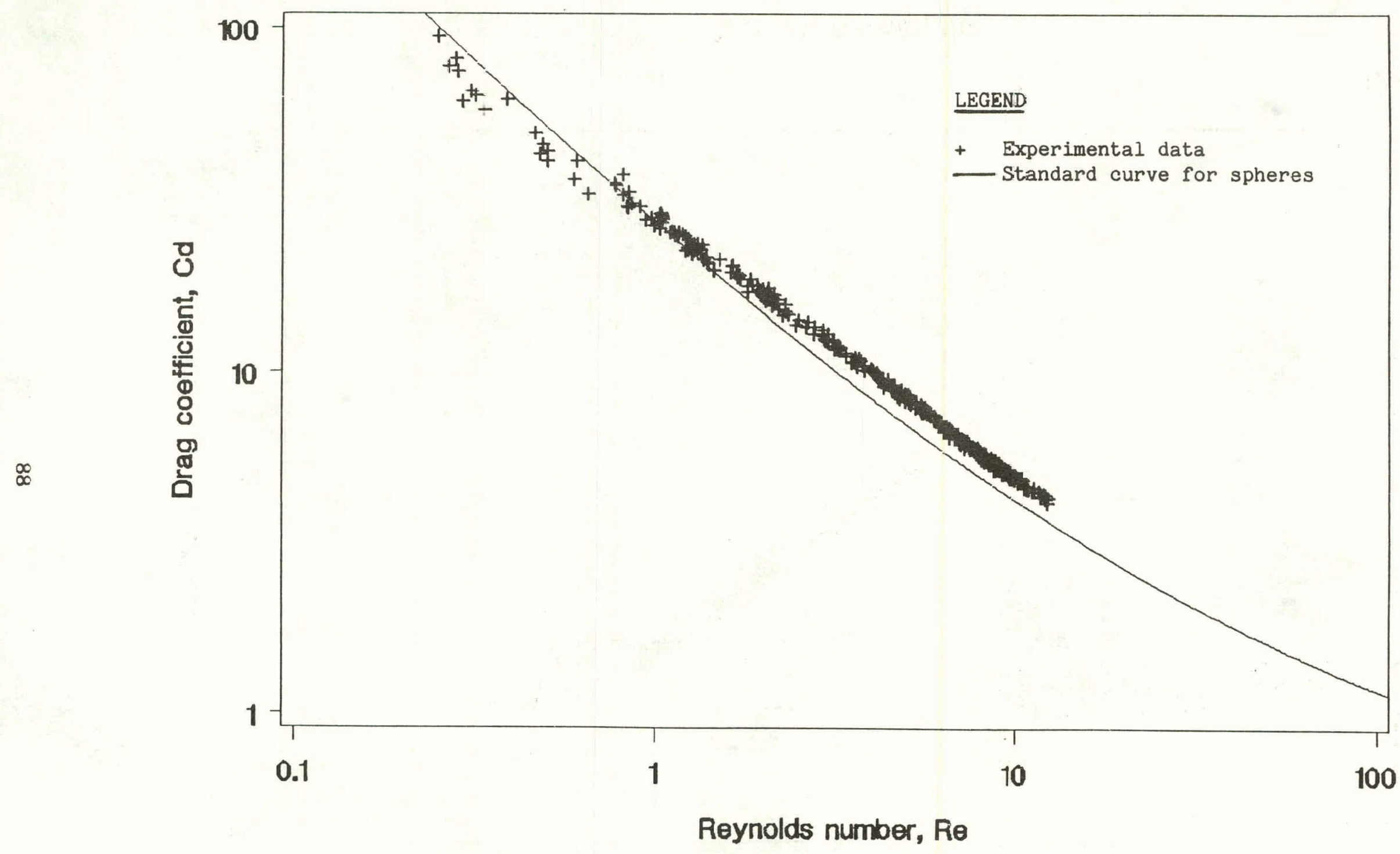

Fi巨ure 6.3. Drag Data for Ten Spheres of Diameter $160 \mu \mathrm{m}$. 




Figure 6.4. Drag Data for Thirteen Coal Particles. 


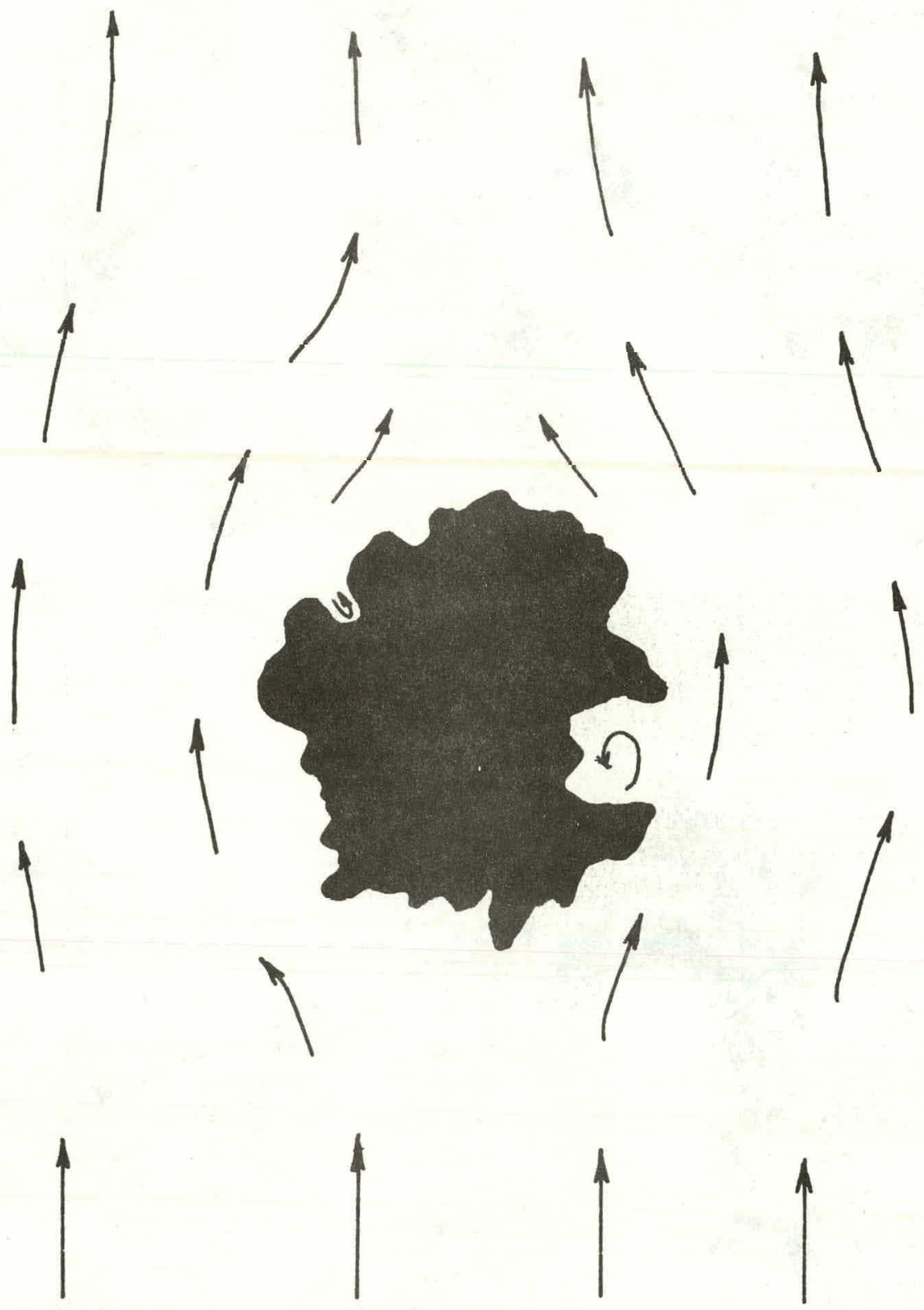

Figure 6.5. Fluid Flow around a Nonspherical Particle with Rough Surface. 


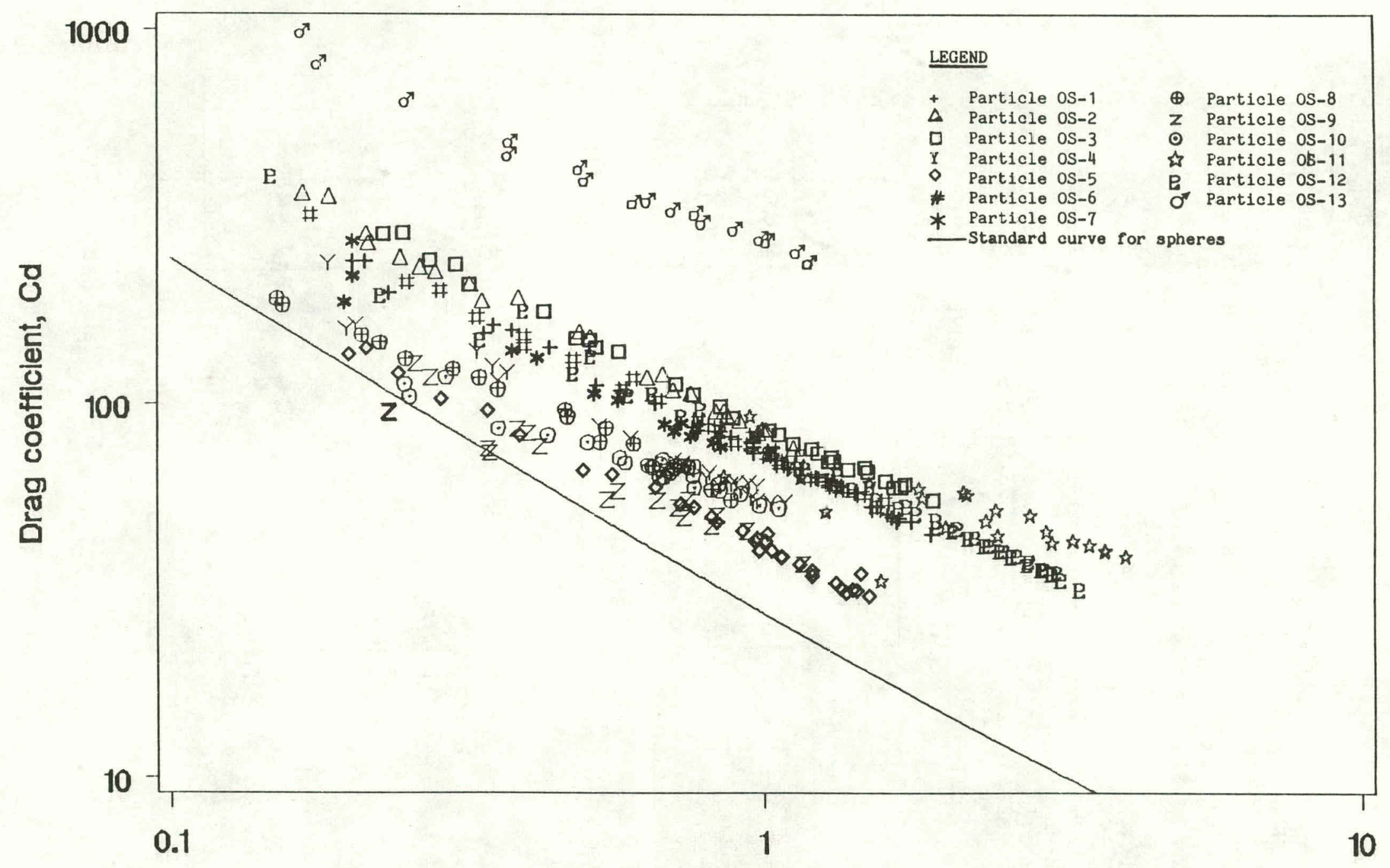

Reynolds number, Re

Figure 6.6. Drag Data for Thirteen Oil Shale Particles. 

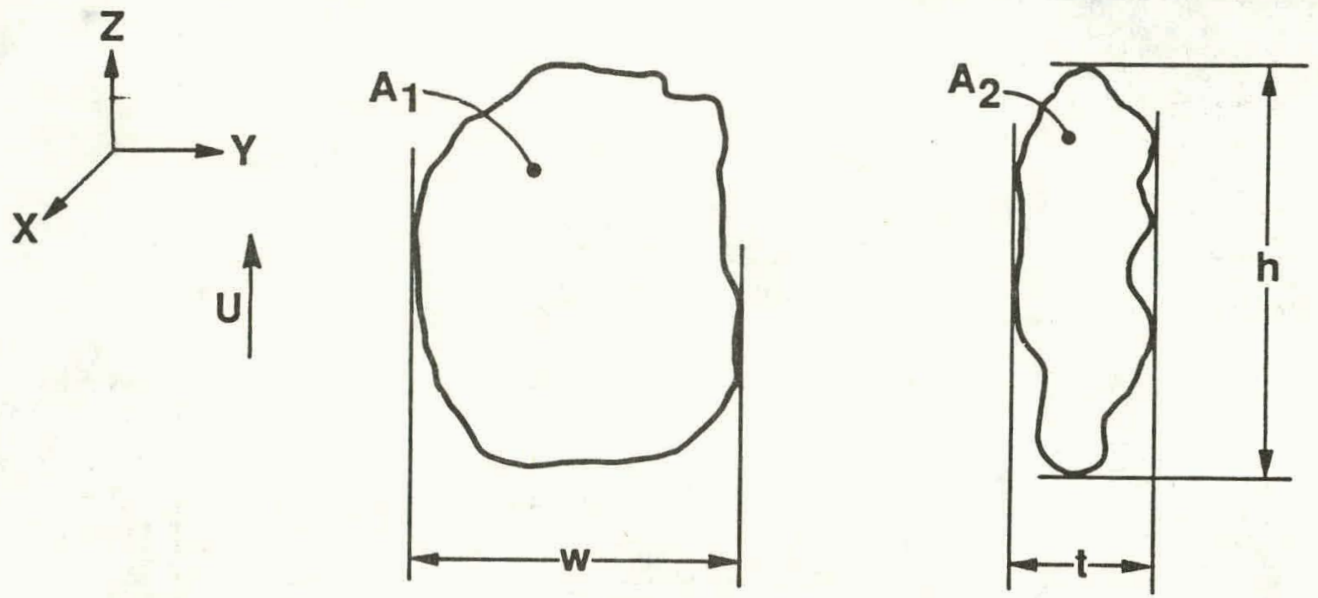

(a) Typical Oil Shale Particle
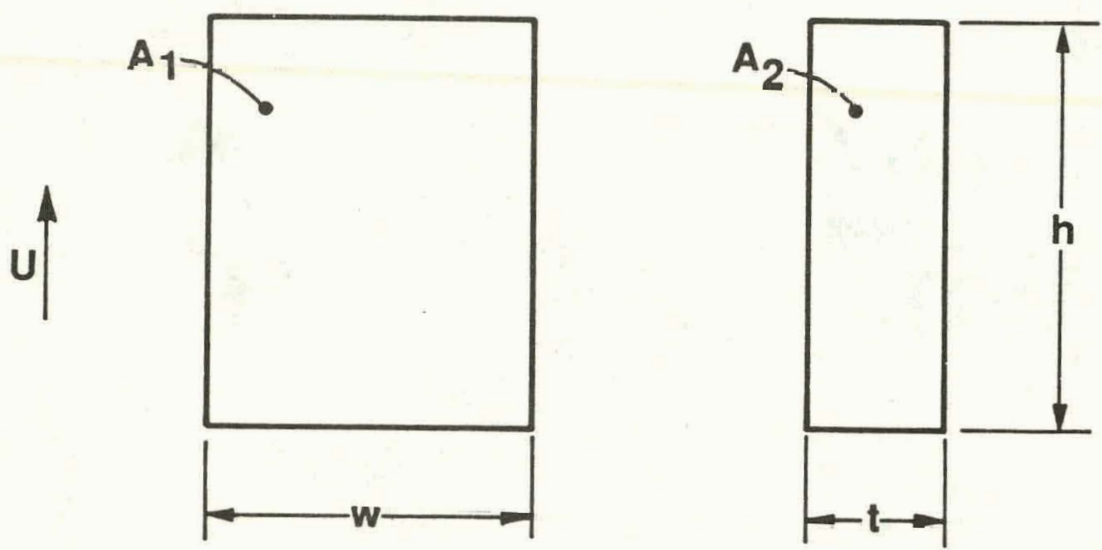

(b) Rectangular Flake
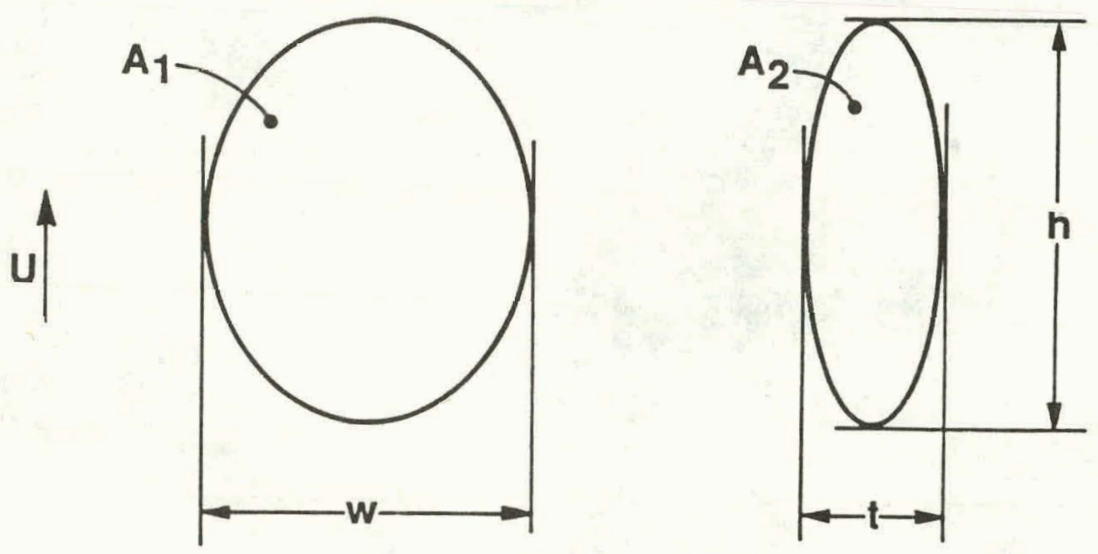

(c) Ellipsoidal Flake

Figure 6.7. Two Orthogonal Views for Three Flake Shapes. 


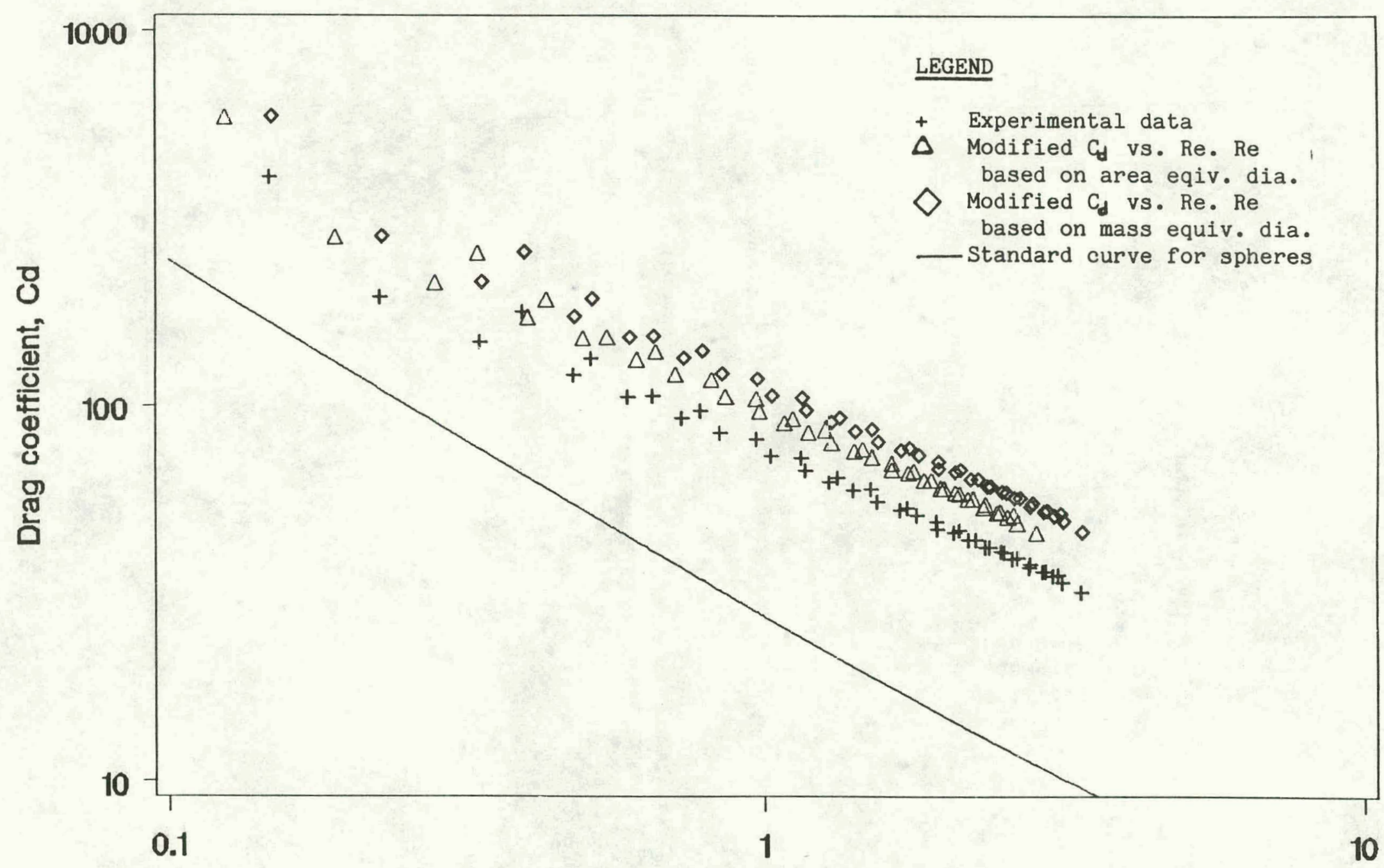

\section{Reynolds number, Re}

Figure 6.8. Effects of Shape on the Drag Characteristics of an Oil Shale Particle (OS-12). The Particle has been approximated as a Rectangular Flake. 




Figure 6.9. Effects of Shape on the Drag Characteristics of an Oil Shale Particle (OS-12). The Particle has been approkimated as an Ellipsoid. 

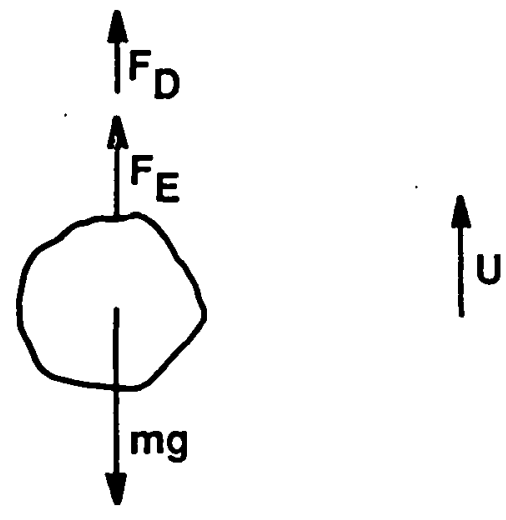

(a) Negligible Lift Force
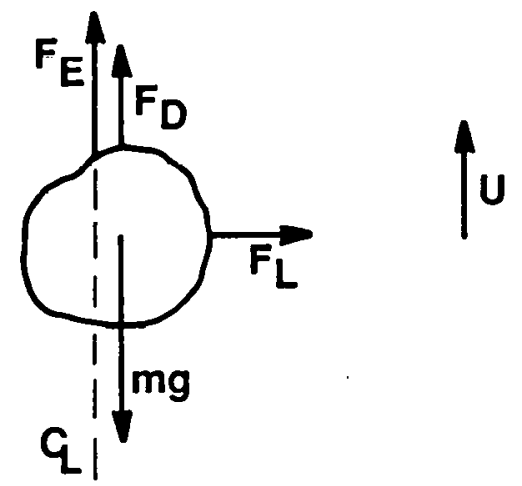

(b) Unstable Offcenter Position

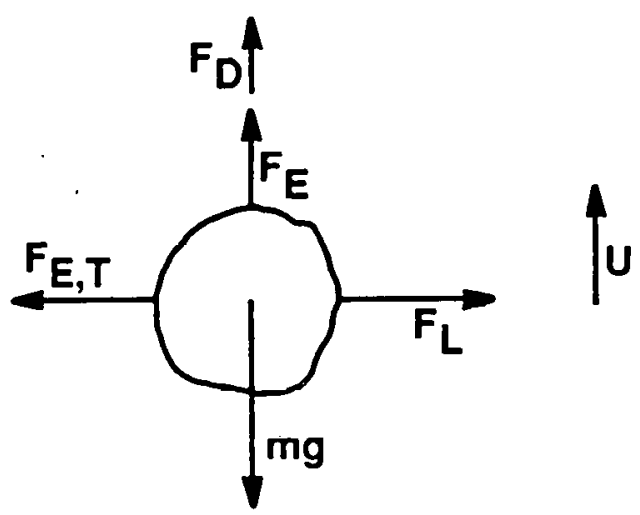

(c) Stable Offcenter Positton

Figure 6.10. Forces on a Nonspherical Particle suspended in an Electrodynamic Balance. 


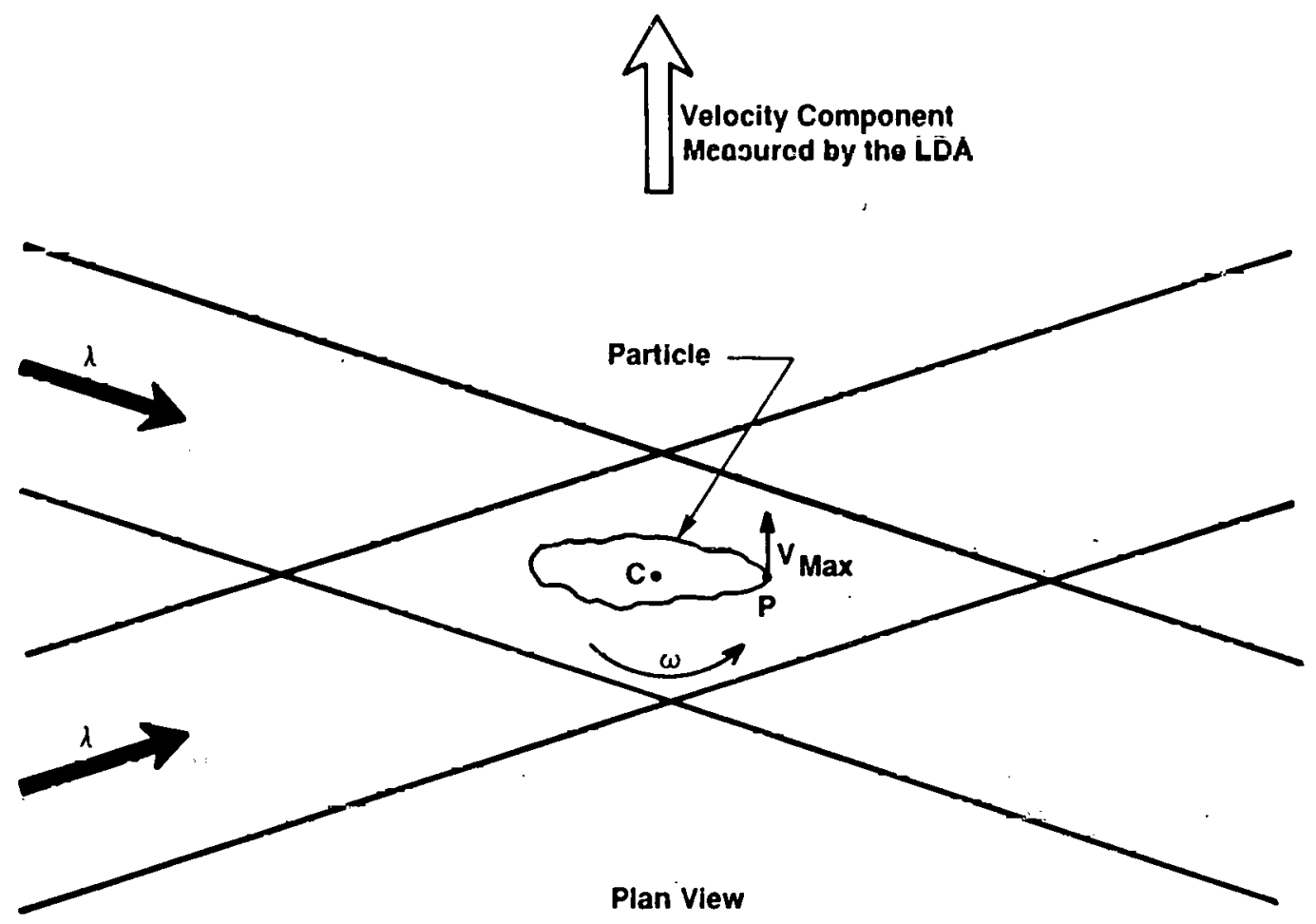

Figure 6.11. Principle for Measuring Particle Rotation Velocity by a Single Component Laser Doppler Anemometer. 


\section{Chapter 7}

\section{CONCLUSIONS}

\subsection{Conclusions} follows:

The major conclusions of this research can be summarized as

(a) An electrodynamic balance was successfully used to study the aerodynamics of single particles, both spherical and nonspherical in shape. The device is capable of making accurate measurements of the drag coefficient on a particle.

(b) Drag data for spheres agrees very well with standard data available in published literature for Reynolds numbers in the range from 0.2 to 13 .

(c) Coal and oil shale particles exibit higher drag coefficients than spheres at comparable Reynolds numbers. The present data provides a lower estimate on the drag of coal and oil shale particles.

(d) Over the range of parameters studied, the drag coefficients for all the particles exibit a power. law relationship with the. Reynolds number of the form:

$\mathrm{C}_{\mathrm{d}}=\mathrm{K} \cdot \mathrm{Re}^{\mathrm{n}}$

The values of the pre-exponent, $K$, and the exponent, $n$, are as follows:

$$
\begin{array}{lll}
\text { For spheres: } & K=28.40, & \mathbf{n}=-0.758 \\
\text { For coal: } & \mathrm{K}=38.88, & \mathbf{n}=-0.815, \text { and } \\
\text { For oil shale: } & \mathrm{K}=64.37, & \mathbf{n}=-0.718
\end{array}
$$

The characteristics for individual particles vary from the above mean by upto $\pm 20 \%$ for coal and $-20 \%$ to $+40 \%$ for oil shale.

(e) The drag characteristics of coal particles are not significantly affected by the choice of the characteristic dimension. However, the characteristic dimension significantly affects the drag characteristics of oil shale particles.

(f) Nonspherical particles (coal and oil shale) were observed to rotate about the jet direction in the presence of the air flow. This rotation speed depended on the $\mathrm{AC}$ field frequency also and, hence, quantitative information on particle rotation cannot be obtained using the electrodynamic balance. In general, the particle rotation speed increased with increasing jet velocity. However, this rotation did not affect the drag characteristics of a particle.

(g) A single component LDA was successfully used to measure the 
rotational velocity of a single particle. Extensive studies of this technique were not performed for reasons mentioned in item (f) above.

\subsection{Recommendations for Future Work}

The drag data obtained during the course of this research is unique, especially for coal and oil shale particles. In its present form this data can be used to develop more accurate predictions of the flow of these fuels in engineering applications such as combustors and fluidized beds.

However, in the wake of this research, several new questions have been brought. up. These relate to particle dynamics, rotation characteristics, effect of random variations in shape on the trajectory of a particle in a uniform flow, and characterization of particle dimensions. It may not be possible to study all of the above aspects using the electrodynamic balance, but some other aspects are worthy of experimentation. By radiatively heating a suspended particle, the effects of temperature on drag characteristics can be explored using the present apparatus. It would also be possible to measure mass transfer from evaporating liquid drops and subliming solid particles using the present device. Further, it will be interesting to measure the effects of heat and mass transfer on particle drag, a situation common to several important engineering applications. By introducing turbulent or unsteady jet flow, it would also be possible to study these effects on particle drag. Experimental data in these areas is currently very scarce, if not altogether lacking, and this recommended research could fill vital gaps in the understanding of single particle phenomena. 


\section{REFERENCES}

Beddow, J. K., and T. P. Meloy, 1980, "Testing and Characterization of Powders and Fine Particles", Heyden and Son, London.

Beddow, J. K., 1980, Particulate Science and Technology, Chemical Publishing Co., New York, N.Y., pp. 338-350.

Besnard, D., and F. H. Harlow, 1986, "Nonspherical Particles in Two-phase Flow", Intl. J. Multiphase Flow, v. 12, n. 6, pp. 891-912.

Brenner, H., 1963, "The Stokes Resistance of an Arbitrary Particle", Chem. Engg. Sc., v. 18, pp. 1-25.

Brenner, H., 1964, "The Stokes Resistance of an Arbitrary Particle-II, An Extension", Chem. Engg. Sc., v. 19, pp. 599-629.

Carmichael, G. R., 1982, "Estimation of the Drag Coefficient of Regularly Shaped Particles in Slow Flows from Morphological Descriptors", Ind. Eng. Chem. Procese Des. Dev., v. 21, pp. 101-403.

Clift, R., and W. H. Gauvin, 1971, "Motion of Entrained Particles in Gas Streams", Can. J. Chem. Engg., v. 49, August, pp. 439-448.

Dahneke, B. E., 1973, "Slip Correction Factors for Nonspherical Bodies I; Introduction and Continuum Flow", Aerosol Sc., v. 4, pp. 139-145.

Davis, E. J., 1985, "Electrodynamic Balance Stability Characteristics and Applications to the Study of Aerocolloidal Particles", Langmuir, v. 1, pp. $379-387$.

Davis, E. J., and A. K. Ray, 1980, "Single Aerosol Particle Size and Mass Measurement Using an Electrodynamic Balance", J. Colloid and Interface Sc., v. 75, n. 2, pp. 566-576.

Davis, E. J., and R. Periasamy, 1985, "Light Scattering and Aerodynamic Size Measurements for Homogeneous and Inhomogeneous Microspheres", Langmuir, v. 1, n. 1, pp. 373-379.

Davis, E. J., S. Zhang, J. H. Fulton, and R. Periasamy, 1987, "Measurement of the Aerodynamic Drag Force on Single Aerosol Particles", Aerosol Sc. and Tech., v. 6, pp. 273-287.

Farin, D., D. Avnir, and P. Pfeifer, 1984, "Fractal Dimensions of Surfaces. The Use of Adsorption Data for the Quantitative Evaluation of Geometric Irregularity", Particulate Sc. and Tech., v. 2, pp. 27-35.

Flemmer, R. L. C., and C. L. Banks, 1986, "On the Drag Coefficient of a Sphere", Powder Tech., v. 48, pp. 217-221.

Gavalas, G. R., and R. C. Flagan, 1986, "Kinetics of Coal Pyrolysis and Combustion", Proceedings of AR\&TD Direct Utilization Contractors 
Review Meeting, U.S. Department of Energy, pp. 66-67.

Jeffery, G. B., 1915, "On The Steady Rotation of a Solid of Revolution in a Viscous Fluid", Proc. Lond. Math. Soc., v. 14, pp. 327-338.

Kale, S. R., W. P. Webster, and R. J. Anderson, 1987, "Application of an Electrodynamic Balance to Study Mass Transfer from a. Single Particle", Developments in Experimental Techniques in Heat Transfer and Combustion, Editors R. O. Warrington, Jr, M. M. Chen, J. D. Felske and W. L. Grosshandler, ASME vol. HTD - 71, New York, pp. 83-90.

Kline, S. J., and F. A. McClintock, 1953, "Describing Uncertainties in Single-sample Experiments", Mechanical Engineering, January, pp. 3-8.

Maloney, D. J., J. F. Spann, L. O. Lawson, G. E. Fasching, and M. Sitarski, 1986, "Combustion Mechanisms for Coul Derived Fuels: Task-I: Single Particle Combustion Studies", Proceedings of AR\&TD Direct Utilization Contractors Review Moeting, U.3. Depanlment of Energy, pp. 1-2.

Mandelbrot, B. B., 1982, The Fractal Geometry of Nature, Freeman, San Fransisco.

Ogawa, A., 1984, Separation of Particles from Air and Gases: Volume-1, CRC Press, Boca Raton, Florida.

Pettyjohn, E. S., and E. B. Christiansen, 1948, "Effect of Particle Shape on Free-Settling Rates of Isometric Particles", Chem. Engg. Prog., v. 44, n. 2, pp. 157-172.

Torobin, L. B., and W. H. Gauvin, Iy60, "Fundamental Aspects of Solids-Gas Flow, Part IV: The Effects of Particle Hotation, Roughness and Shape", Can J. Chem. Engg., October, pp. 142-153.

Trinh, E. H., and C. J. Hsu, 1987, "Measuring Shapes of Acoustically Levitated Drops", NASA Tech Briefs, March, pp. 32.

White, F. M., 1974, Viscous Fluid Flow, McGraw Hill, New York, pp. $206-210$.

Wuerker, R. F., H. Shelton, and R. V. Langmuir, 1959, "Electrodynamic Containment of Charged Particles", J. Appl. Physics, v. 30, n. 3, pp. 342-349.

Yin, M. J., J. K. Beddow, and A. F. Vetter, 1986, "Effects of Particle Shape on Two-Phase Flow in Pipes", Powder Tech., v. 46, pp. 53-60.

Zenz, F. A., and D. F. Othmer, 1960, Fluidization and Fluid Particle Systems, Reinhold, New York. 


\section{UNCERTAINTY BSTIMATES IN DRAG MEASUREMENTS}

Details of the uncertainty estimates in drag coefficient and Reynolds number calculations are given in this Appendix. The calculations are based on the method developed by Kline and Mcclintock (1953). From the experimental data, uncertainty in jet calibration is estimated to result in $a \pm 5 \%$ uncertainity in velocity while uncertainity in particle diameter measurement is $\pm 2 \%$. These uncertainities indicate the maximum error (error bands) in these measurements. Uncertainties in other input parameters to the experiment, viz., particle density and DC voltage measurement, are much less and would not affect the total uncertainty in drag measurements.

The uncertainty in Reynolds number can be calculated from the equation:

$$
R e=\frac{U \cdot d}{\nu}
$$

and by the procedure outlined by Kline and McClintock (1953):

$$
\begin{aligned}
\frac{\delta \operatorname{Re}}{\operatorname{Re}} & =\left[\left(\frac{\delta U}{U}\right)^{2}+\left(\frac{\delta d}{d}\right)^{2}\right]^{0.3} \\
& =5.39 \%
\end{aligned}
$$

The uncertainty in drag coefficient measurement can be calculated using the following relations, described in Chapter 4.

$$
\begin{aligned}
C_{d} & =\frac{m g}{\frac{1}{2} \rho_{\mathbf{a}} \cdot \mathrm{K}_{\mathrm{B}} \cdot \mathrm{U}_{\mathrm{dc}} \cdot \mathrm{A}_{\mathrm{p}}} \\
& =\frac{2 \mathrm{mg}}{\rho_{\mathbf{a}} \cdot \mathrm{U}^{2} \cdot \mathrm{A}_{\mathrm{p}}}\left(1-\frac{V_{d c}}{V_{\mathrm{dc}, 0}}\right) \\
\mathbf{m} & =\frac{\pi d^{3}}{6} \cdot \rho \\
\mathrm{K}_{\mathrm{B}} & =\frac{\mathrm{mg}}{V_{\mathrm{dc}, 0}} \\
\mathrm{~A}_{\mathrm{p}} & =\frac{\pi \mathrm{d}^{2}}{4}
\end{aligned}
$$

Using the uncertainty values for $U$ and $d$, the uncertainties in $m, K_{B}$ and $A_{p}$ can be calculated as follows:

$$
\begin{aligned}
\frac{\delta m}{m} & =\left[3\left(\frac{\delta d}{d}\right)^{2}\right]^{0.5} \\
& =3.46 \%
\end{aligned}
$$




$$
\begin{aligned}
\frac{\delta \mathrm{K}_{\mathrm{B}}}{\mathrm{K}_{\mathrm{B}}} & =\frac{\delta \mathrm{m}}{\mathrm{m}}=3.46 \% \\
\frac{\delta \mathrm{A}_{\mathrm{p}}}{\mathrm{A}_{\mathrm{p}}} & =\left[2\left(\frac{\delta \mathrm{d}}{\mathrm{d}}\right)^{2}\right]^{0.5} \\
& =2.83 \%
\end{aligned}
$$

The uncertainty in drag measurement can now be calculated using equation $I-3 a$ and equations $I-7$ thru I-9, as follows:

$$
\begin{aligned}
\frac{\delta C_{d}}{C_{d}} & =\left[\left(\frac{\delta m}{m}\right)^{2}+2\left(\frac{\delta U}{U}\right)^{2}+\left(\frac{\delta A_{p}}{A_{p}}\right]^{2}\right]^{0.5} \\
& =8.37 \%
\end{aligned}
$$

If the drag coefficient were to be calculated using a simplified version of equation $1-3 a$ as given below:

$$
C_{d}=\frac{4 \rho d g}{3 \rho_{a} U^{2}}\left(1-\frac{V_{d c}}{V_{d c, 0}}\right)
$$

then, the uncertainty in drag coefficient would be:

$$
\begin{aligned}
C_{d} & =\left[\left(\frac{\delta d}{d}\right)^{2}+2\left(\frac{\delta U}{U}\right)^{2}\right]^{0.5} \\
& =7.35 \%
\end{aligned}
$$

The above analysis shows that uncertainties in both drag coefficient and Reynolds number measurements are dominated by uncertainties in the jet velocity measurement. 
